\title{
On the Origin of Proteins in Human Drusen: The Meet, Greet and Stick Hypothesis
}

Arthur A. Bergen ${ }^{\mathrm{a}, \mathrm{b}, \mathrm{c}, \text {, }}$, Swati Arya ${ }^{\mathrm{d}}$, Céline Koster ${ }^{\mathrm{a}}$, Matthew G. Pilgrime, Dagmara WiatrekMoumoulidis ${ }^{\mathrm{d}}$, Peter van der Spek ${ }^{\mathrm{f}}$, Stefanie M. Hauck ${ }^{\mathrm{g}}$, Camiel J. F. Boon ${ }^{\mathrm{b}, \mathrm{h}}$, Eszter Emri ${ }^{i}$, Alan J. Stewart ${ }^{\mathrm{d}}$ and Imre Lengyel $\mathrm{l}^{\mathrm{e}} \mathrm{i}$

\section{Affiliations:}

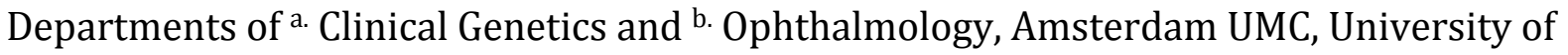
Amsterdam, Meibergdreef 9, 1105 AZ, Amsterdam, The Netherlands (NL).

c. Netherlands Institute for Neuroscience (NIN-KNAW), Amsterdam, NL.

d. School of Medicine, University of St Andrews, St Andrews, United Kingdom (UK).

e. UCL Institute of Ophthalmology, University College London, London, UK. Division of Biomaterials and Tissue Engineering, UCL Eastman Dental Institute, UCL, London, UK.

f. Dept. of Pathology, division Clinical Bioinformatics, Erasmus MC, Rotterdam, NL.

g. Research Unit Protein Science, Helmholtz Zentrum München, German Research Center for Environmental Health GmbH, Neuherberg, Germany.

h. Department of Ophthalmology, Leiden University Medical Center, Leiden, NL.

i. Centre for Experimental Medicine, School of Medicine, Dentistry and Biomedical Sciences, Queen's University, Belfast, Northern Ireland, UK

*Corresponding author:

Meibergdreef 9, 1105 AZ, Amsterdam, The Netherlands

Email address: aabergen@amc.uva.nl (A.A. Bergen).

Key words: Drusen proteins, Retinal Pigment Epithelium (RPE), Bruch's membrane, Blood, Age-related Macular Degeneration (AMD), Alzheimer's disease.

\section{Acknowledgments:}

This research was part-supported by de Algemene Nederlandse Vereniging ter Voorkoming van Blindheid (ANVVB), de Stichting Blinden-Penning, de Gelderse Blinden Stichting, de Landelijke Stichting voor Blinden en Slechtzienden (LSBS), Stichting Oogfonds Nederland, Stichting MD Fonds and Stichting Retina Nederland Fonds (represented by Uitzicht, grants 2011-6 and 2014-7 to A.A.B.), de Rotterdamse Stichting Blindenbelangen (RSB), de Haagse Stichting Blindenhulp, Stichting Lijf en Leven, Stichting Ooglijders (to A.A.B.); ZonMW grant nr 446001002 (to A.A.B. and C.K.) ; the Bill Brown Charitable Trust, Moorfields Eye Hospital Special Trustees, Mercer Fund from Fight for Sight, the Eye-Risk project funded by the European Union's Horizon 2020 research and innovation programme under grant agreement No 634479 (I.L. and E.E.), Fight for Sight project grant (I.L. and A.S.), the Bright Focus Foundation grant nr M2015370 (to SMH). The authros thank Dr J Booij for partly unpublished data and the reviewers for their invaluable commentsto improve the manuscript.

\section{Conflict of interest statement:}

The authors do not have any competing financial interest to declare. 
1 Title: On the Origin of Proteins in Human Drusen: The Meet, Greet and Stick Hypothesis

3 Abstract: Retinal drusen formation is not only a clinical hallmark for the development of 4 age-related macular degeneration (AMD) but also for other disorders, such as

5 Alzheimer's disease and renal diseases. The initiation and growth of drusen is poorly

6 understood. Attention has focused on lipids and minerals, but relatively little is known

7 about the origin of drusen-associated proteins and how they are retained in the space

8 between the basal lamina of the retinal pigment epithelium and the inner collagenous

9 layer space (sub-RPE-BL space). While some authors suggested that drusen proteins are

10 mainly derived from cellular debris from processed photoreceptor outer segments and

11 the RPE, others suggest a choroidal cell or blood origin.

12 Here, we reviewed and supplement the existing literature on the molecular composition 13 of the retina/choroid complex, to gain a more complete understanding of the sources of 14 proteins in drusen. These "drusenomics" studies showed that a considerable proportion 15 of currently identified drusen proteins is uniquely originating from the blood. A smaller, 16 but still large fraction of drusen proteins comes from both blood and/or RPE. Only a 17 small proportion of drusen proteins is uniquely derived from the photoreceptors or 18 choroid. We next evaluated how drusen components may "meet, greet and stick" to each 19 other and/or to structures like hydroxyapatite spherules to form macroscopic deposits 20 in the sub-RPE-BL space. Finally, we discuss implications of our findings with respect to 21 the previously proposed homology between drusenogenesis in AMD and plaque formation in atherosclerosis. 
1. Drusen.

\section{Functional annotation of drusen proteins.}

2.1. Biological or disease motifs and canonical pathways.

2.2. Molecular networks.

2.2.1. Network 1.1, 1.2, 1.3: Complement, collagens and crystallins.

2.2.2. Network 2.4: development, genetics ophthalmic disorders.

2.2.3. Network 3.5: Immunological response.

2.2.4. Network 4.6: Cell-to-cell signaling and systemic involvement, lipid metabolism.

3. Drusenomics, part I: Where do drusen proteins come from: the literature.

3.1. The neural side of drusen.

3.1.1. Histopathological, retinal imaging observations.

3.1.2. Proteomic level observations.

3.2. The systemic side of drusen.

3.2.1. Bruch's membrane.

3.2.2. Choroidal capillaries.

3.2.3. Contribution of blood proteins.

4. Selection of transcriptomic and proteomic datasets to determine the origin of drusen proteins.

4.1. Selection criteria and considerations.

4.2. Description of expression datasets used for drusenomics.

4.3. Functional annotation of the photoreceptor (cPR-ET) and choroidal (cChorET) datasets.

5. Drusenomics, part II: Qualitative analysis.

5.1. Comparative study design considerations.

5.2. Where do proteins in drusen come from? A qualitative comparison.

5.2.1. Network 1.1: The complement gene cluster.

5.2.2. Network 1.2: The collagen cluster.

5.2.3. Network 1.3: The crystallin cluster.

5.2.4. Network 2.4: Genetic and developmental ophthalmic disorders.

5.2.5. Network 3. 5: Injury, inflammation and dermatological disease.

5.2.6. Network 4.6: Cell to cell signaling; systemic involvement.

\section{Drusenomics, part III: A quantitative approach.}

6.1. Quantitative analysis and curation of datasets.

6.1.1. Ten out of 89 drusen proteins originate uniquely from the PR/RPE.

6.1.2. Twenty-three of 89 drusen proteins originate from both the "neural 
and systemic side" of drusen.

6.2. Nineteen drusen proteins out of 89 were not assigned.

6.3. Blood proteins are an important source of drusen proteins.

68

69

7. Drusen and hydroxyapatite.

70

8. Drusen and plaques: age-related macular degeneration and atherosclerosis.

8.1. Clinical and epidemiological studies.

8.2. Histological and pathobiological similarities.

8.3. Genetics and molecular biology.

\section{Future directions and conclusions.}




\section{Drusen.}

Drusen are extracellular deposits of bio-materials underneath the retinal pigment epithelium (RPE) in the eye (Farkas et al., 1971b; Sarks, 1976). They are considered clinical hallmarks for a number of diseases, including age-related macular degeneration (AMD) (Hogan, 1965; Sarks, 1976; Hageman et al., 2001; Khan et al., 2016), Alzheimer disease (AD) (Csincsik et al., 2018) and dense deposit disease (DDD) (Duvall-Young et al., 1989; Mullins et al., 2000; Boon et al., 2009). AMD is the leading cause of severe visual impairment, affecting $4 \%$ of the population over 60 years old (de Jong, 2006). AD is the biggest cause of dementia, affecting millions of people in the western world. DDD is a relatively rare juvenile disease characterized by kidney malfunction (Ito et al., 2017; Wang et al., 2017; Cunningham and Kotagiri, 2018). Despite the potential relevance for diseases, little is known about the composition of drusen and how and why biomaterials accumulate these deposits.

Drusen are heterogeneous in terms of size, shape, color on retinal imaging, retinal location and molecular content (Sarks, 1976; Sarks et al., 1980; Sarks et al., 1999; Crabb et al., 2002; Khan et al., 2016). In the clinic, drusen can be identified as yellow spots on funduscopy and color fundus images or dome shaped objects of different sizes under the RPE on Optical Coherence Tomography (OCT)(Marshall et al., 1992; Bird et al., 1995; Loeffler and Lee, 1998; Khan et al., 2016). Histopathological examination of drusen showed that are located between the basal lamina of the RPE cells and the Inner collagenous layer of the Bruch's membrane, a space that had been termed recently as sub-RPE-BL space (Balaratnasingam et al., 2016; Li et al., 2018). Clinical definition of drusen depends on size, color, auto fluorescence, and retinal location (Sarks, 1976; Bird et al., 1995) (Figure 1). Drusen may appear in the macula, peri-macular area or in the mid-and/or far periphery (Lengyel et al., 2015; Domalpally et al., 2017; Csincsik et al., 2018). A particular druse can be termed as "hard", when it's appearance is small, round and well demarcated, with a size of $<63 \mu \mathrm{m}$. "Intermediate" drusen have a size of approximately 63-125 $\mu \mathrm{m}$, while "soft" drusen are $>125 \mu \mathrm{m}$ in size, and frequently have more ill-defined edges (Bird et al., 1995). A few $(<5)$ small hard (sub-clinical) drusen in the macula does not raise alarm bells, but when numbers of hard drusen increase, or the size of drusen increases such that they become "intermediate" and/or- "soft" drusen, the likelihood to progression to AMD is increased significantly (Bird et al., 1995). Drusen 
110 should be distinguished from reticular pseudodrusen (or subretinal drusenoid deposits) 111 that occur between the RPE and photoreceptor (PR) in the subretinal space (Zweifel et 112 al., 2010; Spaide et al., 2018). Relatively little is known about pseudo-drusen and as 113 such, they are excluded from this review. Drusen are formed in the sub-RPE-BL space, 114 between the basement membrane of the RPE and the inner collagenous layer of Bruch's 115 membrane (BrM).

116 The RPE is a multifunctional single neuro-epithelial cell-layer that act as a metabolic 117 interface between the choroid and the neurosensory retina (Strauss, 2005). The RPE 118 cells are connected by intercellular tight junctions, together forming the outer blood119 retina barrier. On the apical side, the photoreceptor cells line the RPE. On the basal side 120 the interposing BrM separates the basement membrane of the RPE from the choroidal 121 micro-vasculature (choriocapillaris). The choroidal capillaries are fenestrated, and not 122 surrounded by pericytes or smooth muscle cells. The BrM consists of three interleaved 123 layers: the inner and outer collagenous layers with an elastic layer in between them 124 (Booij et al., 2010a). Often, the basement membranes of the endothelium and the 125 epithelium are classified as part of the BrM but we will refer here to the BrM structure 126 as tri-laminar (rather than as penta-laminar). Embedded in the BrM are macromolecules 127 such as proteins and proteoglycans to help remodeling the extra cellular matrix (with 128 age)(Guo et al., 1999; Guymer et al., 1999; Del Priore et al., 2006; Beattie et al., 2010; 129 Booij et al., 2010a; Hussain et al., 2011). The diffuse thickening of BrM is also a 130 characteristic age-related feature (Hogan, 1965; Sarks et al., 1999). This is largely due to 131 the entrapment of proteins and lipids within the ECM (Curcio et al., 2011; Curcio and 132 Johnson, 2012). The diffuse build-up of extracellular bio-materials between the 133 basement membrane of the RPE and the inner collagenous layer of the BrM is called 134 basal linear deposits while the deposit formation between the basement membrane and 135 the cell membrane of the RPE are called basal laminar deposits (Sarks, 1976; Sarks et al., 136 1980; van der Schaft et al., 1993; Abdelsalam et al., 1999; Curcio and Millican, 1999;

137 Spraul et al., 1999). Due to the lack of information of the composition of these deposits, 138 these specific classifications are excluded from our analysis. The deposits in BrM result 139 in a decline in the conductivity of the membrane creating in a diffusion barrier that 140 further enhances the accumulation of biomaterials (Green and Enger, 1993; Moore et al., 141 1995; Starita et al., 1997; Curcio and Millican, 1999; Curcio et al., 2011; Curcio, 2018b). 
142 This phenomenon may be a general "passive" pathophysiological process that resembles 143 plaque formation in disorders such as $\mathrm{AD}$ or atherosclerosis.

144 Even more detailed insights into sub-RPE-BL space deposits originated from molecular and histochemical studies on isolated drusen material. Recent investigations have

146 shown that drusen contain lipids, trace elements, including zinc, iron and calcium, as

147 well as a wide array of different proteins (Crabb et al., 2002; Curcio et al., 2011;

148 Thompson et al., 2015; van Leeuwen et al., 2018). The distribution of these components

149 is not uniform, neither within nor between drusen, further emphasizing the

150 heterogeneous nature of the deposits (Thompson et al., 2015).

151 Oxidative modification of lipids and proteins may result in the cross-linking of these 152 molecules and may contribute to deposit formation and drusenogenesis. Subsequently, 153 local cellular damage at the very early onset of AMD, via the complement cascade attack 154 on drusen compounds and the NLRP3 inflammasome (Edwards and Malek, 2007; Yuan 155 et al., 2010; Doyle et al., 2012), can lead to retinal damage and more advanced AMD.

156 Relatively few studies addressed the origin of proteins in the initiation and progression 157 of drusen (Mullins et al., 2000; Nordgaard et al., 2006; Cryan and O'Brien, 2008; Wang et 158 al., 2010; Crabb, 2014). A number of studies (Johnson et al., 2011; Kunchithapautham et 159 al., 2014) have yielded conflicting data as to where drusen proteins originate from, and 160 whether the accumulation of this apparent depositioning of biomaterials in BrM is a 161 passive or an active process. Several questions remain, which include: to what extent do 162 proteins in drusen originate from photoreceptors, RPE, choroidal endothelium or even 163 the circulating blood? How do drusen form and how are drusen components recruited 164 and deposited in the sub-RPE-BL space? What is the extent of the (molecular)

165 heterogeneity that exists within and between drusen? Here, we will review and combine 166 data from the existing literature, and supplement these with our own (new and recently 167 published) data from subretinal transcriptomic, proteomic and immunohistochemical 168 staining experiments. To enable this, we have functionally annotated a compiled list of 169 drusen proteins and compared these proteins with those identified in specific 170 transcriptomic and proteomic datasets derived from cells and tissues of the various 171 relevant compartments. These include both subretinal and choroidal tissues, as well as 172 the plasma proteome. Collectively, these analyses increase our understanding of 173 drusenogenesis, which may provide clues for the prevention of drusen formation and, 174 ultimately, for the prevention of drusen associated disorders (Khan et al., 2016) 


\section{Functional annotation of drusen proteins.}

177 One of the key aims of this study is to identify the most likely original sources of drusen proteins. More specifically, do drusen proteins only come from the neural tissues (photoreceptors and RPE) or is there also a choroidal or systemic component? In the next chapters, we try to answer this question through a literature search and by using a variety of qualitative and quantitative transcriptomics and proteomics meta-analyses of the relevant genes and proteins involved.

We did not distinguish between various drusen types, sizes and/or drusen locations, since little -omics data are available for each drusen subtype. Essentially, we followed the (sub-clinical) drusen type description used by Crabb and coworkers (Crabb et al., 2002) who defined drusen to appear as opaque, 0 to $250 \mu \mathrm{m}$ spherical to irregular deposits that remained attached to BrM after removing the RPE from human donor globes, both in the macular and the retinal periphery.

Based on relevant studies in the literature (Mullins et al., 2000; Crabb et al., 2002; Wang et al., 2010), we curated a list of 89 drusen proteins (Table 1). This was achieved by combining the published datasets and removing incomplete, duplicate or ambiguous entries. Several entries did not correspond to a single full-length cDNA annotated in the knowledge database Ingenuity (www.ingenuity.com) and were left out. Since the complement gene pathway is likely the best and most extensively studied pathway (compared to other pathways) we only added a few complement proteins to the list, to avoid bias toward one pathway and the "winner's curse". In addition, we also searched the literature for confirmatory immunohistochemistry (IHC) studies and manually added proteins from such smaller-scale studies. We realize this list may not be complete. For example, individual entries like the locally produced vitronectin (Hageman et al., 1999; Wasmuth et al., 2009) present in drusen is missing in Table 1 and an entry like elastin may be present as contamination of the BrM rather than a "specific" drusen protein. The problem with selecting these proteins lies with the heterogeneity of drusen (one protein may be present in one drusen but not in the other), lack of uniform criteria "what is drusen-specific (?)", lack of uniformity in healthy or diseased stage of examined samples and overall, how much evidence is needed to assign proteins to drusen (see also discussion section). Nonetheless, we believe that, for the purposes of this study, our 
selection of 89 proteins, largely based on the proteomic study of Crabb and colleagues

208 (Crabb et al., 2002) provides us with a sufficient representative drusen protein dataset

209 for the purpose of this study.

210 We used the 89 drusen protein data set first to investigate the molecular aggregation

211 and the functional annotation of drusen proteins. A similar study was previously carried

212 out by Crabb and coworkers (Crabb et al., 2002; Crabb, 2014). However, here we used a

213 slightly different list of drusen proteins and subjected this to additional, advanced

214 bioinformatics analysis. Consequently, we ran an Ingenuity knowledge database core

215 analysis using our list of drusen components (Table 1) which yielded biological motifs,

216 canonical pathways and molecular structural or functional networks. A summary of the

217 results of this analysis is shown in Table 2.

\subsection{Biological or disease motifs and canonical pathways.}

219 The functional annotation of the 89 drusen proteins (Table 2), revealed that these proteins (motifs or aggregates) can be associated with a number of functional or disease entities, such as "hereditary disorders", "ophthalmic disease”, "organismal injury or abnormalities" and "metabolic disease and developmental disorders". Although these annotation categories are broad and not very specific, they do point to a wide range of potential sources of drusen components from both local and systemic origin. Ingenuity analysis also yielded a number of canonical pathways. A canonical pathway is the simplest linear representation of an established chain of biochemically related molecules in a given system or cellular environment. The software recognizes enriched canonical pathways specific for "acute phase response signaling", the "retinoid- and farnesoid X receptors (LXR/RXR and FXR/RXR) response”, "atherosclerosis signaling" and "IL-12 signaling in macrophages" in the drusen dataset.

"The acute phase response" is a fast-systemic inflammatory response triggered by infection, tissue injury and/or immunological disease (Serhan et al., 2015). The response

233 is mediated by the hypothalamus and several acute phase plasma proteins. These

234 proteins have a broad-working spectrum: they kill micro-organisms and modulate complement activation, enzyme activity and the immune response. How and why these proteins potentially end up in drusen is not clear (Johnson et al., 2000). Although not undisputed, Despriet and coworkers found independently, that AMD is associated with 
acute phase plasma protein levels and with genetic variation in C-reactive protein (CRP), one of the principal acute phase proteins (Despriet et al., 2006). Chirco and Potempa showed that CRP protein acts as a mediator of complement activation and inflammatory signaling in AMD (Chirco and Potempa, 2018). It is generally assumed that acute phase proteins are present in the blood; suggesting that some drusen proteins can originate from this pathway and have a systemic origin. While choroidal CRP apparently correlate to serum levels (Chirco et al., 2018), it cannot be said with certainty that these proteins are not (transiently and/or locally) produced by the choroid as well in cases of (nearby) low-grade inflammation.

“The retinoid X receptors (RXRs)" are nuclear retinoid receptors that regulate, via the ligand LXR, lipid and cholesterol metabolism as well as inflammation (Hiebl et al., 2018). Cholesterol metabolism is essential for many retinal functions (Pikuleva and Curcio, 2014), while ocular (para-) inflammation is crucial for maintaining retinal homeostasis (Xu et al., 2009). In the eye, retinoid X receptor activation contributes to retinal photoreceptor differentiation, survival, and disease (Forrest and Swaroop, 2012), and more specifically, for docosahexaenoic acid-mediated protection of photoreceptors (German et al., 2013). The presence of this protein signature in drusen points toward a local cellular origin of this protein. LXR can form heterodimers with "the farnesoid X receptor (FXR)" which is also a nuclear receptor, and is an important regulator of a variety of bile acid, glucose and lipid-related metabolic pathways, including the removal of cholesterol (Tu et al., 2000; Hiebl et al., 2018). FXR protein was detected in a variety of tissues, including heart, ovary, thymus and eye. Both LXR and FXR may be involved in cholesterol homeostasis in RPE and retina (Zheng et al., 2015). The presence of these receptor proteins in drusen points toward a local cellular origin.

"Atherosclerosis signaling": Atherosclerosis is a low grade chronic inflammatory disorder characterized by local plaque deposition in the vessel wall, formed by a local accumulation of modified plasma lipoproteins and macrophage activation. The major cause of coronary events is rupture and thrombosis. Interestingly, clinical, epidemiological, pathobiological and molecular evidence suggest that an overlap exists between drusen in AMD and plaque formation in atherosclerosis. Indeed, like AMD, atherosclerosis is now considered as a low-grade chronic inflammatory process resulting from interaction (in) between plasma lipoproteins and the vascular wall (Mullins et al., 2000). In AMD, not only plasma lipoproteins, but also local lipoproteins 
are involved. In section 8 of this manuscript, we describe the potential molecular and pathobiological overlap between drusen/AMD and vascular plaques in detail. Taken together, the homology between drusen and atherosclerotic plaques points toward a systemic origin of some drusen proteins.

"IL-12 Signaling and Production in Macrophages": The production of the cytokine IL-12 by activated (incoming) macrophages in damaged or diseased retinal tissue, is well known (Zamiri et al., 2006; Chen et al., 2013). However, IL-12 exerts an autocrine effect since macrophages and dendritic cells also respond to IL-12 by producing interferons that stimulates T-helper cell differentiation. The RPE is apparently able to suppress inflammation by modulating IL-12 production (Zamiri et al., 2006). Cao and coworkers showed that cultured RPE cell in vitro secrete several cytokines, including IL-12, under conditions of oxidative stress and replicative senescence (Cao et al., 2013). Therefore, the molecules identified in this category (IL-12 signaling) can originate from both the circulation as well as from the local cellular environment.

\subsection{Molecular networks.}

Molecular networks in Ingenuity are built up from a myriad of relevant literature connections and they are formed on the basis of most likely physical or functional interactions between (input) genes and/or proteins. For example, see molecular network 1 in Figure 2a. Based on millions of experimentally verified and curated data points, these networks represent the most likely functional associations between components of the "biological soup" in the context of the input molecules. Structural, functional and mixed molecular networks exist. Structural networks contain primarily networks of structurally and physically interacting entries. Functional networks are dominated by functional relationship between participating molecules. A third, "mixed" network, contains both structural and functional associations. The molecular network analysis of drusen proteins yielded 4 significant networks, with 6 distinct functional clusters. Note that the networks are not a prioribuilt through their possible relationship with drusen or AMD per se.

\subsubsection{Network 1.1, 1.2 and 1.3: Complement, collagens and crystallins.}

The most significant network formed in the data-driven Ingenuity drusen analysis, is presented in Figure 2a. This network consists of three functionally more or less specific molecular clusters: the complement protein cluster, the collagen protein cluster and the 
crystallin heat shock protein cluster (Table 3). The presence of complement proteins in drusen (and the choriocapillaris) was previously shown in older and AMD affected eyes through immunohistochemistry, long before the genetic involvement of CFH and other complement factors in drusen formation and AMD became genetically apparent (Johnson et al., 2000; Hageman et al., 2001; Edwards et al., 2005; Hageman et al., 2005; Haines et al., 2005; Klein et al., 2005). Analyzing the drusen proteome, we confirmed the involvement of the terminal complement protein complex by identifying the complement factors C7, C8A, C8B, C8G, and the membrane attack complex (MAC) in drusen. Of note, the MAC was initially identified in drusen from unspecified retinal locations, but was later shown not to be present in macular drusen (Johnson et al., 2000; Mullins et al., 2014). The MAC is the final downstream event of the complement cascade. It results from the binding of $\mathrm{C} 5 \mathrm{~b}$ to blood plasma complement proteins $\mathrm{C} 6, \mathrm{C} 7, \mathrm{C} 8$, and C9, forming transmembrane pores that leads to cell lysis and death. In the same cluster, we found the Prolyl endopeptidase-like protein (PRELP), a small leucine-rich proteoglycan (SLRP) (Hultgardh-Nilsson et al., 2015), which among others, is involved in the inhibition of complement activation (Warwick et al., 2014). The main complement cascade regulator $\mathrm{CFH}$ is another member of the complement cascade that is present in the drusen proteome. Genetic variation in $\mathrm{CFH}$ may regulate complement activation on RPE cells (Radu et al., 2014). Of note, is that a certain degree of low-grade complement activation and para-inflammation is always present in healthy aging eyes, to maintain local health (Xu et al., 2009). In a recent review, Warwick et al. concluded that complement deposition in the retina could be of local and/or systemic origin (Warwick et al., 2014). The majority of complement genes are expressed in the liver, resulting in an abundance of complement proteins in the blood. However, the RPE expresses several key complement genes which may modulate the complement attack on RPE and drusen (Chen et al., 2007; Kim et al., 2009; Pao et al., 2018). Interestingly, locally produced CFH is, at least in cultured RPE cells, secreted apically, and not basally (Kim et al., 2009; Pao et al., 2018). Consequently, the potential regulating role of locally produced CFH in vivo, and other complement factors, potentially involved in the complement attack on drusen, needs to be further investigated. A diversity of collagen proteins, such as COLA1, A2, 6A1, 6A2 and 8A1 were previously consistently identified in basal laminar deposits and basal linear deposits, and, occasionally, in drusen (Newsome et al., 1987; Booij et al., 2010a; Curcio and Johnson, 2012). Newsome and coworkers (1987) noted that the 
involvement of extracellular matrix components in drusen is variable but these findings have not been confirmed in other studies. These molecules may primarily present as a remnant from the (ab)normal turnover of BrM components (Newsome et al., 1987). Alternatively, they may be secreted by the RPE in response to challenges presented by drusen or by the conditions that lead to drusen formation. Interestingly, collagen IV is not present in our curated drusen dataset, despite the fact that collagen IV accumulations are found in autosomal dominant radiant drusen in Doyne Honeycomb Retinal Dystrophy caused by EFEMP1(EGF-containing fibulin extracellular matrix protein 1) mutations (Sohn et al., 2015). In fact, in the absence of detailed electron microscopic examination it is not clear whether these are drusen or basal laminal deposits. The presence of crystallin proteins in drusen had been shown by Crabb and co-workers (Crabb et al., 2002) and functionally studied by Nakata et al. (Nakata et al., 2005). These authors found that BrM, drusen and part of the choroidal connective tissue, when affected by AMD, showed higher immunoreactivity for $\alpha$ - and $\beta$-crystallins than healthy control tissues. Retinal crystallins are also up-regulated in a variety of other retinal pathologies, including diabetic retinopathy, ischemia, mechanical injury and uveitis. The $\alpha$-crystallin family plays a crucial role in neuroprotection and inflammation (Fort and Lampi, 2011), while the $\beta$ - and $\gamma$-crystallins are small proteins with a possible ganglion cell protective role in glaucoma (Anders et al., 2017) and a role in retinal tissue remodeling and repair (Thanos et al., 2014). Consequently, the presence of these proteins in drusen points to a local cellular origin.

\subsubsection{Network 2.4 development, genetics of ophthalmic disorders.}

The fourth cluster in our drusen protein analysis is actually similar to the entire network

3602 which is functionally annotated as "network of genetic and developmental disorders".

361 The components of this cluster are functionally presented in detail in Figure 2b; Table 3.

362 This network contains annexin A2 (ANXA2), a relatively small calcium and

363 phospholipid-binding protein involved in multiple intra-cellular transport functions. The 364 RPE secretion data set, called RPE-IVS (Table 3; STable 1) reveals that this protein is 365 indeed secreted basally by the RPE (Pao et al., 2018). The protein was initially assigned 366 to drusen (Crabb et al., 2002). However, the same authors showed, using IHC in a 
number of human donor eyes, that ANXA2 is not associated with the interior of drusen, but with the basal lamina of the RPE close to the drusen surface.

\subsubsection{Network 3.5: Immunological response.}

The fifth functional cluster in our drusen protein analysis represents network three: "Injury and inflammatory response; dermatological disease" (Figure 2c). The components are given in Table 3. This network contains, among others, annexin A1 (ANXA1). ANXA1 antibodies intensely stained whole drusen, but also the BrM and choroid (Rayborn et al., 2006). Given its positive staining in entire drusen, we consider it here as a drusen protein. Apolipoprotein E (APOE) is also present in this group. APOE is classically thought of as a cholesterol carrier. Risk alleles of the APOE gene were associated with a variety of diseases including $\mathrm{AMD}, \mathrm{AD}$ and atherosclerosis (Klaver et al., 1998; Ashford, 2004; Song et al., 2004; Tikellis et al., 2007). Its presence in laminar deposits and drusen was initially established by Klaver and colleagues (Klaver et al., 1998) and later confirmed by Anderson and Malek (Anderson et al., 2001; Malek et al., 2003). Interestingly, in an RPE cell culture model that mimics drusen formation, Pao (2018) and coworkers found that APOE is secreted basally by these cells. Subsequent exposure of these cultures to human serum led to heterogeneous sub-RPE-BL space deposits, some of which were rich in serum-derived proteins such as vimentin, clusterin and amyloid P (Pao et al., 2018). In addition to ANXA1 and APOE, the serum amyloid proteins S100A7, S100A8 and S100A9 are part of this functional cluster and the drusen proteome. S100 proteins are a family of small calcium-binding proteins, produced in the nucleus and cytoplasm of a wide variety of cells (Gross et al., 2014; Narumi et al., 2015; Cunden et al., 2017).

\subsubsection{Network 4.6 Cell-to-cell signaling and systemic involvement, lipid metabolism.}

The sixth cluster "cell-to cell signaling and systemic involvements" (Figure 2d; Table 3) points to proteins which come from an extracellular environment. For example, The APOA1, APOA4 and SAA1 lipoproteins and S, and the protein-groups related to the LDL, HDL, VLDL metabolism (that have been added by Ingenuity to construct a meaningful network) are most likely derived from the blood, and not from the retina. However, cautious interpretation of these general data is warranted, since the RPE is also capable of secreting a number of lipoproteins, such as APOB (Li et al., 2005b). The mechanisms 
398 of biogenesis of lipid-laden soft drusen has been recently reviewed elsewhere (Curcio, 399 2018a, b) as has the role of lipids in AMD (van Leeuwen et al., 2018).

400 In at least two blood proteomics datasets (Table 3) the ORM1 (acute phase plasma 401 protein of unknown function; www.genecards.org) and the SERPINA1 (serine protease 402 inhibitor; www.genecards.org) proteins occur, which point also at a systemic origin of 403 these drusen proteins. Furthermore, in this cluster we see the drusen protein clusterin 404 (CLU), which is expressed in many cell types, including photoreceptors or RPE, and is 405 also present in blood (Garcia-Aranda et al., 2018). The presence of annexin 6 (ANXA6) in 406 drusen (and BrM) was previously confirmed using immunohistochemistry (Rayborn et 407 al., 2006). Finally, we observe also the presence of the (systemic) HRG protein, which is 408 extensively discussed in section 7 of this manuscript. 


\section{Drusenomics, part I: Where do drusen proteins come from: the literature.}

410 Multiple epidemiological, genetic, biochemical and pathophysiological studies in the

411 literature address the origin of drusen. While many studies address the origins of metal

412 ions or lipids in drusen, here we focus on the likely source of proteins. Drusen proteins

413 could originate from either the neural side of drusen (Photoreceptors, RPE), the

414 systemic side (BrM, choroid complex, blood) BrM, or both (Penfold et al., 2001; Curcio

415 and Johnson, 2012).

\section{3.1. The neural side of drusen.}

417 Theories on drusen accumulation from the neural side vary: proteins may either come 418 from dying PR and RPE cells, or from (basal) secretion of proteins generated by the 419 normal functions of the RPE (Crabb et al., 2002; Kinnunen et al., 2012). Respectively, 420 cellular debris or secreted proteins may get trapped in BrM or drusen. Evidence for 421 these origins was gathered from histopathological investigation, retinal imaging, and 422 proteomics studies.

\subsubsection{Histopathological and retinal imaging observations.}

424 Drusen formation goes hand in hand with hypo- or hyperpigmentation (Curcio et al., 425 1998) of the RPE, especially in the early stages of AMD. Indeed, retinal cells overlying 426 drusen exhibit numerous irregular structural and molecular abnormalities which are confined to areas directly internal to drusen (Farkas et al., 1971b; Hogan, 1972; Burns and Feeney-Burns, 1980; The Eye Disease Case-Control Study, 1992; Johnson et al., 2003). Deflection and shortening of rod inner and outer segments of rod photoreceptors have been postulated to contribute to sub-RPE deposit formation (Farkas et al., 1971a). Drusen have been also associated with more indirect changes, such as alterations in the synaptic terminals of photoreceptor cells and an increase in vimentin and glial fibrillary acidic (GFAP) protein within Müller cells (Johnson et al., 2003). Other retinal cells, such as bipolar, horizontal, amacrine and ganglion cells are most likely unaffected by drusenogenesis (Johnson et al., 2003). Using immunohistochemical, molecular biological and biochemical approaches, Hageman and coworkers found that RPE cell loss is correlated with increasing drusen density (Hageman et al., 2001). More recent OCT studies, focusing on the integrity of the 
intact overlying RPE, and that in $28.1 \%$ of cases, the RPE was irregular but continuous

441 (Schlanitz et al., 2018). In 30.6\% of cases, the RPE layer adjacent to drusen was

442 discontinuous. Larger drusen were associated with higher probability of RPE loss

443 (Schlanitz et al., 2018). Taken together, these results suggest that RPE or PR cell death is

444 associated with drusenogenesis. However, it is not clear whether the observed cellular

445 damage is a cause or consequence of sub-RPE deposit formation.

446 The presence of cytoplasmic (Burns and Feeney-Burns, 1980), fibrous and

447 membranous/lipoid material (Fine, 1981; Young, 1987; Green and Enger, 1993; Loeffler

448 and Lee, 1998; Curcio and Millican, 1999) in drusen suggest that deposits are formed

449 after cellular degeneration. According to Coats, small colloid bodies derived from

450 degenerated RPE cells, develop into larger drusen due to uptake of biomolecules

451 through a defective BrM (Coats, 1905) and clinical support was provided for the

452 existence of these bodies (Pauleikhoff et al., 1990). Later, necrotic RPE cells were

453 presumed to be incorporated into existing drusen (Young, 1987). However, these

454 findings also did not distinguish between cause or consequence of deposit formation. To

455 complicate matters further, there are a number of reports in the literature describing

456 drusen regression; in an experimental study after laser photocoagulation and in clinical

457 studies using fluorescein angiograms (FAs) fundus photography (Bressler et al., 1995)

458 and OCT (Yehoshua et al., 2011). A similar observation were done in rhesus monkeys

459 (Duvall and Tso, 1985) in APOE mice with thickened BrM as well as AMD patients

460 (Jobling et al., 2015). This intriguing phenomenon may be linked to transiently

461 increasing the RPE-mediated release of active MMP enzymes that alter the turnover of

462 BrM (Zhang et al., 2012).

463

464

465

466

467

468

469

470

471

\subsubsection{Proteomic level observations.}

Proteomics studies into drusenogenesis can be divided into studies on (archived) human post-mortem eyes, in vitro RPE culture, and proteomic studies on retinas of animal models. A variety of techniques, such as 2D gels and LC-MS/MS analysis have been used. To date, up to over 500 healthy and AMD-affected post-mortem human eye tissue specimens (numerous contributions of Sarks, Hageman, Mullins, Lutty, Bergen, Lengyel, and Curcio) have been examined by light, confocal, or electron microscopy, in conjunction with proteomics and with antibodies to specific drusen-associated proteins (Curcio et al., 2017). These studies emphasize the heterogeneity of drusen, a concept 
472

473

474

475

476

477

478

479

480

481

482

483

484

485

486

487

488

489

490

491

492

493

494

495

496

497

498

499

500

501

502

initially developed by Sarks and coworkers (Sarks et al., 1980; Sarks et al., 1994; Sarks et al., 1999) and strongly suggest that chronic local inflammation at the level of BrM is an important contributor to drusenogenesis.

In vitro, the transcriptome and proteome of RPE cells, such as cultured primary retinal cells (fetal or from postmortem human donor eyes) (Alge et al., 2003; Oshikawa et al., 2011; Pao et al., 2018) has been determined. Stable isotope labeling of amino acids showed that these cells secrete a variety of extracellular matrix proteins, complement factors, and protease inhibitors, that have also been reported to be major constituents of drusen (An et al., 2006). In addition, abnormal protein secretion by human primary RPE cultures derived from AMD patients has been observed compared to age-matched controls (An et al., 2006). However, the fact that major components of drusen can be reproduced by RPE cells without the need for PR outer segments, supports a crucial role of RPE in drusen formation (Pilgrim et al., 2017). At the same time, it suggests that PRs may contribute but are not essential for drusenogenesis. Off note, it is important to emphasize that cells in culture were treated with heat-inactivated serum, and that the contribution of components from this material to drusenogenesis, as "dietary" contribution, is highly likely (Bretillon et al., 2008; Pikuleva and Curcio, 2014; Pilgrim et al., 2017).

Wang and coworkers found that, after simultaneous mass spectrometry analysis of both archived drusen and RPE material, similar protein profiles, but with higher intensities and greater variability in the drusen. Within the limits of unavoidable sample contamination, these data suggest that other than RPE alone, additional local cells or tissues contribute to formation of debris in the sub-RPE-BL space (Wang et al., 2010).

\subsection{The systemic side of drusen.}

Drusenogenesis theories have focused on the role of lipids and immune-mediated effects. Lipoproteins, neutral lipids (Curcio et al., 2011), complement-activating molecules and other immune mediators as well as monocyte-derived cellular processes have been identified within drusen (Hageman et al., 2001; Penfold et al., 2001; Anderson et al., 2010; Molins et al., 2018), which indicates the biogenesis or propagation of drusen from the systemic side.

\subsubsection{Bruch's membrane.}


503

504

505

506

507

508

509

510

511

512

513

514

515

516

517

518

519

520

521

522

523

524

525

526

527

528

529

530

531

532

533

534

The main functions of BrM are structural, to support the RPE, and to regulate the transport of fluid, ions and biomolecules from the choroid to the RPE, and vice versa (Curcio and Johnson, 2012). BrM thickening and decline of hydraulic conductivity have been observed during aging (Hussain et al., 2010; Cankova et al., 2011). Studies suggest diffuse thickening of the inner aspect of BrM is associated with retinal pigment epithelial hypopigmentation, focal atrophy, and soft (large) drusen formation (Bressler et al., 1994). A variety of extracellular matrix components have been detected in diffuse thickenings of BrM (Fernandez-Godino et al., 2016). Immunohistochemical reactivity of BrM showed age-related accumulation of type I collagen and localized changes associated with some drusen (Newsome et al., 1987; Curcio and Johnson, 2012). The tissue inhibitor of metalloproteinases-3 (TIMP-3) protein, a major component of the drusen proteome, showed high immune-reactivity in human drusen and in BrM (Fariss et al., 1997). The continuous turnover of BrM during life could provide a continuous local supply of BrM proteins. Some of the remnants may be cleared to the blood but some of them might end up in drusen. Please note, that most studies on the aspects of BrM thickening have been performed by light microscopy on paraffin sections. In future studies, it will require TEM or high resolution light microscopy to confirm the majority of these findings, and to distinguish, for example, between "BrM thickening" and basal laminar deposits.

\subsubsection{Choroidal capillaries.}

The choriocapillaris is located directly underneath the RPE and BrM. It is composed of a unique vascular network which provides nutrients and fluid for the RPE and the retina (Bernstein and Hollenberg, 1965). The abundance of fenestrations on the RPE aspect of the choriocapillaris endothelium makes this vascular bed much leakier than nonfenestrated vessels (Bernstein and Hollenberg, 1965). A compromised interface can result in various abnormalities such as choroidal neovascularization (CNV) and AMD (Lutty et al., 2010).

With age and in AMD, the choroid thins. The choriocapillaris loses density and covers an increasingly smaller portion of BrM. At the same time, increased drusen deposition occurs, as witnessed by histopathological evidence (Ramrattan et al., 1994; Ida et al., 2004). OCT Angiography (OCTA) showed atrophy of choriocapillaris underneath and beyond the region of photoreceptors and RPE loss (Wakatsuki et al., 2015; Moreira-Neto 
et al., 2018), in agreement with previous and parallel histopathological studies (McLeod et al., 2009; Biesemeier et al., 2014). In human macular sections, histopathological evaluation of the sub-RPE-BL deposits together with potential vascular changes, showed that vascular density was inversely correlated with sub-RPE-BL deposit density (Biesemeier et al., 2014). Curcio and coworkers observed that modest endothelial cell loss in the choriocapillaris also occurred directly adjacent to basal linear deposits and subretinal drusenoid deposits (Curcio et al., 2013). Sub-RPE-BL deposits showed a positive correlation with the number of ghost vessels in the choroid, suggesting that vascular endothelial cell loss could contribute to deposit formation (Mullins et al., 2011). It has also been shown that the presence of complement components and specifically, MAC, in the choroid increases with aging, and increases even more in AMD-affected eyes (Mullins et al., 2014; Chirco et al., 2016). In fact, C5b-9 complement complexes are present in hard drusen, BrM, and extend to the choriocapillaris in some cases (Johnson et al., 2000; Anderson et al., 2002). C5b-9 complexes were not observed in soft drusen (Mullins et al., 2014).

On whole-mount hydrated preparations of the choroid and BrM, (hard) drusen were located to the intercapillary pillars of the choroid, suggesting a close relationship between drusen formation and the capillary bed (Lengyel et al., 2004). This was observed in earlier studies, but not systematically examined (Friedman et al., 1963). It was suggested that drusen are a manifestation of (a) disturbed transport mechanism(s) of substances across the capillary wall or BrM (Penfold et al., 2001). Whether this indicates that drusen deposition is the result of slower clearance at the intercapillary pillars or a manifestation of a disturbed transport mechanism of substances across the capillary wall, or both, needs additional investigation. Of note, further pathological compromise of the vascular bed and BrM leads eventually to the development of subretinal neovascularization and wet AMD.

\subsubsection{Contribution of blood proteins.}

Penfold and coworkers suggested that breakdown of the normal choroidal vascular function allows the movement of plasma proteins to the sub-RPE-BL space and this leakiness is one of the cause of initiating the progression to AMD (Penfold et al., 2001). Another study involved the analysis of age-related changes in various proteins and lipids in the BrM using multiplexed Raman spectroscopy and found age dependent change in 
567 heme signals (Beattie et al., 2010). However, there are no detailed and definitive studies 568 how these plasma molecules end up in the sub-RPE-BL space. Involvement of

569 fenestrations, breakdown of tight junctions, active vesicle transport (caveola) and

570 receptor-mediated endocytosis (for macromolecules) have been suggested.

571 Fenestrations are found predominantly on the endothelial vessel wall closest to the RPE

572 (Bernstein and Hollenberg, 1965; Pino, 1985; Mancini et al., 1986). Rodent studies

573 suggested that the number of fenestrae initially increases with age; but in advanced age

574 and in AMD the number of fenestrae decreases (Burns and Hartz, 1992; McLeod et al.,

575 2009). Transport through fenestrae is likely to be tightly regulated but it is not yet fully

576 characterized (Pino and Essner, 1981; Essner and Gordon, 1983). Tight junctions of the

577 choroidal capillaries show a tendency to become leaky with age, and lack transport

578 regulation which may facilitate movement of plasma proteins from the choroid towards

579 to the RPE (Nakanishi et al., 2016) (Aiello et al., 1998). Finally, vesicle- or receptor-

580 mediated transport of proteins also exist in the choroid. (Smith et al., 1989). Taken

581 together, transport of proteins at the choroid/BrM interface is complex and warrants

582 further investigation.

583

584 It has long been speculated that both blood plasma and incomplete digestion of

585 photoreceptor outer segments contribute to the buildup of drusen material (Farkas et

586 al., 1971a). It has also been suggested that drusen formation in the retina may be similar

587 to plaque formation in arterial walls (Curcio et al., 2001), which, again, suggests that the

588 contribution of blood proteins may be more important than previously thought (see

589 section 8 on "drusen and plaques"). However, there is a paucity of information as to

590 what extent proteins from the blood really contribute to drusen formation. It is thus

591 plausible that some molecules exit the choroidal vessels into the extracellular space

592 adjacent to the RPE, especially as the barriers in place to prevent such an event from

593 happening, become compromised with age. 

proteins

596

597

598

599

600

601

602

603

604

605

606

607

608

609

610

611

612

613

614

615

616

617

618

619

620

621

622

623

624

\subsection{Exclusion criteria and considerations.}

One of the main goals of this study was to compare subretinal cellular transcriptomics and proteomics as well as the blood proteome with proteins that are present in drusen.

To achieve this, we made use of a subset of studies from the literature as well as our own data. Apart from the drusen protein studies, which date back to 2002, we only considered here mRNA and protein studies published over the last 8 years; we did not include retinal microRNA studies, non-coding RNA, metabolomics, imprinting studies and data from (differences in) single-cell expression studies, simply because there are relatively few confirmed and validated studies for the various types of retinal tissues available yet.

Multiple excellent transcriptomics and proteomics studies have been published on different layers of the retina/RPE/choroid complex, these are reviewed by a number of authors recently (Skeie and Mahajan, 2014; Tian et al., 2015; Zhang et al., 2015a). However, the studies currently available differ in many aspects, including study design, retinal area and retinal cell type examined, sample source selection, sample handling, sample numbers investigated, probe labeling methodology, microarray- or RNA sequencing- methodology as well as the platform, quality and type of bioinformatics programs used for analysis. It is not our goal here to describe and compare all the retinal transcriptomic or proteomic data in the literature. Nonetheless, if one wants to compare different sources (subretinal transcriptomics and proteomics, blood proteomics) and/or outcomes (drusen proteins), similarity of the components and parameters of the comparison(s) is obviously, highly desirable (Ahmad et al., 2018).

In the relevant transcriptomics literature, at least three phases can be observed: studies before and after the introduction of the MIAME (Minimum Information $\underline{\text { About a }}$ Microarray Experiment) quality guidelines studies (Brazma et al., 2001); studies before and after the introduction of whole genome microarrays (at least 22000 genes (22 K or more)) and studies before and after the introduction of RNA-Seq and GTex criteria. Over time, a similar technological development has taken place in the proteomics field: from 2-D gels to high pressure liquid chromatography columns coupled and high throughput 
mass-spectrometry-based studies (Geyer et al., 2016). In principle, the quality of largescale transcriptomics and proteomics studies has continued to improve, and better and more complete datasets may become available in time that may change some of the interpretations described here.

There are several obvious differences between transcriptomics and proteomics studies. In principle, transcriptomics techniques are highly sensitive and highly quantitative, but as such, highly susceptible to RNA contamination or degradation. In addition, transcriptome changes may not equate with changes on coded proteins and as such are further away from biological function.

Proteomics studies, however, are usually less sensitive and quantitation can only be achieved under certain circumstances, but proteomes per se are closer to function. During disease progression, transcriptomics and proteomics profiles of a tissue can change rapidly depending on disease stage. Also, a single tissue under study can be affected by two or more consecutive disease stages at the same time. For example, in AMD, new hard drusen continue to appear in the sub-RPE-BL space, while other drusen in the same tissue already become confluent, and perhaps part of the same retina is already prone to neovascularization. Consequently, for a disease like AMD, where the RPE is subject to consecutive, insidious and overlapping disease stages, it is very difficult to sift out useful and consistent healthy and disease stage specific expression profiles for this cell layer.

Obviously, transcriptomics and proteomics studies cannot be translated one-to-one, due to, for example, differences in RNA and protein synthesis and turnover rates. The sound interpretation of both transcriptomics and proteomics is highly dependent on the use of advanced bioinformatics and knowledge databases, which combine millions of datapoints from human, mouse, and rat studies. Nonetheless, it is the investigator, with knowledge of disease pathology, molecular biology and bioinformatics alike, who can make the difference.

There are two goals with most transcriptomics (or proteomics) studies: One type of study aims to find a complete molecular blueprint of the cells or tissues of interest; these studies usually yield an enriched expression data set for the cell of interest. This type of study usually includes both genes specifically expressed in the cell type of interest, but also genes expressed in similar cell types. For example, the RPE is probably defined by a few hundred RPE-specifically expressed genes, a few thousand neural cell-type 
expressed genes, many expressed housekeeping genes for basic functions, as well as many genes which are on "standby". The genes that are on "standby" have a very low (leaky) expression if the cell in is a state of homeostasis. However, if the environment changes, these very low expressed genes can rapidly be expressed to adapt the cell to a changing environment. For example, the RPE shares most likely the RNA expression of a large portion of its transcriptome: neural cell type genes, the household genes, and lowlevel expressed genes, with the other (neural) cell types in the retina (own observations). Finally, there are many specific non-expressed genes in a certain celltype. An example of expression studies which aim to find a molecular blueprint of the cell is the uncurated RPE expression dataset, RPE-ET (Table 3), which contains 10\% of the biologically highest expressed genes in the RPE (Booij et al., 2009).

The other type of study aims to find only a maximum of genes specifically expressed in only the cells or tissue of interest. These few hundred genes, in the context of the more generally expressed genes, give the cells of interest their specific cell type-associated functionalities. An example is the dataset, RPE-ST (Bennis et al., 2015), which contains 170 RPE-specific expressed genes derived from previous RPE expression studies (Booij et al., 2009; Booij et al., 2010b; Strunnikova et al., 2010) (STable 2).

\subsection{Description of expression datasets used for drusenomics.}

Apart from the 89 drusen protein data set, we used in this review 11 additional subretinal and blood data-sets derived from previous transcriptomics and proteomics studies; this is summarized in Table 3. We found that these transcriptomics and proteomics databases complement each other and, together, give a more complete overview of relevant expressed genes/proteins per tissue investigated. A common feature of all high throughput studies is that they generate, by default, a small percentage of misidentifications. This is due to cellular or molecular contaminations, or mis-representation due to experimental sample handling. Therefore, individual gene findings usually need to be confirmed by at least a second technique which focuses on the analysis of single genes or proteins.

We used pure, enriched and curated cellular expression datasets. Pure datasets are those without possible contaminations of other cell types while enriched datasets are those datasets that have a certain degree of contamination of adjacent cell types. Finally, curated datasets are those which are manually enriched either by bioinformatics or by 
690 literature search to remove inevitable contaminations or irrelevant data as much as

691 possible. The curation strategies employed are presented in Figure 3.

692 Most of the (non-curated) data were used for qualitative studies, have been published

693 and analyzed elsewhere, and are mentioned below for reference. For the quantitative

694 studies, we used curated datasets. The photoreceptors and choroidal transcriptome

695 datasets, cPR-ET and cChor/ET (Booij et al., 2010b) (GEO database accession number

696 GSE20191) have not been fully published before and therefore, their description will

697 receive a little more attention here.

698

699 First of all, we used (1) a combined data set for drusen proteins, curated by hand as

700 described above (Table 1). Furthermore, we used (2) a photoreceptor outer segment

701 proteomics dataset published by Kiel and coworkers (Kiel et al., 2011), which contains

702 proteins reflecting a multiscale signaling network associated with rhodopsin, the major

703 protein component of rod photoreceptor outer segments. It was constructed by

704

705

706

707

708

709

710

711

712

713

714

715

716

717

combining relevant proteomics datasets, structural and functional literature mining and bioinformatics approaches (Table 3; STable3). Most likely, this database listing contains some contamination from adjacent cell types, the RPE and choroid. Therefore, a curated list was used for the quantitative studies: we subtracted the most highly expressed sequences of the choroid (top 10\% chor Booij; Chor-ET; and the uniquely expressed sequences of the RPE (RPE-ST, Bennis)) from this database listing. The acronym used for this dataset in this manuscript is PRos-EP ( Photoreceptor outer segment-enriched proteomics). The annotation of the curated version (c) of this dataset is cPRos-EP. (3) The RPE-specific database with 170 entries was constructed by bioinformatic curating and combining other (highly) enriched RPE gene expression databases (Booij et al., 2010b; Strunnikova et al., 2010; Bennis et al., 2015). This database listing should be viewed as a minimal number of RPE-specific expressed genes based on previous -omics studies; the acronym used here is RPE-ST (ㅁppecific Transcriptomics) (Table 3; STable 2). (4) The RPE secretome data from (Pao et al., 2018) that was published recently. RPE cells were grown in vitro to confluency while adding various amounts of zinc to the culture medium. Both the apically and basally secreted RPE proteomes were determined. Here, we use the basal secretome proteomics listing which contains 276 entries. (Table 3; STable 1). Due to its nature, this dataset does not contain contamination from other cell types but may contain contaminants from the culture 
medium. In addition, its in vitro basis may not be fully representative of the in vivo situation, particularly in the disease state. The acronym for this database in this study is RPE-IVS (in vitro secreted) (Table 3).

(5) The RPE/choroid proteomics dataset from Zhang and coworkers that contain proteins extracted from RPE/choroid tissues of eyes from five individuals, fractionated and separated using SDS-PAGE and analyzed using mass spectrometry (Zhang et al., 2016). In the RPE/choroid the authors identified 2755 non-redundant proteins. This dataset is rather large in components and is likely to contain entries from multiple celltypes (RPE, choroid, blood and possibly PR), and not only (RPE/choroid), given the inevitable contaminations of the PR sample with RPE and vice versa, and the contamination of the choroid with blood. The authors deposited their data to the ProteomeXchange Consortium via the PRIDE partner repository with the dataset identifiers PXD001424 and PXD002194. The acronym for this database in this manuscript is RPE/chor-EP (르/choroid-enriched proteomics) Table 3.

(6) The blood proteome listing by Geyer and coworkers was produced by a new efficient plasma proteome profiling pipeline (Geyer et al., 2016). Using a modified mass spectrometry-based workflow they were able to identify and quantify at least 1000 plasma proteins. Given the nature of the samples, it is unlikely to contain other retinal cells or proteins as contamination. The acronym for this database in this study is BL-SP1 (미ood plasma-specific proteomics; no 1) (Table 3; STable 4) (Geyer et al., 2016). (7) The blood proteome dataset by Farrah and coworkers contains a non-redundant set of 1929 protein sequences from human plasma detected by tandem MS (Farrah et al., 2011). The full data are available via PeptideAtlas, a large, international database of publicly accessible peptides identified in tandem MS experiments in a multitude of organisms. This is also a "pure" database listing. The original dataset contains endogenous chemicals, which we removed for our analyses. The acronym for this database in this study is BL-SP2 (ㅁlood plasma-specific proteomics, no $\underline{2}$ ); (Table 3). (8) The BL-PHP blood proteome dataset consists of 262 HAP binding proteins from AMD patients and controls, as recently described (Arya et al., 2018). Plasma samples were taken from 23 individuals aged 65-90 with late stage AMD, each displaying drusen and choroidal neovascularization in clinical images and attending the anti-VEGF injection clinic at Moorfields Eye Hospital, London (STable 5). 
(9) The atherosclerosis plaque proteomics dataset contains 3196 entries based on a

756 comprehensive review of the literature in this field (Bleijerveld et al., 2013). The

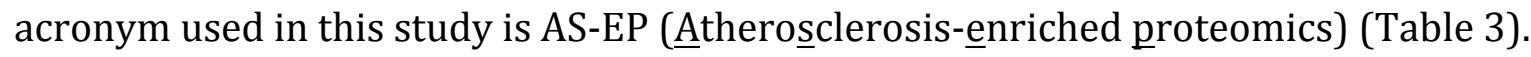
The (large) dataset is available as supplementary file to the authors' publication. (10-12) Transcriptomics datasets of the photoreceptor (acronym: PR-ET: Photoreceptor; enriched transcriptomics), the choroid (acronym: Chor-ET: $\underline{\text { Choroid- }}$ enriched transcriptomics.) (Table 3), and RPE (acronym: RPE-ET: RPE-enriched transcriptomics) were produced using the same Agilent methodology and platform. For functional annotation and quantitative analyses, curated versions of these databases were constructed, named, respectively, cPR-ET (STable 6) and cChor-ET (STable 7). The (c)RPE(-ET) database has been extensively published elsewhere (Booij et al., 2009; Booij et al., 2010b).

\subsection{Functional annotation photoreceptor (cPR-ET) and choroidal (cChor-ET) datasets.} The PR-ET and Chor-ET datasets contain, respectively, the averaged top 10\% highest expressed genes in the photoreceptor and choroid. The isolation methods, study design and methodological issues for these datasets have been extensively discussed elsewhere (Booij et al., 2009; Booij et al., 2010b). These raw datasets were used for the qualitative studies in this manuscript. The experimental studies were performed in agreement with the declaration of Helsinki concerning the use of human material for research and followed both MIAME and GTex criteria (Brazma et al., 2001; Consortium, 2013). We curated both datasets PR-ET and Chor-ET according to scheme C in Figure 3. In order to obtain cell-specific datasets for photoreceptor and choroid, which are useful for both cell-specific functional annotation and for quantitative studies described elsewhere in this manuscript. Consequently, we removed from the PR-ET and Chor-ET datasets all expressed genes that overlap between them (either contaminations or truly shared gene expression). This resulted in two smaller curated datasets. Subsequently, we also removed all potentially present RPE-expressed unique sequences (RPE-ST dataset) to generate the cPR-ET and cChor-ET datasets. Thus, the resulting cPR-ET and cChor-ET datasets contain less, but highly cell-specific entries compared to PR-ET and Chor-ET. Hence, we ended up with a highly photoreceptor-enriched gene expression dataset consisting of 745 genes (STable 6) and a highly enriched expression dataset for the choroid of 848 entries (STable 7). 
We ran an Ingenuity core analysis (www.ingenuity.com) on both cPR-ET and cChor-ET datasets. This type of analysis typically yields data-driven functional annotations (i.e. it produces biological motifs, canonical pathways and molecular networks enriched in the dataset). The results of the cPR-ET analysis are presented in Table 4; PDF summary. We found some very basic and very specific functional features related to established photoreceptor function. The basic annotations included "cancer", "cellular function and maintenance" as well as "tissue morphology". One could speculate that these relate to the unique shape of the photoreceptor cell, and its unique ability to renew its photoreceptor outer segments. More specific (highly ranked) annotations included "photo transduction cascade", "visual system development and function" and "neurological disease". These data-driven results clearly fit with reported specific photoreceptor functionalities from the literature (Diamond, 2017; Musser and Arendt, 2017; Fain and Sampath, 2018).

800 The choroidal transcriptomics dataset cChor-ET was generated in a similar way to the photoreceptor cPR-ET dataset described above. Obviously, the choroid is not a single tissue, but consists of multiple cell types, including endothelial cells, fibroblast cells, melanocytes, macrophages, and resident lymphocytes. The choroid is unavoidably contaminated with blood cells and proteins. Nevertheless, after curation, we obtained 848 genes with a highly enriched choroidal expression in the cChor-ET dataset (STable 7). Following Ingenuity core analysis, the resulting functional picture of the choroid is, as expected, completely different from that of the photoreceptors (Table 5; PDF summary). We found that two of the top five biological motifs ("inflammatory response" and "inflammatory disease") and three canonical pathways ("antigen presentation pathway", "acute phase response signaling" and "complement system") are all involved with the immune system. This confirms the crucial role of the choroid and blood in external immune surveillance of the eye (Dick, 2017). The second highlight of this analysis was the canonical pathway "atherosclerosis signaling" which again points to an important resemblance between healthy or disease processes going on at the BrM (choroidal-RPE

interface) and the vessel walls (see also section 8).

816 Finally, both the canonical pathways and the highest ranked networks identified in this 817 cChor-ET analysis indicate tissue damage and injury. One possible explanation is that 818 this damage refers to early molecular complement attack already present or setting in, 819 which may be well before any morpholocial changes or damage may be visible. 
820 Alternatively, although we used data from healthy post-mortem eyes, performed the 821 studies according to MIAME and GTex guidelines, 3' primer design which avoids

822 potential problems due to 5' directed degradation, as well as very stringent RNA quality 823 controls, the tissue damage and injury might still be due to post-mortem damage.

824 Detailed data relating to both cPR-ET and cChor-ET analyses are available on request. 


\section{Drusenomics, part II: Qualitative analysis.}

826

827

828

829

830

831

832

833

834

835

836

837

838

839

840

841

842

843

844

845

846

847

848

849

850

851

852

853

854

855

\subsection{Comparative study design considerations.}

From the previous sections, it has become clear that a systematic investigation into the origin of proteins in drusen is lacking in the literature. Authors suggest a variety of protein sources, frequently on the basis of single observations. Systematic investigation of this phenomenon is hampered by the heterogeneity of source samples, methodology, and analysis. Large scale transcriptomics or proteomics studies frequently end up with a rather abstract annotation analysis, allowing a certain error rate and lack of detail; small scale studies frequently lack sufficient technical, methodological or biological replicates. In a first attempt to investigate the origin of drusen-proteins systematically, we used the presence of functional protein clusters identified in drusen (described in section 2).

Subsequently, we investigated whether expression of entities in these clusters also (partly) occurs in the various non-curated expression database sets selected for this study. An overview of this comparison is presented in Table 3. This comparison serves two purposes: Firstly, the presence or absence of clusters in subcellular databases or blood may give a qualitative indication of the origin of (the proteins in) the cluster and secondly, it gives an indication of the completeness, quality, and contamination in each of the databases listed.

We argued above (section 4.2.) in detail that all individual transcriptomic and proteomics database lists used here (and those in the literature) are incomplete and, as a rule, have a degree of RNA/protein/cellular contamination due to original mixed cell sampling. How do we compare incomplete, contaminated datasets?

First of all, one should have some knowledge of the study-design and character of the dataset under study, to understand why certain entries do, or do not, appear. The characteristics of the databases used are described in section 4.2 above. As an example, in the study of RPE/Chor-EP expression dataset (Table 3) we systematically identified that a large number of functional cluster queries/entries are indeed present. However, this is most likely due to the fact that the RPE/Chor-EP study contains proteins from photoreceptor, RPE, choroid and blood. Thus, we decided to use this dataset as a positive control (i.e., a dataset where almost all genes relevant to the study are expressed/present). Similarly, we used either the unique sequences from the RPE-ST 
dataset, or the consequent absence of an entry in a set of similar dataset listings, as a negative control.

In our qualitative comparison, the incompleteness and potential contaminations of the various non-curated datasets (Table 3) may be largely overcome by considering similar data from different studies at the same time. For example, a specific query may be present in all photoreceptor studies, and, at the same time be absent from all blood proteomics studies.

\subsection{Where do proteins in drusen come from? A qualitative comparison.}

We will now turn to the interpretation of the highlights of the comparative study results presented in Table 3. In the first column (top to bottom) the functional gene clusters from the molecular networks of drusen (Figure 2a-2d) are presented together with their individual gene content (column 2) and functional annotation (column 3). On the top rows (fourth column onward), subretinal transcriptomics and proteomics as well as blood proteomics data(sets) from the literature are given. For full length names of the abbreviated gene/proteins, see Table 1.

\subsubsection{Network 1.1: The complement gene cluster.}

The first functional cluster (Table 3; Figure 2a), in our analysis consists of the complement end proteins: C7, C8 isoforms as part of the/and the Membrane Attack (MAC) protein group in general as well as the multifunctional PRELP protein. Mutations in PRELP cause myasthenic syndrome (Engel, 2018). Among other functions, PRELP is involved in regulation of the complement cascade (Engel, 2018). As expected, we observed that the (alternative pathway) complement gene transcripts/proteins are absent from all photoreceptor and/or RPE transcription and proteomics datasets (PRosEP, PR-ET, RPE-ET, RPE-ST, RPE-IVS). The only possible exception is the presence of these proteins in the RPE/chor-EP dataset (positive control), where they most likely originate from the choroid/blood component of the sample (please note again that the choroid sample is inevitably contaminated with blood). In contrast, in 2 out of 3 bloodplasma datasets (BLP-SP1 and BLPHP) this cluster is present, except for PRELP. The latter entry is apparently uniquely present in the Chor-ET listing (and in the positive control RPE/Chor-EP) and is probably produced in the choroid. Interestingly, this leads us to suggest that the systemic driven complement attack from the blood is locally regulated by PRELP produced by choroidal cells (Happonen et al., 2012). 
889

890

891

892

893

894

895

896

897

898

899

900

901

902

903

904

905

906

907

908

909

910

911

912

913

914

915

916

917

918

919

\subsubsection{Network 1.2: The collagen cluster.}

The second functional cluster is that of the collagens and related molecules (Table 3; Figure 2a). Here, the picture directly becomes, perhaps understandably, more complicated. Collagen proteins are likely to be produced (RNA, protein) by the basal secretion of the RPE and apical secretion of choroidal cells, and become part of the acellular BrM (Booij et al., 2010a) and, at least theoretically, by the apical RPE and by the PR for the interphotoreceptor matrix (IPM). Indeed, proteomics of apical RPE secretion in vitro (Fort and Lampi, 2011) and functional annotation of the in vivo human RPE and photoreceptor predicted secretomes (based on transcriptomics of the RPE and photoreceptor cells; Bergen, unpublished), suggest that several specific collagen proteins may (transiently) be present in the IPM, although their presence was never detected by immunohistochemistry (yet).

During life, there is a constant turnover of ECM's, resulting in a mix of newly synthesized and (partly) digested collagen fragments shuttling around the subretinal area. Interestingly, the unique RPE-ST database (170 entries) does not contain any collagen related entries, thereby confirming that, if the RPE produces collagen, none of these collagens are made exclusively by the RPE (but also by adjacent tissues like the choroid). Further to this, it is of interest to note that collagen (type 8A1) is produced or present in the PR-ET, RPE-ET, Chor-ET and the RPE/CHOR-ET datasets, which supports the hypothesis that the (two collagenous layers of the) BrM, at least in part, are built from both the RPE and choroid sides side (Booij et al., 2010a). The data in Table 3 further suggest that the BrM proteins COL1A2, COLA1 and COLA2 are produced or are present exclusively (or at least mainly) in the Chor/blood, and not in the PR and RPE datasets. COL6A1 is secreted basally by the RPE in vitro (Pao et al., 2018) (Table 3), and is part of the BrM (Booij et al., 2010a). Consequently, the protein may end up in the drusen dataset either as a contamination, or as a remnant of the turnover of BrM components. The proteins THBS4 and TNC occur only in one of the blood proteomics datasets (BLSP1). The presence of other entities (RBP3, EFEMP1, PLG, GPNMB, SEMA3B, TBHS4) from this cluster in multiple PR/RPE and Chor/blood listings suggest that these genes/proteins can be derived from different sources.

\subsubsection{Network 1.3: The crystallin cluster.}


The third cluster of drusen proteins to be discussed are the crystallins (Crabb et al., 2002; Nakata et al., 2005) (Figure 2a), frequently referred to as heat-shock proteins, which act as chaperones to prevent or reduce protein degradation in stressed or aging cells. Although they may have a more structural role, it is possible that the expression of crystallins is increased only in those studies in which cells or tissues have been exposed to a relatively large amount of stress. This would mean that further systematic and methodological analysis of consistent (differences in) expression does not make sense. It is remarkable however, that the CRYBB2 protein is present in the PRos-PT, RPE-IVS, and the RPE/Chor-EP studies and in drusen. Consequently, this protein may originate from the PR outer segments, processed, transported and secreted by the RPE and then accumulates in drusen. To our knowledge, this is the only photoreceptor protein known to possibly make it through phagocytosis and lysosomal processing in the RPE and end up in drusen (Feeney-Burns et al., 1988; Hoppe et al., 2001).

\subsubsection{Network 2.4: Genetic and developmental ophthalmic disorders.}

The fourth functional gene cluster (Network 2, Figure 2b) can be considered as a pathobiological cluster of developmental and ocular disease. The comparative analysis (Table 3) shows that ATP5F1B, ACTB and annexin2 (ANXA2), are present in a number of PR/RPE and Chor/blood expression datasets. These entries may thus be expressed in multiple cell types or blood. ANXA2 is included here "within brackets", since it was initially assigned to drusen using proteomics, but later the same authors stained for ANXA2 in human donor eyes and concluded it was not present in drusen (Crabb et al., 2002; Nakata et al., 2005). The CRYAB, ENO2 and SPTAN1 proteins cannot be clearly assigned, but appear to be of a local cellular origin (PR, RPE, or Chor) and not from the blood. The subcellular/systemic assignment of the FN1 and MYH9 entries are not clear. The BFSBP1 and BFSP2 proteins neither occur in the subretinal datasets, the blood proteomics lists, nor the positive control (RPE/Chor-EP; Table 3). According to the literature, both are structural proteins that specifically form filaments in the cytoskeleton of lens-cells (www.ingenuity.com). We therefore conclude that these are very weakly expressed genes which express proteins that build up slowly and/or with a long half-life. The only other explanation that could be offered is that they are contaminations within the drusen dataset.

\subsubsection{Network 3.5: Injury, inflammation and dermatological disease.}


952 The fifth functional drusen cluster (Network 3; Figure 2c) is related to interacting genes 953 and proteins involved in injury, inflammation and dermatological disease. A substantial 954 number of entries of this group seem to have both a cellular as well as a systemic 955 presence or origin since they are present in at least two database listings from PR/RPE 956 and Chor/blood category. These include ANXA1, ANXA5, CKB, GAPDH, PRDX1 and 957 S100A8.

958 The SERPINA3 and ALDH1A1 proteins appear only in at least two of the RPE-Chor-EP, 959 Chor-ET, BL-SP1, BL-SP2 and the BL-PHP datasets, but not in the PR/RPE dataset. Thus, 960 both proteins appear to come from the systemic side of drusen. FRZB (SFRP3)

961 (www.genecard.org) is present in 3 PR/RPE listings (Table 3), including the RPE-specific 962 listing (RPE-ST), and in only one choroid-enriched list (Chor-ET). We tentatively assign 963 this drusen protein primarily to the RPE, and as a contamination in the (PR and/or) Chor 964 database listings. S100A7 is only once present in the PRos-EP proteomics dataset. 965 Assignment of S100A9, TYRP1, LAMB2, APOE, and FrzB or LUM to a single source cannot 966 be done on the basis of this comparison.

967 5.2.6. Network 4.6: Cell to cell signaling; systemic involvement.

968 As can be expected from the functional annotation "cell to cell signaling; systemic 969 involvement", almost all of the entries of this category of drusen proteins, appear in the 970 Chor/blood datasets (Table 3). The exceptions are clusterin (CLU), ANXA6 and HRG. 971 From the literature, we know that CLU is a ubiquitously expressed gene that is 972 expressed in all cell types (Wilson and Zoubeidi, 2017). It is therefore not surprising that 973 it features in both the PR/RPE as well as the Chor/blood listings. The final assignment of 974 ANXA6 and HRG, on the basis of this comparison is not clear. The role of the systemically 975 derived HRG drusen protein is discussed in detail below (section 7). Of particular 976 interest is the expression of $\mathrm{CFH}$, given its central regulatory role in the complement 977 attack on (chemically modified) drusen components. There is compelling evidence in the 978 literature that $\mathrm{CFH}$ is present in the blood, the neural retina and that it is also expressed 979 by the RPE (Li et al., 2014; Mullins et al., 2014; Whitmore et al., 2014; Chirco et al., 2016; 980 Chirco and Potempa, 2018; Toomey et al., 2018). The presence of CFH protein in the 981 blood corresponds with the data and proteomics listings of blood in Table 3. What is not 982 entirely clear is why CFH does not pop up in the RPE listings. This can perhaps be 983 explained as follows: The enriched RPE-ET transcriptomics list contains only the highest 
$98410 \%$ expressed genes in the RPE. Apparently, CFH is somewhat lower expressed and so 985 does not belong to this group (Warwick et al., 2014). Also, the RPE-ST specific listing 986 only contains 170 entries uniquely expressed by the RPE; whilst CFH is produced in 987 other cells or blood as well. Finally, CFH does not occur in the RPE-IVS basal secretion 988 proteomics listing, which is not entirely unexpected as recent evidence suggests that 989 CFH is secreted apically, not basically by the RPE (Kim et al., 2009; Pao et al., 2018).

990 5.2.7: Conclusion.

991 On the basis of our qualitative comparison, we suggest that a number of (functional 992 clusters of) drusen proteins come from the blood, while others come from a subretinal 993 cellular compartment. These results are in line with the findings in the literature.

994 However, it is not clear yet how many of the drusen proteins come from each particular 995 compartment. The latter may be estimated by a more quantitative analysis, which is the 996 subject of the next section.

997 


\section{Drusenomics, part III: A quantitative approach}

999

1000

6.1. Quantitative analysis and curation of datasets.

1001 In this chapter, we quantitatively compare drusen proteins with transcripts and proteins

1002 from adjacent retinal compartments (photoreceptor, RPE, choroid) and blood. As

1003 described in section 2 above, the drusen protein list was compiled manually according

1004 to the curation strategy presented in Figure 3, scheme A. Similar to the qualitative

1005 studies, the quantitative analysis of the origin of drusen proteins is also hampered by

1006 two problems: (a) most large scale cellular transcriptomics and proteomics datasets

1007 contain some contamination (both RNA and/or protein) from adjacent cells or tissues,

1008 and (b) most of the datasets are incomplete due to differences in the study design and

1009 methodology used in contributing studies. In other words, we need to use a quantitative

1010 comparison strategy that maximizes the signal (number of entries to be compared) and

1011 minimizes the noise (number of contaminations in datasets). We overcame the

1012 incompleteness of various datasets by pooling the entries from various similar (cell-type

1013 specific) studies, to get a more complete numerical picture (Figure 3, scheme 3A).

1014 With regard to possible contaminations, we used two types of datasets. The first

1015 category includes datasets that, by definition or by previous curation in the literature,

1016 contain cell-specific expressed entries only, such as the RPE-ST, RPE-IVS, BL-SP1 and the

1017 BL-SP2 datasets (section 4.2 and/or Table 3). . The curation of datasets PR-ET and Chor-

1018 ET into cPR-ET (STable 6) and cChor-ET (STable 7) was already described above

1019 (section 4.2). The other category datasets used (PRos-EP, PR-ET, Chor-ET) were newly

1020 curated, as presented in Figure 3 and 4, in such a way that they, after curation, also only

1021 contained cell-type specific entries

1022 The PRos-EP dataset was curated according to the curation strategy presented in Figure

1023 3, scheme 3C: We removed from the PRos-EP dataset (in principle containing

1024 photoreceptor outer segment expressed genes only) all choroidal highly expressed

1025 genes (from Chor-ET) as well as potentially present uniquely RPE expressed entries

1026 (from RPE-ST) resulting in the curated cPRos-EP dataset (STable 6). The removed

1027 choroidal and RPE entries were (potentially) present in the PRos-EP dataset due to truly

1028 overlapping gene expression between these different cell types and/or due to

1029 contaminations in the original cell sample. Of note, cPRos-EP does still contain entries

1030 from both photoreceptor and RPE since contamination between these two is inevitable. 
1031 Together, the database listings cPRos-EP, cPR-ET, RPE-ST and RPE-IVS form the neural 1032 side of drusen database listings (Figure 4). Similarly, the cChor-ET, the BL-SP1 and the

1033 BL-SP2 constitute the systemic side of proteins found in the drusen dataset. In summary,

1034 we ended up with three large datasets suitable for further robust analysis: The drusen

1035 protein dataset, the "neural source of drusen" database, and the 'systemic source" of 1036 drusen dataset (Figure 4).

1037 Next, we compared the entries present in the "neural source listing" and in "the systemic 1038 source listing" with the proteins present in drusen. The result of this analysis is 1039 summarized in the Venn-diagram in Figure 5. The comparison revealed that 10 proteins 1040 appeared to be uniquely derived from the neural side (Table 6) and 37 proteins are 1041 derived from the systemic drusen side (STable 8). In addition, there were 23 proteins 1042 that come (potentially) from both the neural and systemic side (STable 9). For 19 drusen 1043 proteins (out of the 89), the origin remained unclear as they were neither present in the

1044 "neural source" nor in the "systemic source" expression datasets (STable 10).

\subsubsection{Ten out of 89 drusen proteins originate uniquely from the PR/RPE.}

1046 Our analysis yielded 10 drusen proteins that originate from the PR or RPE (Figure 5;

1047 Table 6). They are both uniquely present in the drusen proteomics dataset and the 1048 neural source of drusen database listing. We traced these proteins back to their original 1049 source(s), and we observed that three of them (FRZB, RDH5 and RGR) originally came 1050 from the unique entries in the RPE-ST dataset, five came from the RPE-IVS dataset 1051 (CRYBA1, CRYBA4, CRYBB2, ENO2 and TUBB3), and the remainder from the cPRos; cPR1052 ET datasets. Taken together, 8 out of the 89 drusen proteins originated uniquely from 1053 the RPE, while 2 came from the curated PR/RPE database listings (cPROS; CPR-ET) 1054 (Table 3). Finally, we also reviewed the psychochemical properties and molecular 1055 weight (Mw) of these 10 proteins (Table 6). We do not know the HAP binding properties 1056 of these proteins, but they do not occur in the BH-PLP HAP-binders' dataset (STable 5). 1057 In conclusion,, we did not observe any common signatures of these proteins that would 1058 explain why they in particular are trapped in the sub-RPE-BL space (whilst other 1059 proteins are not).

1060 6.1.2. Twenty-three of 89 drusen proteins originate from both neural and systemic 1061 sources. 
1062 From our analysis, 23 drusen proteins were present in both the "neural source" as the

1063 "systemic source" datasets (Figure 5; STable 9). From these, only 1 protein (S100A9)

1064 falls in the curated PR/RPE category (Figure 4). Additional groups of two and twenty

1065 proteins come from the unique RPE RPE-ST and the RPE-IVS datasets, respectively. At

1066 the same time, all 23 of these proteins are also present in the blood. Remarkably, in this

1067 shared category the majority of proteins are either secreted basally by the RPE or

1068 present in a soluble form in the blood plasma. We hypothesize that the proteins in this

1069 category enter the sub-RPE-BL from both sides, where they "meet, greet and stick", i.e.

1070 form aggregates that cannot be cleared and therefore contribute to drusenogenesis.

1071 Functional and pathobiological annotation of (combinations of) these proteins can be

1072 found in STable 9a.

1073 6.1.3. Thirty-seven out of 89 drusen proteins originate from the choroid/blood.

1074 We found that 37 out of 89 drusen proteins uniquely originate from choroid or blood

1075 datasets (STable 8). From these, 31 proteins came from the plasma-proteomics datasets

1076 (BL1-SP1 and BL-SP2). The remaining six entries (ANXA6, FLBN5, HLA-DRA, MFAP4,

1077 PRELP, SEMA3B) are present in cChor-ET database listing and thus originate from either

1078 the choroid or blood. Functional and pathobiological annotation of (combinations of)

1079 these proteins can be found in STable 8a.

1080 In summary, we again observed a large proportion of drusen proteins are most likely

1081 originating from the blood. If we take this unique category (31 proteins from plasma)

1082 and the shared contribution of plasma (23 proteins) from the previous paragraph into

1083 account, we can conclude that as many as 54 out of 89 drusen proteins ( $>60 \%)$ are (co-)

1084 derived from blood plasma.

6.2. Nineteen drusen proteins out of 89 were not assigned.

1086 We can, in the end, still not determine the possible origin of 19 out of 89 drusen proteins

1087 (STable 10) Why is this not possible? Do these proteins have a number of characteristics

1088 in common that prevents us to determine their origin? To attempt to answer these

1089 questions we need to take a closer look at these remaining drusen proteins. The

1090 functional annotation of these proteins is presented in STable 10a and they can be

1091 divided in five groups: (1) a gamma-crystallin group; (2) a histone cluster group; (3)

1092 (remnants from) BrM turnover group (4) a beaded filament group; (5) a rest group

1093 containing a variety of proteins that do not belong to a specific functional group. 
1094 In group one, we observed several gamma-crystallin-isoforms in drusen, which have not 1095 been assigned to a specific source (as yet). Crystallins are commonly found in the lens 1096 but are also present in soluble form in the retina (Jones et al., 1999) and probably act as 1097 chaperone proteins after (oxidative) stress. Indeed, in the mouse retina, crystallin 1098 expression has a binary nature in which either they are highly upregulated, or their 1099 expression is extremely low (Templeton et al., 2013). Gamma-crystallins may have a 1100 neuroprotective role (Thanos et al., 2014). At least one specific type of crystalline 1101 (alphaB type) is known to be secreted by the RPE through micro-vesicle release (Kannan 1102 et al., 2016). In conclusion, the source assignment of gamma-crystallin isoforms in 1103 drusen, in our comparison, may be hampered by this binary expression. More 1104 specifically, it will simply be absent from a number of subretinal expression datasets and, as such, too little evidence exists to make a definite assignment.

1106 Next, we found a group consisting of HIST1H1E, HIST1H2BJ, HIST1H2BL and

1107 HIST2H2BE. Histones are highly basic proteins that have an essential role in the

1108 maintenance of nuclear DNA structure and gene transcription. HIST1H1E is a 219-amino

1109 acid protein that binds to the linker DNA stretch between nucleosomes, while HIST2,

1110 together with HIST3 and HIST 4, are part of the nucleosome core (Tessarz and

1111 Kouzarides, 2014). Damaged or dying cells (potentially RPE or endothelial cells of the

1112 choroid) can release cellular as well as nuclear fragments that may contain histones.

1113 Alternatively, high concentrations of serum histones have been detected in several

1114 human diseases (Yang et al., 2015). These extracellular histones may get trapped in BrM 1115 and drusen. Interestingly, extracellular histones trigger activation of multiple signaling 1116 pathways related to cell death, growth and inflammation and may play a role in auto1117 immunity, aging and disease (Allam et al., 2014; Kalbitz et al., 2015; Zhang et al., 2015b). 1118 Why these specific histone proteins (and not others) are trapped in drusen and cannot 1119 be assigned to a source remains to be elucidated.

1120 The third drusen protein group with an as yet unassigned source contains elastin (ELN), 1121 collagen 8A1 (COL8A1), biglycan (BGN) and tissue inhibitor of metalloproteinase 3 1122 (TIMP-3) proteins. These proteins may come from an as yet little considered drusen 1123 protein source: the BrM and its (turnover) components (Booij et al., 2010a; Curcio and 1124 Johnson, 2012). TIMP-3 is expressed in the RPE (Ruiz et al., 1996) and is crucial for the 1125 maintenance of BrM. Mutations in TIMPO-3 caused Sorsby Fundus dystrophy, a 
monogenic disease that resembles the phenotype of AMD (Weber et al., 1994). Indeed,

1127 as described previously, BrM is dynamic in nature, not only in a physiological sense, but

1128 its composition and properties vary with age. Proteins involved in BrM and its turnover

1129 may be absent from (some of) our subretinal transcriptomics and proteomics datasets, if

1130 the relative expression levels of such entries are low. The middle layer of the BrM

1131 consists of elastin so it is conceivable that the RPE and/or choroidal cells make this

1132 protein. Within the BrM, elastin turnover might be relatively low, thus little "new"

1133 elastin is needed. While elastin protein fragments (tropo-elastin) might be present in

1134 some drusen as a remnant from BrM-turnover, there is little evidence in the literature

1135 that they accumulate in drusen.

1136 Fourth, two members of the beaded filament structural protein family, BFSP1 and

1137 BFSP2, remain unassigned. Similar to crystallins, these proteins were initially

1138 discovered as lens fiber proteins. To our knowledge, it is not clear whether they also

1139 play a role in retina/RPE or maybe even the BrM. How these proteins end up in drusen

1140 and their origin remains unclear.

1141 The fifth, yet unassigned group contains a number of, apparently, unrelated proteins,

1142 including retinol binding protein 3 (RBP3), tyrosinase protein-like 1 (TYRP1), spectrin

1143 alpha, non-erythrocytic 1 (SPTAN1), disco interacting protein homologue (DIP2C),

1144 forkhead-associated phosphor peptide (FHAD1), and scavenger receptor class B

1145 member 2 (SCARB2).

1146 The RBP3 gene is transcribed in the PR and its protein is located in the

1147 interphotoreceptor matrix (IPM). It binds to retinoids which are shuttled from the PR to

1148 the RPE, and vice versa (Gonzalez-Fernandez et al., 1993). The TYRP1 gene belongs to

1149 the tyrosinase family transcribed in the RPE and encodes an enzyme in the melanin

1150 biosynthetic pathway (Lai et al., 2018). Mutations in this gene are one of the causes of

1151 albinism (Kamaraj and Purohit, 2014; Kruijt et al., 2018). Both RBP3 and TYRP1 genes

1152 may be absent from our datasets given their relatively low, transient or binary

1153 expression in the relevant tissues.

1154 Finally, FHAD1 is a small protein that recognizes phosphorylated epitopes on a wide

1155 range of proteins as part of an evolutionarily ancient mechanism enabling assembly of

1156 protein complexes (Durocher and Jackson, 2002). The expression of FHAD1 is very low

1157 in many tissues including the retina but is high in the testis and lungs. Since the 
1158 expression is very low, the transcript and protein production or presence may go

1159 undetected in the subretinal and blood transcriptomics and proteomics studies we used

1160 in this study. However, once the FHAD1 protein has accumulated, as apparently in

1161 drusen, it may be (more) detectable there. DIPC2 is a ubiquitously expressed protein

1162 that shares homology with a Drosophila protein that interacts with the transcription

1163 factor disco (www.ncbi.nlm.nih.gov). It is possible that the expression of this type of

1164 protein is transient or binary; and it may go undetected in our retinal compartment and

1165 blood transcriptomics and proteomics studies for that reason.

1166 Finally, the last two proteins, SPTAN1 and SCARB2 may have related functionalities. The

1167 SPTAN1 protein is a part of the cytoskeletal spectrin protein family that is involved in

1168 stabilizing membranes of both cell and organelles (Tohyama et al., 2015). It is highly

1169 expressed in the brain, and still expressed to a significant level in multiple other tissues.

$1170 S C A R B 2$ is a ubiquitously expressed gene that encodes a lysosomal type III plasma

1171 membrane glycoprotein (Gonzalez et al., 2014). Given the involvement of this type of

1172 proteins in the lysosomal digestion of cellular material, it is tempting to speculate that

1173 these proteins come from (transiently present in high numbers) lysosomal membrane

1174 fragments basally secreted by the RPE.

1175 6.3. Blood proteins are an important source of drusen proteins.

1176 If we summarize the combined data from our literature search and our qualitative and

1177 quantitative analyses, we conclude that blood proteins are an important protein source

1178 for drusen development. Further studies are needed to confirm and enhance our data,

1179 especially on the single-protein level. Given the apparent contribution of blood to the

1180 formation of drusen, the next chapters will discuss the role of hydroxyapatite as a

1181 retainer of blood proteins during drusen formation, and the similarities that exist

1182 between drusen and atherosclerotic plaques, which occur exclusively in the vasculature. 


\section{Drusen and hydroxyapatite}

1184 Our analyses provide strong evidence that proteins in drusen come from multiple

1185 sources. The next logical step was to consider how proteins arrive and how they are

1186 retained in the sub-RPE-BL space. One possibility is that proteins may bind to

1187 constituents of the BrM (Tabas et al., 2007). Another is the formation of large oligomers

1188 in the sub-RPE-BL space in the presence of the high concentration of trace metals

1189 (Lengyel et al., 2007; Nan et al., 2013; Flinn et al., 2014). In addition, it was recently

1190 hypothesized that proteins might be retained in the sub-RPE-BL space due to their

1191 binding to hydroxyapatite spherules recently identified in human drusen (Thompson et

1192 al., 2015) (Figure 6). Since this hypothesis is relatively new, it is described in more detail

1193 below.

1194 Using confocal microscopy and hydroxyapatite (HAP)-specific fluorescent dyes, small

1195 hollow spherical structures ranging from $0.5 \mu \mathrm{m}$ to $20 \mu \mathrm{m}$ in diameter were identified

1196 within sub-RPE-BL deposits in retinal tissue sections of human cadaveric eyes

1197 (Thompson et al., 2015). The HAP spherules were present in all deposits examined

1198 (Thompson et al., 2015). Protein constituents of drusen, such as amyloid-beta,

1199 vitronectin and complement factor $\mathrm{H}$, were localized to the surface of the HAP spherules,

1200 either individually or in combination (Thompson et al., 2015). Although not all

1201 investigated drusen proteins appeared to bind to the surface of HAP (Thompson et al.,

1202 2015), this finding proved that the retention of proteins can, at least partly, occur

1203 through this protein-HAP interaction. These results also suggested that the binding of

1204 proteins to HAP spherules is a wide ranging, though selective, process and thus

1205 understanding which proteins can bind to HAP might be important. The plasma protein-

1206 binding capacity and selectivity of HAP was recently examined using a quantitative

1207 proteomic approach called Sequential Window Acquisition of all theoretical fragment-

1208 ion spectra-Mass Spectrometry (SWATH-MS) (Arya et al., 2018). Using this approach,

1209242 proteins with the propensity to binding HAP were identified and quantified (Table

1210 3; STable 5) (Arya et al., 2018). Taking advantage of the quantitative nature of the

1211 analysis the binding of samples from participants with wild type and the AMD associated

1212 high risk CFH variant, T1277C were compared. Quantitative differences in the

1213 abundance of at least 34 proteins were identified, suggesting that the genetic

1214 background is likely to affect the protein composition of drusen "simply" due to the 
1215 availability of proteins in the blood. This approach also highlighted that there are 1216 proteins, whose presence and potential role in sub-RPE deposit formation and in AMD 1217 had not previously been explored. One such example is the pregnancy zone protein 1218 (Arya et al., 2018), a plasma protein whose levels are known to increase in pregnancy 1219 and some disease states such as AD (Nijholt et al., 2015).

1220 It appears therefore that while drusen deposition is a hallmark of AMD, HAP deposition 1221 is a hallmark of drusen formation. The study by Thompson and coworkers was not the 1222 first to identify calcified components of drusen (Thompson et al., 2015). Spherical 1223 particles of similar size were previously identified within drusen and BLinD (Green and 1224 Key, 1977), and electron microscopy (Ulshafer et al., 1987; van der Schaft et al., 1992; 1225 van der Schaft et al., 1993; Thompson et al., 2015). Particles size observed in these 1226 studies ranged from $0.5 \mu \mathrm{m}$ to $10 \mu \mathrm{m}$ in diameter and contained calcium and phosphate 1227 as determined by elemental analysis (Ulshafer et al., 1987). More recent studies using 1228 von Kossa staining, a silver enhancement technique that identifies phosphates salts also 1229 indicated that calcium phosphates were present within deposits in the sub-RPE-BL 1230 space (Suzuki et al., 2015).

1231 The precipitation of calcium phosphate from an aqueous solution is a complex process 1232 (Kani et al., 1983; Tas, 2000; Jang et al., 2014). At neutral pH, HAP is considered the most 1233 thermodynamically stable form of calcium phosphate. In fact, it is possible that HAP is 1234 stable enough that once the lipid or protein components of the drusen regress (Sallo et 1235 al., 2009; Toy et al., 2013; Novais et al., 2015), HAP still remains and continues to 1236 interact with its environment. This may suggest that HAP interactions, not only with the 1237 BrM and the RPE but also with the remanence of photoreceptor cells or other parts of 1238 the neurosensory retina (Bird et al., 2014) may require further investigation.

1240 Figure 7 summarizes the model of HAP associated deposit initiation. Under normal 1241 circumstances, there is a physiological exchange of material between the RPE and the 1242 choroidal circulation (Fig.7A and A'), and this includes the exchange of lipid particles 1243 (Curcio et al., 2011). With age and disease lipid particles start accumulating in the sub1244 RPE space including the BrM (Fig.7B and B') (Curcio et al., 2011). In the presence of lipid droplets and homeostatic changes in calcium and phosphate availability in the sub-RPE1246 BL space, HAP can precipitate on the surface of the lipid droplets (Fig.7C and C'). Then, 1247 on the surface of the HAP spherules drusen proteins can accumulate (Fig.7D and D') via 
directly interacting with HAP (Arya et al., 2018). Based on fluorescence labeling of HAP in human eyes, it is appeared that HAP spherules can exist without drusen (Fig.7C'), but drusen have not been seen without HAP spherules (Fig.7D and D') (when specifically looked for) thus far (Thompson et al., 2015). Based on these observations it was proposed that HAP deposition is a seeding point for drusen formation (Thompson et al., 2015).

1254 The next obvious question to ask is where the HAP spherules are originating from? Could they be blood or RPE derived? Do they exist as spherules only in the sub-RPE-BL space or is the material present in the surrounding tissues? Spherules have not been detected in any of the cellular or intercellular spaces although the calcium phosphate crystals had been showed in mitochondria (Carafoli, 2010). Therefore, it appears that HAP spherules are deposited in the retina exclusively in the sub-RPE-BL space. In fact, it had been shown that HAP deposition can occur in primary RPE cell models which showed that HAP deposition can be initiated by the RPE alone, although contribution of the culture medium cannot be ruled out (Pilgrim et al., 2017). Whether spherical structures can develop in a cell culture system that are co-cultured with endothelial cells and/or fed with photoreceptor outer segments will need to be investigated.

HAP mineralization in the retina clearly differs from classical mineralization in bone, but it may, or may not, share some key features with general soft tissue/elastin calcification (Figure 8). Obviously, the retina lacks extracellular matrix forming osteoblasts. Also, no relationship has been found between spherule mineralization and general HAP deposition on elastin and/or collagen. However, systemic driven HAP deposition can take place in the BrM, as reported before (Gorgels et al., 2012). Indeed, a systemic lack of inorganic PPi in the blood (Jansen et al., 2013) may be involved in local HAP deposition in BrM, facilitated by local conditions, such as oxidative stress (Mungrue et al., 2011). Interestingly, investigation of the ultrastructure and composition of vascular microcalcifications associated with uremia showed the presence of spherical particles in the media of the kidney, with internal structures comparable to those observed in the

1276 human eye (Schlieper et al., 2010). Similarly, the loose stroma of the choroid plexus of 1277 the aging or Alzheimer's disease brain contain psammoma bodies, which are entities 1278 with distinct HAP cores and multiple concentric rings or swirls of collagen wrapped around it (Alcolado et al., 1986). More recently, similarly structured spherules were also 
1280 identified within patients with osteoporosis and in cardiovascular disease (Bertazzo et 1281 al., 2013; Shah et al., 2017). Thus, comparable mineralization mechanisms in a variety of 1282 non-osseous tissues appear to be associated with a number of different disease 1283 conditions.

1284 Alternatively, transcriptomic data suggests that part of the elements of the physiological 1285 mineralization process are (also) present in the RPE cells (Booij et al., 2009), or at the 1286 RPE/choroid interface (Whitmore et al., 2014). This evidence suggests that the 1287 molecular machinery required for general physiological mineralization (depicted in 1288 Figure 8) could (also in part) be assembled in the outer retina. Given that the bulk of the 1289 calcium is extracellular, while phosphate is mainly localized intracellularly, the 1290 conditions that allow mineralization to happen could be present locally, in the sub-RPE1291 BL space. This concept is novel and has not been investigated previously but may lead to 1292 HAP-based treatment strategies and/or new early detection mechanisms. 


\section{Drusen and plaques: age-related macular degeneration and atherosclerosis}

1294

1295

1296

1297

1298

1299

1300

1301

1302

1303

1304

1305

1306

1307

1308

1309

1310

1311

1312

1313

1314

1315

1316

1317

1318

1319

1320

1321

1322

1323

1324

The finding that a substantial number of drusen proteins are blood-borne prompted us to re-summarize a possible relationship between initiation and propagation of drusen and atherosclerotic plaques. A possible link between these two diseases was previously suggested based on (controversial) epidemiological evidence, the involvement of similar lipoproteins in the formation of extracellular deposits in AMD and atherosclerosis and structural commonalities between the vessel wall and Bruch's membrane (Curcio et al., 2001; Sivaprasad et al., 2005).

AMD is a disease starting with (multiple macular) drusen formation. Drusen consist of (oxidatively-modified) lipids and proteins as well as minerals (Sarks et al., 1988; Green and Enger, 1993; Curcio and Millican, 1999; Crabb, 2014; Flinn et al., 2014; Handa et al., 2017; Pilgrim et al., 2017; Spaide et al., 2018). Drusen constituents most likely invoke a complement attack and sustain a continuous low-grade inflammation, which leads to serious events such as RPE cell loss, neovascularization and ultimately, central vision loss (Bird et al., 1995; de Jong, 2006).

Atherosclerosis is a disease associated with the build-up of plaques also composed of (oxidatively-modified) lipids, proteins as well as minerals in the vessel wall of arteries that, via complement attack and low-grade inflammation, can lead to serious events including heart attack, stroke or aneurysm (Simmons et al., 2016).

There are a number of clear differences between AMD and atherosclerosis, such as location of the deposition, the local metabolic physiology (Stefansson et al., 2011), involvement of other (different) genes or molecules and obviously, aspects of the pathological consequences of deposition build up (Hageman et al., 2001; Hopkins, 2013). For example, other than in plaques in atherosclerosis, deposit (drusen) formation in AMD most likely blocks the exchange of biomolecules between the retina and the choroid. It is thought that this interferes with the "nourishment" of the sensory cells in the retina causing them to die. Over time the cells cannot be replaced leading to a loss of vision, typically within the macula, which progressively deteriorates over time contributing to the AMD pathology (Bhutto and Lutty, 2012).

Nonetheless, a relatively large number of commonalities have been found between both drusen and atherosclerotic plaque formation and their associated diseases. Available 
evidence comes from clinical, epidemiological, genetic, histological and pathobiological investigations (see below).

\subsection{Clinical and epidemiological studies.}

1328 Verhoeff and Grosmann were the first to suggest a relationship between vascular 1329 disease and AMD (Verhoeff and Grossman, 1937). Except for a few reports (Gass, 1967;

1330 Kornzweig, 1977), this observation was largely ignored for over forty years when 1331 Maltzman and Hyman (Maltzman et al., 1979; Hyman et al., 1983) pioneered a plethora 1332 of subsequent epidemiological studies on the subject (Vidaurri et al., 1984; Vingerling et 1333 al., 1995; Snow and Seddon, 1999). Some studies between atherosclerosis (and similar 1334 diseases) and AMD showed positive associations (The Eye Disease Case-Control Study, 1992; Klein et al., 1993), while others did not (Hyman et al., 1983). These controversial results, especially in the early investigations, were partly due to differences in description of the clinical phenotype, use of different end phenotypes, study design, population size, lack of suitable replication populations, and insufficient knowledge of possible confounders. Nonetheless, this issue has not been resolved up until today. A wide range of epidemiological studies have also suggested that there are certain risk factors which are common to both AMD and atherosclerosis (-associated cardiovascular disease). These most consistently include environmental factors, such as age and tobacco smoking (Woodell and Rohrer, 2014). These studies indicate that, mechanistically, oxidative stress and potentially lipid metabolism may play an important role in both disorders (Serban and Dragan, 2014; Gehlbach et al., 2016; George et al., 2018; van Leeuwen et al., 2018; Wilson et al., 2018).

\subsection{Histological and pathobiological similarities.}

1348 Histological and pathobiological similarities between drusen and atherosclerotic 1349 plaques and their associated diseases include similarities of lipid and mineral content and structural similarities between the BrM and the vascular wall, endothelial cell dysfunction, and proteoglycan turnover. Curcio and coworkers proposed, for the first time, a relationship between drusen and atherosclerotic plaques since both contain similar neutral lipids and both accumulate cholesterol esters (Curcio et al., 2001). This finding was confirmed by others (Chung et al., 2005; Wang et al., 2010). These and subsequent studies made clear that diseases related to this type of accumulations may 
1357 of lipids in drusen and atherosclerosis has recently been reviewed elsewhere in detail

1358 (Pikuleva and Curcio, 2014; van Leeuwen et al., 2018; Xu et al., 2018).

1359 Sivaprasad and coworkers observed that the BrM and the vascular intima share a

1360 number of common structural modalities, and age-related changes (Sivaprasad et al.,

1361 2005). Indeed, similar to the vessel wall, and given the presence of local fenestrated

1362 choroidal capillaries, BrM acts a collagen and elastin rich physical barrier for the blood.

1363 Both the BrM and vascular intima thicken through accumulation of extracellular lipids

1364 and other debris and become less flexible with age (Chung et al., 2005; Curcio and

1365 Johnson, 2012).

1366 Another important feature of the ECM of both the vessel wall and BrM are the presence

1367 and turnover of a variety of proteoglycans. In BrM, the ratio between several

1368 proteoglycan types, most notably heparan sulfate and chondroitin sulfate, changes

1369 dramatically during aging and the development of AMD (Barzegar-befroei et al., 2012).

1370 In atherosclerosis and AMD, (oxidatively) modified proteoglycans may bind and retain

1371 specific apolipoproteins from the circulation in, respectively the artery wall (Williams

1372 and Tabas, 1995; Tabas et al., 2007) and the BrM (Curcio et al., 2009; Al Gwairi et al.,

1373 2016) BrM. Indeed, proteoglycans may play an, as so far underestimated, role in

1374 regulating the complement response and the development of both AMD and

1375 atherosclerosis pathology (Tate et al., 1993; Toomey et al., 2018). Happonen and

1376 coworkers (2012) recently showed that small proteoglycans, such as PRELP, are

1377 regulators of the complement cascade (Happonen et al., 2012). Please note that

1378 choroidal cells produce PRELP (as suggested in the current study) and that this protein

1379 apparently accumulates in drusen. There are a few reports which have established the

1380 different patterns of distribution of large (Clark et al., 2011) and small proteoglycans

1381 (Keenan et al., 2012); the latter including biglycan, decorin, fibromodulin, lumican,

1382 mimecan, opticin, and prolargin in post-mortem eye or vascular tissue.

1383 Both atherosclerosis and AMD patients may suffer from endothelial cell dysfunction.

1384 Accumulating evidence suggests that endothelial cell dysfunction may be the initiating

1385 step in atherosclerosis (Miteva et al., 2018). In their AMD studies, Schaumberg and

1386 coworkers provided epidemiological evidence that at least one marker for endothelial

1387 dysfunction and inflammation, sICAM-1 is linked to drusen formation and

1388 neovascularization (Schaumberg et al., 2007). Interestingly, higher levels of circulating

1389 endothelial cells (CECs), a biomarker for a diversity of systemic complications, including 
1390 vascular disorders, were found in AMD patients compared to controls (Machalinska et 1391 al., 2011).

1392 While these studies focused on common risk factors and parallel development of drusen 1393 and plaques, the possibility that atherosclerosis plays a direct role in the development of 1394 AMD cannot be ruled out. Using FA, a slow filling of the choroidal capillaries over time 1395 has been observed in AMD patients (Pauleikhoff et al., 1990). This may be due to (a 1396 combination of) thickening of the BrM, a declining function of the RPE or by decreased 1397 atherosclerosis-driven perfusion of these capillaries. Reduced capillary blood flow could 1398 directly enhance the initiation of drusen or development of AMD.

1399 As with drusen, deposition of calcified mineral, that includes hydroxyapatite (Lee et al., 1400 2012) is associated with the formation of atherosclerotic plaques (Doherty et al., 2003). 1401 Such mineral is readily quantifiable using radiography and even serves as a marker for 1402 atherosclerosis. It has been reported that the presence of mineral in cardiovascular soft 1403 tissue can be used to predict mortality (Okuno et al., 2007; Kestenbaum et al., 2009), and 1404 morbidity of cardiovascular disease in various forms (Arad et al., 2000; Keelan et al., 1405 2001). The specific molecular mechanisms underlying mineral formation in such tissues 1406 remains to be fully elucidated. However, both AMD and atherosclerosis are associated 1407 with low grade inflammation in the respective affected tissues (Hansson et al., 2006;

1408 Kauppinen et al., 2016), and it has been proposed that soft tissue mineralization may be 1409 best conceptualized as a convergence of bone biology with inflammatory pathobiology 1410 (Doherty et al., 2003).

\section{8.3. Genetics and molecular biology.}

1412 Early candidate gene association studies found an association between genetic variation 1413 in APOE in both AMD (Klaver et al., 1998; Toops et al., 2016) and atherosclerosis (Zhang 1414 et al., 2018), thereby implicating lipid metabolism and transport in both disorders.

1415 Genetic variations in apolipoproteins and complement factors showed strong 1416 associations with AMD and CVD conditions. For example, polymorphisms in the CFH and 1417 a number of other complement factor genes confer at-risk genotypes for AMD (Klein et 1418 al., 2005), whilst similar associations between complement C5 and the complement 1419 receptor 1 genes confer an increased risk of atherosclerosis (Hoke et al., 2012; de Vries 1420 et al., 2017). Of note, although the same genes may be frequently associated with both 1421 (or other) diseases, different alleles are frequently implicated in the associations found 
between these disorders. A well-known example is the APOE4 allele, that increases the risk of Alzheimer's disease, and perhaps atherosclerosis (Mahley, 2016), but is protective in age-related macular degeneration (Klaver et al., 1998). Indeed, these observations were confirmed and extended by large GWAS studies that implicated regulation of lipid metabolism, extracellular matrix remodeling and the immune system low-grade inflammation in both AMD and atherosclerosis (Fritsche et al., 2016; Schunkert et al., 2018). A recent study by the International AMD consortium explored the overlap between 34 AMD-associated loci with other complex diseases (Grassmann et al., 2017). Surprisingly, the authors found that an increased risk of AMD correlates with a reduced risk for cardiovascular disease.

A key similarity between atherosclerotic plaque and drusen formation are the molecular components involved. Both types of deposit have a significant lipid component (including cholesterol and neutral fats) and mineral content, as described above. It has also been reported that drusen contains a number of proteins that are also common to atherosclerotic deposits (Mullins et al., 2000; Klein et al., 2005; Booij et al., 2010a). To gain information as to the degree of this overlap in proteins contributing to these pathologies we compared a dataset of 3196 proteins known to be present in atherosclerotic plaques from Bleijerveld and coworkers (Table 3) with our drusen data set, as shown in Figure 9a (Bleijerveld et al., 2013). The resultant Venn-diagram revealed that out the 89 drusen-associated proteins, 64 of these (72\%) were also present in atherosclerotic plaques. Indeed, 50 out of 60 drusen proteins derived from blood are also present in atherosclerotic plaques (Figure 9b). Details of proteins found to be common to both plaques and drusen can be found in STable 11 and STable 11a.

Closer inspection of proteins common to both atherosclerotic plaques and drusen as defined in this manuscript revealed a number of functional classes of protein in this group including apolipoproteins (APOA1, A2 and E), complement factors (C7, C8A, C8B, C8G and complement factor $\mathrm{H}$ ), as well as lipid- and $\mathrm{Ca}^{2+}$-binding annexins (annexins-1, 2, 5 and 6). Obviously, our analysis may not be fully comprehensive, since it is limited to the entries which are present in both database listings. Another limitation is that similar proteins still may originate from different sources. For example, the previously suggested presence of APOB as principal protein of LDL in both sub-RPE-BL deposits and cardiovascular plaques (Curcio et al., 2001) is missing from the current overlap, 
1454 since detailed investigation of the (presence and origin) of this lipoprotein (Li et al., 1455 2005a) suggested that APOB isolated from BrM thickenings is (also) present in a 1456 distinct, non-LDL lipid profile. Consequently, it was suggested that APOB in BrM 1457 thickenings is made locally, while APOB in plaques is probably from systemic origin.

1458 Cytoskeletal proteins (actinin $\alpha 1$, tubulin $\alpha 1 \mathrm{c}$ and tubulin $\beta 3$ ) as well as extracellular 1459 matrix proteins such as collagens (type $1 \alpha 2$, type $6 \alpha 1$, type $6 \alpha 2$ and type $8 \alpha 1$ ), 1460 tenascin C, microfibril-associated protein 4 and vimentin were found to be present in 1461 both BlamD deposits and atherosclerotic plaques (Fernandez-Godino et al., 2016;

1462 Pelisek et al., 2016). Analysis of proteins common to both plaques and drusen in 1463 biological processes revealed significant contribution of this group of proteins to other 1464 diseases and processes including various cancers, development of the vasculature, cell 1465 movement and AD (tauopathy and amyloidosis; see STable 11a). The involvement of 1466 these proteins in AD is particularly interesting as it is another disorder of which 1467 extracellular deposits are a feature (Figure 9c). Furthermore, drusen reside on the 1468 interface between the neural and cardiovascular system, so it may share properties of 1469 both types of atherosclerosis and Alzheimer's plaques (Booij et al., 2010a). 


\section{Future directions and conclusions.}

1471 Our review of the literature and the qualitative and quantitative meta-analysis of retinal 1472 and blood transcriptomic and proteomic data all point in the same direction: proteins in 1473 drusen originate from multiple sources. Based on the data we have available, the largest 1474 number of protein contribution from a single source appears to be the blood. The

1475 second-most prominent source of number of specific proteins in drusen is from the RPE, 1476 while the contribution from the choroid and the photoreceptors appears to be relatively 1477 modest. However, the varying number of proteins cannot be directly translated to 1478 concentration. There is the possibility that a relatively small number of proteins 1479 contribute the bulk of proteins in drusen.

1480 How proteins get recruited to and retained in the sub-RPE-BL space is still not fully 1481 understood. In vivo and in vitro BrM conductance studies suggest that human proteins 1482 of average size, such as proteins of $53 \mathrm{kDa}$ (source: NCBI), can readily diffuse through 1483 healthy BrM, while macromolecular migration through BrM is slower and/or limited 1484 (Curcio and Johnson, 2012). Moore and Clover found that proteins of $200 \mathrm{kDa}$ could 1485 readily cross young BrM (Moore and Clover, 2001). More recent work suggested that the 1486 transport exclusion size limit in healthy young BrM can be as high as 180-500 kDa, well 1487 over the size of macro molecules like HDL (Hussain et al., 2010; Cankova et al., 2011). In 1488 our current study, we found that 9 out of 10 drusen proteins that are uniquely derived 1489 from the RPE had a Mw of less than $50 \mathrm{kDa}$ (Table 6). Moreover, we took a random 1490 sample of 30 proteins from the RPE-IVS basal secretion dataset (Table 3), containing 1491 proteins which are likely to encounter BrM in vivo, and determined their average Mw: $149295 \mathrm{kDa}$ ). After taking three extremely large proteins out (APOB, AHNAK, and C4B; 1493 proteins that we did not identify in drusen in this study) that average dropped to $60 \mathrm{kDa}$ 1494 (data not shown). Six of these 30 proteins are present in drusen (ALB, ANXA1, ANXA2, 1495 APOA4, APOE, ATP5F1B) and have a MW <66.5 kDa. Although the overall transport 1496 capability BrM decreases substantially in the AMD-affected and aging retina (Hussain et 1497 al., 2010; Cankova et al., 2011; Curcio and Johnson, 2012; Lee et al., 2015), older BrM 1498 was found to be still permeable to proteins in excess of $100 \mathrm{kDa}$ (Moore and Clover, 1499 2001). Taken together, entrapment of proteins in the sub-RPE-BL space is unlikely to be 1500 due to size if single molecules. They might become entrapped by forming aggregates that 1501 are no longer capable of leaving through BrM, as was suggested for CFH (Nan et al., 
1502

1503

1504

1505

1506

1507

1508

1509

1510

1511

1512

1513

1514

1515

1516

1517

1518

1519

1520

1521

1522

1523

1524

1525

1526

1527

1528

1529

1530

1531

1532

1533

1534

2008; Nan et al., 2011; Nan et al., 2013). Therefore, drusen proteins, especially the ones that come from multiple sources, "meet, greet and stick" to form sub-RPE-BL space deposits.

There are several ways proteins can interact in BrM to form larger aggregates: they can interact among themselves, with other lipids, proteins and/or mineral deposits, or stick to the ECM of BrM itself. These interactions may be enhanced by chemical modification, (Blaum et al., 2010) including oxidative damage and glycosylation of lipids, proteins and carbohydrates (Crabb et al., 2002; Hollyfield et al., 2010) and they may be further facilitated by the structure and dynamic nature of BrM (Booij et al., 2010a). Over time, several changes in BrM occur, that may hinder protein clearance from the sub-RPE-BL space. Remodeling of BrM ECM takes place, including proteoglycan changes and turnover, elastin changes and eventually mineralization takes place. BrM becomes laden with lipids to form a hydrophobic barrier ("lipid wall") and accumulates other debris (Curcio and Johnson, 2012). Consequently, the role of the structure and function of BrM and the chemical state of the sub-RPE-BL space may be even more important in subRPE-BL space deposit formation than its exact protein composition.

An important source of entrapment of proteins in BrM may be the formation of HAP surfaces in the sub-RPE-BL space (Thompson et al., 2015). In our current study, at least $30 \%$ of the 89 drusen proteins can bind to HAP. This percentage increases towards at least $50 \%$ if only the blood borne proteins are counted (data not shown). Thus, HAP readily binds a substantial number, but not all drusen proteins (Arya et al., 2018). The finding that blood proteins are seemingly the most important contributors to drusen formation provides a new target to prevent the initiation and propagation of subRPE-BL space deposits. Reducing the concentration of blood proteins that interact with HAP may lead to a reduction of the source of drusen components and ultimately postpone, or potentially even stop, the progression to AMD.

Finally, it is also important to mention that the non-specific interaction of proteins with HAP will also affect their ability to carry out their physiological function. For example, once $\mathrm{CFH}$ binds to the HAP surface it may not be able to regulate the alternative complement pathway. Therefore, this interaction with HAP could be a double whammy: it increases the bulk of sub-RPE-BL space deposits and stops the local protein function. It will be important to understand the role of the blood-derived proteins in the sub-RPE- 
1535 BL space, if any. The study and potential modification of these interactions is now possible and could lead to intervention strategies through modified diet, supplementation or through manipulation of retinal molecular or cellular processes.

1538

1539

1540

1541

1542

1543

1544

1545

1546

1547

1548

1549

1550

1551

1552

1553

1554

1555

1556

1557

1558

1559

1560

1561

1562

1563

1564

1565

An important specific question in the context of this study that needs still to be resolved is how plasma proteins find their way into the sub-RPE-BL space. Apart from the mechanisms already described above (chemical modification of interacting biomolecules, dynamic structure and functional changes BrM, and HAP-binding) it is tempting to speculate that not only blood composition but also blood pressure plays a role. Why blood pressure? It was previously shown that a relationship exists between drusen location and choriocapillary pillars. Indeed, by investigating retina whole mounts, initially Friedman, and subsequently, Lengyel and coworkers concluded that drusen deposition is the result of a lower clearance at the choroidal intercapillary pillars (Friedman et al., 1963; Lengyel et al., 2004). Thus, in other words, higher clearance of sub-RPE-BL space debris corresponds with the vascular lumen, through which the blood flows and directly encounters BrM. Much in line with the reflections of Penfold and others (Penfold et al., 2001) , we hypothesize that the pulsating blood pushes debris through endothelial fenestrations into BrM, through relatively open BrM pores; and at the same time, clears debris which was already present in BrM. One could compare that, by analogy, with the sea bringing and taking, wave after wave, debris to and from the beach. Changes in blood composition, choroidal endothelial cell compromise and rising blood pressure with age (Pinto, 2007) may negatively change the dynamics of this proposed "debris-exchange".

Our review further underlines the importance of comparative studies between drusen deposition and atherosclerosis plaque formation. Clinical, (genetic) epidemiological pathobiological and molecular similarities between these two disorders have been highlighted previously (see section 8). Such similarities include that both are extracellular lipid/protein/mineral-based depositions that invoke a low-grade immune response leading to further disease. Several molecular similarities between drusen and plaques have also been described. We currently add the observation that most drusen (and plaque) components are blood-borne. Therefore, the genesis of drusen and plaques may be similar, and should be subject of further multidisciplinary studies. 
1566 While studying the literature for this review, we have made a number of additional 1567 observations that may guide future research directions: First, while the number of 1568 retinal (cell-type-specific) transcriptomics studies are large and proteomics information 1569 is emerging, there are very few proteomics studies on different types of (human) sub1570 RPE-BL space deposits (types). For example, additional proteomics studies of hard 1571 versus soft drusen or macular versus peripheral drusen might improve our 1572 understanding of deposition formation in the sub-RPE-BL space and their association 1573 with different disorders or disease stages. Next, transcriptomics, proteomics, and 1574 immunohistochemical studies have their own conceptual and technical advantages and 1575 limitations. However, in the literature, the description of these strengths and 1576 weaknesses are not always clear and standardization is lacking. International 1577 agreements such as MIAME and MISFISHIE (ㅍinimum information specification for in 1578 situ hybridization and immunohistochemistry experiments) guidelines (Deutsch et al., 1579 2008) are a step in the right direction, but must be seen as initial steps for further 1580 standardization. A few examples for illustration: How many confirmatory 1581 transcriptomics or proteomics studies should be performed before a definite subcellular 1582 assignment can be made? How do we define cellular specificity and cellular enrichment? 1583 How many drusen types should be screened and how many different antibodies should 1584 be used before proteins are clearly assigned as drusen proteins (or as sub-types). When 1585 should we designate labeling drusen specific? Do we consider staining of the border of 1586 hydroxyapatite or drusen important; or is only the staining of the whole inner mass of 1587 drusen relevant? Given the heterogeneity of drusen: what is the exact location of the 1588 drusen under study and its appearance? Indeed, in line with recent similar calls by 1589 Curcio and co-workers (Curcio, 2018a, b) we call here for better considerations, 1590 agreements and definitions of these issues.

1591 Last but not least, it will be interesting to understand whether drusen heterogeneity is a 1592 direct feature of a disease or a reflection of the change in the (micro-) environment that 1593 results in initiation and growth of the deposits. While drusen deposition clearly is a 1594 hallmark of AMD and is associated with a number of other diseases (Khan et al., 2016), 1595 its actual composition might reflect the disease state at the RPE/choroid interface more 1596 than (cause) the disease. The identification of why and not necessarily what proteins 
1597 and lipids are deposited in the sub-RPE-BL space might therefore an important question 1598 to consider for future studies. 


\section{References}

1. Abdelsalam, A., Del Priore, L., Zarbin, M.A., 1999. Drusen in age-related macular degeneration: pathogenesis, natural course, and laser photocoagulation-induced regression. Surv Ophthalmol 44, 129.

2. Ahmad, M.T., Zhang, P., Dufresne, C., Ferrucci, L., Semba, R.D., 2018. The Human Eye Proteome Project: Updates on an Emerging Proteome. Proteomics 18, e1700394. 3. Aiello, L.P., Gardner, T.W., King, G.L., Blankenship, G., Cavallerano, J.D., Ferris, F.L., 3rd, Klein, R., 1998. Diabetic retinopathy. Diabetes Care 21, 143-156.

4. Al Gwairi, O., Thach, L., Zheng, W., Osman, N., Little, P.J., 2016. Cellular and Molecular Pathology of Age-Related Macular Degeneration: Potential Role for Proteoglycans. J Ophthalmol 2016, 2913612. 5. Alcolado, J.C., Moore, I.E., Weller, R.O., 1986. Calcification in the human choroid plexus, meningiomas and pineal gland. Neuropathol Appl Neurobiol 12, 235-250. 6. Alge, C.S., Suppmann, S., Priglinger, S.G., Neubauer, A.S., May, C.A., Hauck, S., Welge-Lussen, U., Ueffing, M., Kampik, A., 2003. Comparative proteome analysis of native differentiated and cultured dedifferentiated human RPE cells. Investigative ophthalmology \& visual science 44, 3629-3641. 7. Allam, R., Kumar, S.V., Darisipudi, M.N., Anders, H.J., 2014. Extracellular histones in tissue injury and inflammation. J Mol Med (Berl) 92, 465-472.

8. An, E., Lu, X., Flippin, J., Devaney, J.M., Halligan, B., Hoffman, E.P., Strunnikova, N., Csaky, K., Hathout, Y., 2006. Secreted proteome profiling in human RPE cell cultures derived from donors with age related macular degeneration and age matched healthy donors. J Proteome Res 5, 2599-2610. 9. Anders, F., Liu, A., Mann, C., Teister, J., Lauzi, J., Thanos, S., Grus, F.H., Pfeiffer, N., Prokosch, V., 2017. The Small Heat Shock Protein alpha-Crystallin B Shows Neuroprotective Properties in a Glaucoma Animal Model. Int J Mol Sci 18.

10. Anderson, D.H., Mullins, R.F., Hageman, G.S., Johnson, L.V., 2002. A role for local inflammation in the formation of drusen in the aging eye. Am J Ophthalmol 134, 411-431.

11. Anderson, D.H., Ozaki, S., Nealon, M., Neitz, J., Mullins, R.F., Hageman, G.S., Johnson, L.V., 2001. Local cellular sources of apolipoprotein $\mathrm{E}$ in the human retina and retinal pigmented epithelium: implications for the process of drusen formation. Am J Ophthalmol 131, 767-781. 12. Anderson, D.H., Radeke, M.J., Gallo, N.B., Chapin, E.A., Johnson, P.T., Curletti, C.R., Hancox, L.S., Hu, J., Ebright, J.N., Malek, G., Hauser, M.A., Rickman, C.B., Bok, D., Hageman, G.S., Johnson, L.V., 2010. The pivotal role of the complement system in aging and age-related macular degeneration: hypothesis re-visited. Prog Retin Eye Res 29, 95-112.

13. Arad, Y., Spadaro, L.A., Goodman, K., Newstein, D., Guerci, A.D., 2000. Prediction of coronary events with electron beam computed tomography. J Am Coll Cardiol 36, 1253-1260. 14. Arya, S., Emri, E., Synowsky, S.A., Shirran, S.L., Barzegar-Befroei, N., Peto, T., Botting, C.H., Lengyel, I., Stewart, A.J., 2018. Quantitative analysis of hydroxyapatite-binding plasma proteins in genotyped individuals with late-stage age-related macular degeneration. Exp Eye Res 172, 21-29. 15. Ashford, J.W., 2004. APOE genotype effects on Alzheimer's disease onset and epidemiology. J Mol Neurosci 23, 157-165.

16. Balaratnasingam, C., Hoang, Q.V., Inoue, M., Curcio, C.A., Dolz-Marco, R., Yannuzzi, N.A., DhramiGavazi, E., Yannuzzi, L.A., Freund, K.B., 2016. Clinical Characteristics, Choroidal Neovascularization, and Predictors of Visual Outcomes in Acquired Vitelliform Lesions. Am J Ophthalmol 172, 28-38. 17. Barzegar-befroei, N., Peto, T., Bergen, A.A., Lengyel, I., 2012. Understanding the Role of Bruch's Membrane in Cnv. Retinal Physician 9, 20-25.

18. Beattie, J.R., Pawlak, A.M., Boulton, M.E., Zhang, J., Monnier, V.M., McGarvey, J.J., Stitt, A.W., 2010. Multiplex analysis of age-related protein and lipid modifications in human Bruch's membrane. FASEB journal : official publication of the Federation of American Societies for Experimental Biology 24, 4816-4824.

19. Bennis, A., Gorgels, T.G., Ten Brink, J.B., van der Spek, P.J., Bossers, K., Heine, V.M., Bergen, A.A., 2015. Comparison of Mouse and Human Retinal Pigment Epithelium Gene Expression Profiles: Potential Implications for Age-Related Macular Degeneration. PLoS One 10, e0141597. 
20. Bernstein, M.H., Hollenberg, M.J., 1965. Fine structure of the choriocappillaris and retinal capillaries. Invest Ophthalmol 4, 1016-1025.

21. Bertazzo, S., Gentleman, E., Cloyd, K.L., Chester, A.H., Yacoub, M.H., Stevens, M.M., 2013. Nanoanalytical electron microscopy reveals fundamental insights into human cardiovascular tissue calcification. Nat Mater 12, 576-583. 22. Bhutto, I., Lutty, G., 2012. Understanding age-related macular degeneration (AMD): relationships between the photoreceptor/retinal pigment epithelium/Bruch's membrane/choriocapillaris complex. Mol Aspects Med 33, 295-317. 23. Biesemeier, A., Taubitz, T., Julien, S., Yoeruek, E., Schraermeyer, U., 2014. Choriocapillaris 2562-2573.

24. Bird, A.C., Bressler, N.M., Bressler, S.B., Chisholm, I.H., Coscas, G., Davis, M.D., de Jong, P.T., Klaver, C.C., Klein, B.E., Klein, R., et al., 1995. An international classification and grading system for age-related maculopathy and age-related macular degeneration. The International ARM Epidemiological Study Group. Surv Ophthalmol 39, 367-374.

25. Bird, A.C., Phillips, R.L., Hageman, G.S., 2014. Geographic atrophy: a histopathological assessment. JAMA Ophthalmol 132, 338-345.

26. Blaum, B.S., Deakin, J.A., Johansson, C.M., Herbert, A.P., Barlow, P.N., Lyon, M., Uhrin, D., 2010. Lysine and arginine side chains in glycosaminoglycan-protein complexes investigated by NMR, crosslinking, and mass spectrometry: a case study of the factor $\mathrm{H}$-heparin interaction. J Am Chem Soc 132, 6374-6381.

27. Bleijerveld, O.B., Zhang, Y.N., Beldar, S., Hoefer, I.E., Sze, S.K., Pasterkamp, G., de Kleijn, D.P., 2013. Proteomics of plaques and novel sources of potential biomarkers for atherosclerosis. Proteomics Clin Appl 7, 490-503.

28. Booij, J.C., Baas, D.C., Beisekeeva, J., Gorgels, T.G., Bergen, A.A., 2010a. The dynamic nature of Bruch's membrane. Prog Retin Eye Res 29, 1-18.

29. Booij, J.C., ten Brink, J.B., Swagemakers, S.M., Verkerk, A.J., Essing, A.H., van der Spek, P.J., Bergen, A.A., 2010b. A new strategy to identify and annotate human RPE-specific gene expression. PLoS One 5, e9341.

30. Booij, J.C., van Soest, S., Swagemakers, S.M., Essing, A.H., Verkerk, A.J., van der Spek, P.J., Gorgels, T.G., Bergen, A.A., 2009. Functional annotation of the human retinal pigment epithelium transcriptome. BMC Genomics 10, 164.

31. Boon, C.J., van de Kar, N.C., Klevering, B.J., Keunen, J.E., Cremers, F.P., Klaver, C.C., Hoyng, C.B., Daha, M.R., den Hollander, A.I., 2009. The spectrum of phenotypes caused by variants in the CFH gene. Mol Immunol 46, 1573-1594.

32. Brazma, A., Hingamp, P., Quackenbush, J., Sherlock, G., Spellman, P., Stoeckert, C., Aach, J., Ansorge, W., Ball, C.A., Causton, H.C., Gaasterland, T., Glenisson, P., Holstege, F.C., Kim, I.F., Markowitz, V., Matese, J.C., Parkinson, H., Robinson, A., Sarkans, U., Schulze-Kremer, S., Stewart, J., Taylor, R., Vilo, J., Vingron, M., 2001. Minimum information about a microarray experiment (MIAME)toward standards for microarray data. Nat Genet 29, 365-371.

33. Bressler, N.M., Munoz, B., Maguire, M.G., Vitale, S.E., Schein, O.D., Taylor, H.R., West, S.K., 1995. Five-year incidence and disappearance of drusen and retinal pigment epithelial abnormalities. Waterman study. Arch Ophthalmol 113, 301-308.

34. Bressler, N.M., Silva, J.C., Bressler, S.B., Fine, S.L., Green, W.R., 1994. Clinicopathologic correlation of drusen and retinal pigment epithelial abnormalities in age-related macular degeneration. Retina 14, 130-142.

35. Bretillon, L., Thuret, G., Gregoire, S., Acar, N., Joffre, C., Bron, A.M., Gain, P., Creuzot-Garcher, C.P., 2008. Lipid and fatty acid profile of the retina, retinal pigment epithelium/choroid, and the lacrimal gland, and associations with adipose tissue fatty acids in human subjects. Exp Eye Res 87, 521-528.

36. Burns, M.S., Hartz, M.J., 1992. The retinal pigment epithelium induces fenestration of endothelial cells in vivo. Curr Eye Res 11, 863-873. 
37. Burns, R.P., Feeney-Burns, L., 1980. Clinico-morphologic correlations of drusen of Bruch's membrane. Trans Am Ophthalmol Soc 78, 206-225.

38. Cankova, Z., Huang, J.D., Kruth, H.S., Johnson, M., 2011. Passage of low-density lipoproteins through Bruch's membrane and choroid. Exp Eye Res 93, 947-955.

39. Cao, S., Walker, G.B., Wang, X., Cui, J.Z., Matsubara, J.A., 2013. Altered cytokine profiles of human retinal pigment epithelium: oxidant injury and replicative senescence. Mol Vis 19, 718-728. 40. Carafoli, E., 2010. The fateful encounter of mitochondria with calcium: how did it happen? Biochim Biophys Acta 1797, 595-606.

41. Chen, M., Forrester, J.V., Xu, H., 2007. Synthesis of complement factor $H$ by retinal pigment epithelial cells is down-regulated by oxidized photoreceptor outer segments. Exp Eye Res 84, 635645.

42. Chen, M., Hombrebueno, J.R., Luo, C., Penalva, R., Zhao, J., Colhoun, L., Pandi, S.P., Forrester, J.V., $\mathrm{Xu}, \mathrm{H}$., 2013. Age- and light-dependent development of localised retinal atrophy in CCL2(-/)CX3CR1(GFP/GFP) mice. PLoS One 8, e61381.

43. Chirco, K.R., Flamme-Wiese, M.J., Wiley, J.S., Potempa, L.A., Stone, E.M., Tucker, B.A., Mullins, R.F., 2018. Evaluation of serum and ocular levels of membrane attack complex and C-reactive protein in CFH-genotyped human donors. Eye (Lond).

44. Chirco, K.R., Potempa, L.A., 2018. C-Reactive Protein As a Mediator of Complement Activation and Inflammatory Signaling in Age-Related Macular Degeneration. Front Immunol 9, 539. 45. Chirco, K.R., Tucker, B.A., Stone, E.M., Mullins, R.F., 2016. Selective accumulation of the complement membrane attack complex in aging choriocapillaris. Exp Eye Res 146, 393-397. 46. Chung, B.H., Franklin, F., Liang, P., Doran, S., Cho, B.H., Curcio, C.A., 2005. Phosphatidylcholinerich acceptors, but not native HDL or its apolipoproteins, mobilize cholesterol from cholesterol-rich insoluble components of human atherosclerotic plaques. Biochim Biophys Acta 1733, 76-89. 47. Clark, S.J., Keenan, T.D., Fielder, H.L., Collinson, L.J., Holley, R.J., Merry, C.L., van Kuppevelt, T.H., Day, A.J., Bishop, P.N., 2011. Mapping the differential distribution of glycosaminoglycans in the adult human retina, choroid, and sclera. Investigative ophthalmology \& visual science 52, 6511-6521. 48. Coats, G., 1905. The structure of the membrane of Bruch, and its relation to the formation of colloid excrescences. J. \& A. Churchill. 49. Consortium, c.G., 2013. The Genotype-Tissue Expression (GTEx) project. Nat Genet 45, 580-585. 50. Coppen, E.M., van der Grond, J., Hart, E.P., Lakke, E., Roos, R.A.C., 2018. The visual cortex and visual cognition in Huntington's disease: An overview of current literature. Behav Brain Res 351, 6374.

51. Crabb, J.W., 2014. The proteomics of drusen. Cold Spring Harb Perspect Med 4, a017194. 52. Crabb, J.W., Miyagi, M., Gu, X., Shadrach, K., West, K.A., Sakaguchi, H., Kamei, M., Hasan, A., Yan, L., Rayborn, M.E., Salomon, R.G., Hollyfield, J.G., 2002. Drusen proteome analysis: an approach to the etiology of age-related macular degeneration. Proc Natl Acad Sci U S A 99, 14682-14687. 53. Cryan, L.M., O'Brien, C., 2008. Proteomics as a research tool in clinical and experimental ophthalmology. Proteomics Clin Appl 2, 762-775.

54. Csincsik, L., MacGillivray, T.J., Flynn, E., Pellegrini, E., Papanastasiou, G., Barzegar-Befroei, N., Csutak, A., Bird, A.C., Ritchie, C.W., Peto, T., Lengyel, I., 2018. Peripheral Retinal Imaging Biomarkers for Alzheimer's Disease: A Pilot Study. Ophthalmic Res 59, 182-192.

55. Cunden, L.S., Brophy, M.B., Rodriguez, G.E., Flaxman, H.A., Nolan, E.M., 2017. Biochemical and Functional Evaluation of the Intramolecular Disulfide Bonds in the Zinc-Chelating Antimicrobial Protein Human S100A7 (Psoriasin). Biochemistry 56, 5726-5738.

56. Cunningham, A., Kotagiri, A., 2018. A long history of dense deposit disease. BMC Ophthalmol 18, 228.

57. Curcio, C.A., 2018a. Antecedents of Soft Drusen, the Specific Deposits of Age-Related Macular Degeneration, in the Biology of Human Macula. Investigative ophthalmology \& visual science 59, Amd182-amd194.

58. Curcio, C.A., 2018b. Soft Drusen in Age-Related Macular Degeneration: Biology and Targeting Via the Oil Spill Strategies. Investigative ophthalmology \& visual science 59, Amd160-amd181. 
59. Curcio, C.A., Johnson, M., 2012. Structure, function, and pathology of Bruch's membrane, in: S. J. Ryan, A.P.S., C. P. Wilkinson, D. R. Hinton, S. Sadda, P. Wiedemann (Ed.), Retina, Londen. Elsevier, pp. 465-481.

60. Curcio, C.A., Johnson, M., Huang, J.D., Rudolf, M., 2009. Aging, age-related macular degeneration, and the response-to-retention of apolipoprotein B-containing lipoproteins. Prog Retin Eye Res 28, 393-422.

61. Curcio, C.A., Johnson, M., Rudolf, M., Huang, J.D., 2011. The oil spill in ageing Bruch membrane. The British journal of ophthalmology 95, 1638-1645.

62. Curcio, C.A., Medeiros, N.E., Millican, C.L., 1998. The Alabama Age-Related Macular Degeneration Grading System for donor eyes. Investigative ophthalmology \& visual science 39, 1085-1096. 63. Curcio, C.A., Messinger, J.D., Sloan, K.R., McGwin, G., Medeiros, N.E., Spaide, R.F., 2013. Subretinal drusenoid deposits in non-neovascular age-related macular degeneration: morphology, prevalence, topography, and biogenesis model. Retina 33, 265-276.

64. Curcio, C.A., Millican, C.L., 1999. Basal linear deposit and large drusen are specific for early agerelated maculopathy. Arch Ophthalmol 117, 329-339.

65. Curcio, C.A., Millican, C.L., Bailey, T., Kruth, H.S., 2001. Accumulation of cholesterol with age in human Bruch's membrane. Investigative ophthalmology \& visual science 42, 265-274.

66. Curcio, C.A., Zanzottera, E.C., Ach, T., Balaratnasingam, C., Freund, K.B., 2017. Activated Retinal Pigment Epithelium, an Optical Coherence Tomography Biomarker for Progression in Age-Related Macular Degeneration. Investigative ophthalmology \& visual science 58, Bio211-bio226. 67. de Jong, P.T., 2006. Age-related macular degeneration. N Engl J Med 355, 1474-1485. 68. De, S., Rabin, D.M., Salero, E., Lederman, P.L., Temple, S., Stern, J.H., 2007. Human retinal pigment epithelium cell changes and expression of alphaB-crystallin: a biomarker for retinal pigment epithelium cell change in age-related macular degeneration. Arch Ophthalmol 125, 641-645. 69. de Vries, M.A., Trompet, S., Mooijaart, S.P., Smit, R.A., Bohringer, S., Castro Cabezas, M., Jukema, J.W., 2017. Complement receptor 1 gene polymorphisms are associated with cardiovascular risk. Atherosclerosis $257,16-21$.

70. Del Priore, L.V., Tezel, T.H., Kaplan, H.J., 2006. Maculoplasty for age-related macular degeneration: reengineering Bruch's membrane and the human macula. Prog Retin Eye Res 25, 539562.

71. Despriet, D.D., Klaver, C.C., Witteman, J.C., Bergen, A.A., Kardys, I., de Maat, M.P., Boekhoorn, S.S., Vingerling, J.R., Hofman, A., Oostra, B.A., Uitterlinden, A.G., Stijnen, T., van Duijn, C.M., de Jong, P.T., 2006. Complement factor $\mathrm{H}$ polymorphism, complement activators, and risk of age-related macular degeneration. Jama 296, 301-309.

72. Deutsch, E.W., Ball, C.A., Berman, J.J., Bova, G.S., Brazma, A., Bumgarner, R.E., Campbell, D., Causton, H.C., Christiansen, J.H., Daian, F., Dauga, D., Davidson, D.R., Gimenez, G., Goo, Y.A., Grimmond, S., Henrich, T., Herrmann, B.G., Johnson, M.H., Korb, M., Mills, J.C., Oudes, A.J., Parkinson, H.E., Pascal, L.E., Pollet, N., Quackenbush, J., Ramialison, M., Ringwald, M., Salgado, D., Sansone, S.A., Sherlock, G., Stoeckert, C.J., Jr., Swedlow, J., Taylor, R.C., Walashek, L., Warford, A., Wilkinson, D.G., Zhou, Y., Zon, L.I., Liu, A.Y., True, L.D., 2008. Minimum information specification for in situ hybridization and immunohistochemistry experiments (MISFISHIE). Nat Biotechnol 26, 305312 .

73. Diamond, J.S., 2017. Inhibitory Interneurons in the Retina: Types, Circuitry, and Function. Annu Rev Vis Sci 3, 1-24.

74. Dick, A.D., 2017. Doyne lecture 2016: intraocular health and the many faces of inflammation. Eye (Lond) 31, 87-96.

75. Doherty, T.M., Asotra, K., Fitzpatrick, L.A., Qiao, J.H., Wilkin, D.J., Detrano, R.C., Dunstan, C.R., Shah, P.K., Rajavashisth, T.B., 2003. Calcification in atherosclerosis: bone biology and chronic inflammation at the arterial crossroads. Proc Natl Acad Sci U S A 100, 11201-11206.

76. Domalpally, A., Clemons, T.E., Danis, R.P., Sadda, S.R., Cukras, C.A., Toth, C.A., Friberg, T.R., Chew, E.Y., 2017. Peripheral Retinal Changes Associated with Age-Related Macular Degeneration in the AgeRelated Eye Disease Study 2: Age-Related Eye Disease Study 2 Report Number 12 by the Age-Related 
Eye Disease Study 2 Optos PEripheral RetinA (OPERA) Study Research Group. Ophthalmology 124, 479-487. 77. Doyle, S.L., Campbell, M., Ozaki, E., Salomon, R.G., Mori, A., Kenna, P.F., Farrar, G.J., Kiang, A.S., Humphries, M.M., Lavelle, E.C., O'Neill, L.A., Hollyfield, J.G., Humphries, P., 2012. NLRP3 has a protective role in age-related macular degeneration through the induction of IL-18 by drusen components. Nat Med 18, 791-798. 78. Durocher, D., Jackson, S.P., 2002. The FHA domain. FEBS Lett 513, 58-66. 79. Duvall, J., Tso, M.O., 1985. Cellular mechanisms of resolution of drusen after laser coagulation. An experimental study. Arch Ophthalmol 103, 694-703.

80. Duvall-Young, J., MacDonald, M.K., McKechnie, N.M., 1989. Fundus changes in (type II) mesangiocapillary glomerulonephritis simulating drusen: a histopathological report. The British journal of ophthalmology 73, 297-302.

81. Edwards, A.O., Malek, G., 2007. Molecular genetics of AMD and current animal models. Angiogenesis 10, 119-132.

82. Edwards, A.O., Ritter, R., 3rd, Abel, K.J., Manning, A., Panhuysen, C., Farrer, L.A., 2005.

Complement factor $\mathrm{H}$ polymorphism and age-related macular degeneration. Science 308, 421-424. 83. Engel, A.G., 2018. Congenital Myasthenic Syndromes in 2018. Curr Neurol Neurosci Rep 18, 46.

84. Essner, E., Gordon, S.R., 1983. Observations on the permeability of the choriocapillaris of the eye. Cell Tissue Res 231, 571-577.

85. Fain, G., Sampath, A.P., 2018. Rod and cone interactions in the retina. F1000Res 7.

86. Fariss, R.N., Apte, S.S., Olsen, B.R., Iwata, K., Milam, A.H., 1997. Tissue inhibitor of metalloproteinases-3 is a component of Bruch's membrane of the eye. Am J Pathol 150, 323-328. 87. Farkas, T.G., Sylvester, V., Archer, D., 1971a. The ultrastructure of drusen. Am J Ophthalmol 71, 1196-1205.

88. Farkas, T.G., Sylvester, V., Archer, D., Altona, M., 1971b. The histochemistry of drusen. Am J Ophthalmol 71, 1206-1215.

89. Farrah, T., Deutsch, E.W., Omenn, G.S., Campbell, D.S., Sun, Z., Bletz, J.A., Mallick, P., Katz, J.E., Malmstrom, J., Ossola, R., Watts, J.D., Lin, B., Zhang, H., Moritz, R.L., Aebersold, R., 2011. A highconfidence human plasma proteome reference set with estimated concentrations in PeptideAtlas. Mol Cell Proteomics 10, M110.006353.

90. Feeney-Burns, L., Gao, C.L., Berman, E.R., 1988. The fate of immunoreactive opsin following phagocytosis by pigment epithelium in human and monkey retinas. Investigative ophthalmology \& visual science 29, 708-719.

91. Fernandez-Godino, R., Pierce, E.A., Garland, D.L., 2016. Extracellular Matrix Alterations and Deposit Formation in AMD. Adv Exp Med Biol 854, 53-58.

92. Fine, B.S., 1981. Lipoidal degeneration of the retinal pigment epithelium. Am J Ophthalmol 91, 469-473.

93. Flinn, J.M., Kakalec, P., Tappero, R., Jones, B., Lengyel, I., 2014. Correlations in distribution and concentration of calcium, copper and iron with zinc in isolated extracellular deposits associated with age-related macular degeneration. Metallomics 6, 1223-1228.

94. Forrest, D., Swaroop, A., 2012. Minireview: the role of nuclear receptors in photoreceptor differentiation and disease. Mol Endocrinol 26, 905-915.

95. Fort, P.E., Lampi, K.J., 2011. New focus on alpha-crystallins in retinal neurodegenerative diseases. Exp Eye Res 92, 98-103.

96. Friedman, E., Smith, T.R., Kuwabara, T., 1963. Senile choroidal vascular patterns and drusen. Arch Ophthalmol 69, 220-230.

97. Fritsche, L.G., Igl, W., Bailey, J.N., Grassmann, F., Sengupta, S., Bragg-Gresham, J.L., Burdon, K.P., Hebbring, S.J., Wen, C., Gorski, M., Kim, I.K., Cho, D., Zack, D., Souied, E., Scholl, H.P., Bala, E., Lee, K.E., Hunter, D.J., Sardell, R.J., Mitchell, P., Merriam, J.E., Cipriani, V., Hoffman, J.D., Schick, T., Lechanteur, Y.T., Guymer, R.H., Johnson, M.P., Jiang, Y., Stanton, C.M., Buitendijk, G.H., Zhan, X., Kwong, A.M., Boleda, A., Brooks, M., Gieser, L., Ratnapriya, R., Branham, K.E., Foerster, J.R., Heckenlively, J.R., Othman, M.I., Vote, B.J., Liang, H.H., Souzeau, E., McAllister, I.L., Isaacs, T., Hall, J., 
Lake, S., Mackey, D.A., Constable, I.J., Craig, J.E., Kitchner, T.E., Yang, Z., Su, Z., Luo, H., Chen, D.,

1860

1861

1862

1863

1864

1865

1866

1867

1868

1869

1870

1871

1872

1873

1874

1875

1876

1877

1878

1879

1880

1881

1882

1883

1884

1885

1886

1887

1888

1889

1890

1891

1892

1893

1894

1895

1896

1897

1898

1899

1900

1901

1902

1903

1904

1905

1906

1907

1908

1909

1910

Ouyang, H., Flagg, K., Lin, D., Mao, G., Ferreyra, H., Stark, K., von Strachwitz, C.N., Wolf, A., Brandl, C., Rudolph, G., Olden, M., Morrison, M.A., Morgan, D.J., Schu, M., Ahn, J., Silvestri, G., Tsironi, E.E., Park, K.H., Farrer, L.A., Orlin, A., Brucker, A., Li, M., Curcio, C.A., Mohand-Said, S., Sahel, J.A., Audo, I., Benchaboune, M., Cree, A.J., Rennie, C.A., Goverdhan, S.V., Grunin, M., Hagbi-Levi, S., Campochiaro, P., Katsanis, N., Holz, F.G., Blond, F., Blanche, H., Deleuze, J.F., Igo, R.P., Jr., Truitt, B., Peachey, N.S., Meuer, S.M., Myers, C.E., Moore, E.L., Klein, R., Hauser, M.A., Postel, E.A., Courtenay, M.D., Schwartz, S.G., Kovach, J.L., Scott, W.K., Liew, G., Tan, A.G., Gopinath, B., Merriam, J.C., Smith, R.T., Khan, J.C., Shahid, H., Moore, A.T., McGrath, J.A., Laux, R., Brantley, M.A., Jr., Agarwal, A., Ersoy, L., Caramoy, A., Langmann, T., Saksens, N.T., de Jong, E.K., Hoyng, C.B., Cain, M.S., Richardson, A.J., Martin, T.M., Blangero, J., Weeks, D.E., Dhillon, B., van Duijn, C.M., Doheny, K.F., Romm, J., Klaver, C.C., Hayward, C., Gorin, M.B., Klein, M.L., Baird, P.N., den Hollander, A.I., Fauser, S., Yates, J.R., Allikmets, R., Wang, J.J., Schaumberg, D.A., Klein, B.E., Hagstrom, S.A., Chowers, I., Lotery, A.J., Leveillard, T., Zhang, K., Brilliant, M.H., Hewitt, A.W., Swaroop, A., Chew, E.Y., Pericak-Vance, M.A., DeAngelis, M., Stambolian, D., Haines, J.L., Iyengar, S.K., Weber, B.H., Abecasis, G.R., Heid, I.M., 2016. A large genome-wide association study of age-related macular degeneration highlights contributions of rare and common variants. Nat Genet 48, 134-143.

98. Garcia-Aranda, M., Serrano, A., Redondo, M., 2018. Regulation of Clusterin Gene Expression. Curr Protein Pept Sci 19, 612-622.

99. Gass, J.D., 1967. Pathogenesis of disciform detachment of the neuroepithelium. Am J Ophthalmol 63, Suppl:1-139.

100. Gehlbach, P., Li, T., Hatef, E., 2016. Statins for age-related macular degeneration. Cochrane Database Syst Rev, Cd006927.

101. George, A.K., Singh, M., Homme, R.P., Majumder, A., Sandhu, H.S., Tyagi, S.C., 2018. A hypothesis for treating inflammation and oxidative stress with hydrogen sulfide during age-related macular degeneration. Int J Ophthalmol 11, 881-887.

102. German, O.L., Monaco, S., Agnolazza, D.L., Rotstein, N.P., Politi, L.E., 2013. Retinoid X receptor activation is essential for docosahexaenoic acid protection of retina photoreceptors. J Lipid Res 54 , 2236-2246.

103. Geyer, P.E., Kulak, N.A., Pichler, G., Holdt, L.M., Teupser, D., Mann, M., 2016. Plasma Proteome Profiling to Assess Human Health and Disease. Cell Syst 2, 185-195.

104. Gonzalez, A., Valeiras, M., Sidransky, E., Tayebi, N., 2014. Lysosomal integral membrane protein2: a new player in lysosome-related pathology. Mol Genet Metab 111, 84-91.

105. Gonzalez-Fernandez, F., Kittredge, K.L., Rayborn, M.E., Hollyfield, J.G., Landers, R.A., Saha, M., Grainger, R.M., 1993. Interphotoreceptor retinoid-binding protein (IRBP), a major 124 kDa glycoprotein in the interphotoreceptor matrix of Xenopus laevis. Characterization, molecular cloning and biosynthesis. J Cell Sci 105 ( Pt 1), 7-21.

106. Gorgels, T.G., Teeling, P., Meeldijk, J.D., Nillesen, S.T., van der Wal, A.C., van Kuppevelt, T.H., Bergen, A.A., 2012. Abcc6 deficiency in the mouse leads to calcification of collagen fibers in Bruch's membrane. Exp Eye Res 104, 59-64.

107. Grassmann, F., Kiel, C., Zimmermann, M.E., Gorski, M., Grassmann, V., Stark, K., Heid, I.M., Weber, B.H., 2017. Genetic pleiotropy between age-related macular degeneration and 16 complex diseases and traits. Genome Med 9, 29.

108. Green, W.R., Enger, C., 1993. Age-related macular degeneration histopathologic studies. The 1992 Lorenz E. Zimmerman Lecture. Ophthalmology 100, 1519-1535.

109. Green, W.R., Key, S.N., 3rd, 1977. Senile macular degeneration: a histopathologic study. . Retina 25, 180-250; discussion 250-184.

110. Gross, S.R., Sin, C.G., Barraclough, R., Rudland, P.S., 2014. Joining S100 proteins and migration: for better or for worse, in sickness and in health. Cell Mol Life Sci 71, 1551-1579.

111. Guo, L., Hussain, A.A., Limb, G.A., Marshall, J., 1999. Age-dependent variation in metalloproteinase activity of isolated human Bruch's membrane and choroid. Investigative ophthalmology \& visual science 40, 2676-2682. 
1911

1912

1913

1914

1915

1916

1917

1918

1919

1920

1921

1922

1923

1924

1925

1926

1927

1928

1929

1930

1931

1932

1933

1934

1935

1936

1937

1938

1939

1940

1941

1942

1943

1944

1945

1946

1947

1948

1949

1950

1951

1952

1953

1954

1955

1956

1957

1958

1959

1960

112. Guymer, R., Luthert, P., Bird, A., 1999. Changes in Bruch's membrane and related structures with age. Prog Retin Eye Res 18, 59-90.

113. Hageman, G.S., Anderson, D.H., Johnson, L.V., Hancox, L.S., Taiber, A.J., Hardisty, L.I., Hageman, J.L., Stockman, H.A., Borchardt, J.D., Gehrs, K.M., Smith, R.J., Silvestri, G., Russell, S.R., Klaver, C.C., Barbazetto, I., Chang, S., Yannuzzi, L.A., Barile, G.R., Merriam, J.C., Smith, R.T., Olsh, A.K., Bergeron, J., Zernant, J., Merriam, J.E., Gold, B., Dean, M., Allikmets, R., 2005. A common haplotype in the complement regulatory gene factor $\mathrm{H}(\mathrm{HF} 1 / \mathrm{CFH})$ predisposes individuals to age-related macular degeneration. Proc Natl Acad Sci U S A 102, 7227-7232.

114. Hageman, G.S., Luthert, P.J., Victor Chong, N.H., Johnson, L.V., Anderson, D.H., Mullins, R.F., 2001. An integrated hypothesis that considers drusen as biomarkers of immune-mediated processes at the RPE-Bruch's membrane interface in aging and age-related macular degeneration. Prog Retin Eye Res 20, 705-732.

115. Hageman, G.S., Mullins, R.F., Russell, S.R., Johnson, L.V., Anderson, D.H., 1999. Vitronectin is a constituent of ocular drusen and the vitronectin gene is expressed in human retinal pigmented epithelial cells. FASEB journal : official publication of the Federation of American Societies for Experimental Biology 13, 477-484.

116. Haines, J.L., Hauser, M.A., Schmidt, S., Scott, W.K., Olson, L.M., Gallins, P., Spencer, K.L., Kwan, S.Y., Noureddine, M., Gilbert, J.R., Schnetz-Boutaud, N., Agarwal, A., Postel, E.A., Pericak-Vance, M.A., 2005. Complement factor $\mathrm{H}$ variant increases the risk of age-related macular degeneration. Science 308, 419-421.

117. Handa, J.T., Cano, M., Wang, L., Datta, S., Liu, T., 2017. Lipids, oxidized lipids, oxidation-specific epitopes, and Age-related Macular Degeneration. Biochim Biophys Acta Mol Cell Biol Lipids 1862, 430-440.

118. Hansson, G.K., Robertson, A.K., Soderberg-Naucler, C., 2006. Inflammation and atherosclerosis. Annu Rev Pathol 1, 297-329.

119. Happonen, K.E., Furst, C.M., Saxne, T., Heinegard, D., Blom, A.M., 2012. PRELP protein inhibits the formation of the complement membrane attack complex. J Biol Chem 287, 8092-8100.

120. Hiebl, V., Ladurner, A., Latkolik, S., Dirsch, V.M., 2018. Natural products as modulators of the nuclear receptors and metabolic sensors LXR, FXR and RXR. Biotechnol Adv.

121. Hogan, M.J., 1965. MACULAR DISEASES: PATHOGENESIS. ELECTRON MICROSCOPY OF BRUCH'S MEMBRANE. Trans Am Acad Ophthalmol Otolaryngol 69, 683-690.

122. Hogan, M.J., 1972. Role of the retinal pigment epithelium in macular disease. Trans Am Acad Ophthalmol Otolaryngol 76, 64-80.

123. Hoke, M., Speidl, W., Schillinger, M., Minar, E., Zehetmayer, S., Schonherr, M., Wagner, O., Mannhalter, C., 2012. Polymorphism of the complement 5 gene and cardiovascular outcome in patients with atherosclerosis. Eur J Clin Invest 42, 921-926.

124. Hollyfield, J.G., Perez, V.L., Salomon, R.G., 2010. A hapten generated from an oxidation fragment of docosahexaenoic acid is sufficient to initiate age-related macular degeneration. Mol Neurobiol 41 , 290-298.

125. Hollyfield, J.G., Salomon, R.G., Crabb, J.W., 2003. Proteomic approaches to understanding agerelated macular degeneration. Adv Exp Med Biol 533, 83-89.

126. Hopkins, P.N., 2013. Molecular biology of atherosclerosis. Physiol Rev 93, 1317-1542.

127. Hoppe, G., Marmorstein, A.D., Pennock, E.A., Hoff, H.F., 2001. Oxidized low density lipoproteininduced inhibition of processing of photoreceptor outer segments by RPE. Investigative ophthalmology \& visual science 42, 2714-2720.

128. Hultgardh-Nilsson, A., Boren, J., Chakravarti, S., 2015. The small leucine-rich repeat proteoglycans in tissue repair and atherosclerosis. J Intern Med 278, 447-461.

129. Hussain, A.A., Lee, Y., Zhang, J.J., Marshall, J., 2011. Disturbed matrix metalloproteinase activity of Bruch's membrane in age-related macular degeneration. Investigative ophthalmology $\&$ visual science $52,4459-4466$. 
130. Hussain, A.A., Starita, C., Hodgetts, A., Marshall, J., 2010. Macromolecular diffusion characteristics of ageing human Bruch's membrane: implications for age-related macular degeneration (AMD). Exp Eye Res 90, 703-710. 131. Hyman, L.G., Lilienfeld, A.M., Ferris, F.L., 3rd, Fine, S.L., 1983. Senile macular degeneration: a case-control study. Am J Epidemiol 118, 213-227. 132. Ida, H., Ishibashi, K., Reiser, K., Hjelmeland, L.M., Handa, J.T., 2004. Ultrastructural aging of the RPE-Bruch's membrane-choriocapillaris complex in the D-galactose-treated mouse. Investigative ophthalmology \& visual science 45, 2348-2354. 133. Ito, N., Ohashi, R., Nagata, M., 2017. C3 glomerulopathy and current dilemmas. Clin Exp Nephrol 21, 541-551. 134. Jang, H.L., Jin, K., Lee, J., Kim, Y., Nahm, S.H., Hong, K.S., Nam, K.T., 2014. Revisiting whitlockite, the second most abundant biomineral in bone: nanocrystal synthesis in physiologically relevant conditions and biocompatibility evaluation. ACS Nano 8, 634-641. 135. Jansen, R.S., Kucukosmanoglu, A., de Haas, M., Sapthu, S., Otero, J.A., Hegman, I.E., Bergen, A.A., Gorgels, T.G., Borst, P., van de Wetering, K., 2013. ABCC6 prevents ectopic mineralization seen in pseudoxanthoma elasticum by inducing cellular nucleotide release. Proc Natl Acad Sci U S A 110, 20206-20211.

136. Jobling, A.I., Guymer, R.H., Vessey, K.A., Greferath, U., Mills, S.A., Brassington, K.H., Luu, C.D., Aung, K.Z., Trogrlic, L., Plunkett, M., Fletcher, E.L., 2015. Nanosecond laser therapy reverses pathologic and molecular changes in age-related macular degeneration without retinal damage. FASEB journal : official publication of the Federation of American Societies for Experimental Biology 29, 696-710.

137. Johnson, L.V., Forest, D.L., Banna, C.D., Radeke, C.M., Maloney, M.A., Hu, J., Spencer, C.N., Walker, A.M., Tsie, M.S., Bok, D., Radeke, M.J., Anderson, D.H., 2011. Cell culture model that mimics drusen formation and triggers complement activation associated with age-related macular degeneration. Proc Natl Acad Sci U S A 108, 18277-18282.

138. Johnson, L.V., Ozaki, S., Staples, M.K., Erickson, P.A., Anderson, D.H., 2000. A potential role for immune complex pathogenesis in drusen formation. Exp Eye Res 70, 441-449.

139. Johnson, P.T., Lewis, G.P., Talaga, K.C., Brown, M.N., Kappel, P.J., Fisher, S.K., Anderson, D.H., Johnson, L.V., 2003. Drusen-associated degeneration in the retina. Investigative ophthalmology \& visual science $44,4481-4488$.

140. Jones, S.E., Jomary, C., Grist, J., Makwana, J., Neal, M.J., 1999. Retinal expression of gammacrystallins in the mouse. Investigative ophthalmology \& visual science 40, 3017-3020.

141. Kalbitz, M., Grailer, J.J., Fattahi, F., Jajou, L., Herron, T.J., Campbell, K.F., Zetoune, F.S., Bosmann, M., Sarma, J.V., Huber-Lang, M., Gebhard, F., Loaiza, R., Valdivia, H.H., Jalife, J., Russell, M.W., Ward, P.A., 2015. Role of extracellular histones in the cardiomyopathy of sepsis. FASEB journal : official publication of the Federation of American Societies for Experimental Biology 29, 2185-2193. 142. Kamaraj, B., Purohit, R., 2014. Mutational analysis of oculocutaneous albinism: a compact review. Biomed Res Int 2014, 905472.

143. Kamei, M., Hollyfield, J.G., 1999. TIMP-3 in Bruch's membrane: changes during aging and in agerelated macular degeneration. Investigative ophthalmology \& visual science 40, 2367-2375. 144. Kani, T., Kani, M., Moriwaki, Y., Doi, Y., 1983. Microbeam x-ray diffraction analysis of dental calculus. J Dent Res 62, 92-95.

145. Kannan, R., Sreekumar, P.G., Hinton, D.R., 2016. Alpha crystallins in the retinal pigment epithelium and implications for the pathogenesis and treatment of age-related macular degeneration. Biochim Biophys Acta 1860, 258-268.

146. Kauppinen, A., Paterno, J.J., Blasiak, J., Salminen, A., Kaarniranta, K., 2016. Inflammation and its role in age-related macular degeneration. Cell Mol Life Sci 73, 1765-1786. 147. Keelan, P.C., Bielak, L.F., Ashai, K., Jamjoum, L.S., Denktas, A.E., Rumberger, J.A., Sheedy, I.P., Peyser, P.A., Schwartz, R.S., 2001. Long-term prognostic value of coronary calcification detected by electron-beam computed tomography in patients undergoing coronary angiography. Circulation 104, 412-417. 
2013

2014

2015

2016

2017

2018

2019

2020

2021

2022

2023

2024

2025

2026

2027

2028

2029

2030

2031

2032

2033

2034

2035

2036

2037

2038

2039

2040

2041

2042

2043

2044

2045

2046

2047

2048

2049

2050

2051

2052

2053

2054

2055

2056

2057

2058

2059

2060

2061

2062

148. Keenan, T.D., Clark, S.J., Unwin, R.D., Ridge, L.A., Day, A.J., Bishop, P.N., 2012. Mapping the differential distribution of proteoglycan core proteins in the adult human retina, choroid, and sclera. Investigative ophthalmology \& visual science 53, 7528-7538.

149. Kestenbaum, B.R., Adeney, K.L., de Boer, I.H., Ix, J.H., Shlipak, M.G., Siscovick, D.S., 2009. Incidence and progression of coronary calcification in chronic kidney disease: the Multi-Ethnic Study of Atherosclerosis. Kidney Int 76, 991-998.

150. Khan, K.N., Mahroo, O.A., Khan, R.S., Mohamed, M.D., McKibbin, M., Bird, A., Michaelides, M., Tufail, A., Moore, A.T., 2016. Differentiating drusen: Drusen and drusen-like appearances associated with ageing, age-related macular degeneration, inherited eye disease and other pathological processes. Prog Retin Eye Res 53, 70-106.

151. Kiel, C., Vogt, A., Campagna, A., Chatr-aryamontri, A., Swiatek-de Lange, M., Beer, M., Bolz, S., Mack, A.F., Kinkl, N., Cesareni, G., Serrano, L., Ueffing, M., 2011. Structural and functional protein network analyses predict novel signaling functions for rhodopsin. Mol Syst Biol 7, 551.

152. Kim, Y.H., He, S., Kase, S., Kitamura, M., Ryan, S.J., Hinton, D.R., 2009. Regulated secretion of complement factor H by RPE and its role in RPE migration. Graefes Arch Clin Exp Ophthalmol 247, 651-659.

153. Kinnunen, K., Petrovski, G., Moe, M.C., Berta, A., Kaarniranta, K., 2012. Molecular mechanisms of retinal pigment epithelium damage and development of age-related macular degeneration. Acta Ophthalmol 90, 299-309.

154. Klaver, C.C., Kliffen, M., van Duijn, C.M., Hofman, A., Cruts, M., Grobbee, D.E., van Broeckhoven, C., de Jong, P.T., 1998. Genetic association of apolipoprotein E with age-related macular degeneration. Am J Hum Genet 63, 200-206.

155. Klein, R., Klein, B.E., Franke, T., 1993. The relationship of cardiovascular disease and its risk factors to age-related maculopathy. The Beaver Dam Eye Study. Ophthalmology 100, 406-414. 156. Klein, R.J., Zeiss, C., Chew, E.Y., Tsai, J.Y., Sackler, R.S., Haynes, C., Henning, A.K., SanGiovanni, J.P., Mane, S.M., Mayne, S.T., Bracken, M.B., Ferris, F.L., Ott, J., Barnstable, C., Hoh, J., 2005. Complement factor $\mathrm{H}$ polymorphism in age-related macular degeneration. Science 308, 385-389. 157. Kobayashi, H., Okamoto, H., Murakami, A., Iwata, T., 2014. Plasma proteome analysis on cynomolgus monkey (Macaca fascicularis) pedigrees with early onset drusen formation. Exp Anim 63, 305-310.

158. Kornzweig, A.L., 1977. Changes in the choriocapillaris associated with senile macular degeneration. Ann Ophthalmol 9, 753-756, 759-762.

159. Kruijt, C.C., de Wit, G.C., Bergen, A.A., Florijn, R.J., Schalij-Delfos, N.E., van Genderen, M.M., 2018. The Phenotypic Spectrum of Albinism. Ophthalmology.

160. Kunchithapautham, K., Atkinson, C., Rohrer, B., 2014. Smoke exposure causes endoplasmic reticulum stress and lipid accumulation in retinal pigment epithelium through oxidative stress and complement activation. J Biol Chem 289, 14534-14546.

161. Lai, X., Wichers, H.J., Soler-Lopez, M., Dijkstra, B.W., 2018. Structure and Function of Human Tyrosinase and Tyrosinase-Related Proteins. Chemistry 24, 47-55.

162. Lee, J.S., Morrisett, J.D., Tung, C.H., 2012. Detection of hydroxyapatite in calcified cardiovascular tissues. Atherosclerosis 224, 340-347.

163. Lee, Y., Hussain, A.A., Seok, J.H., Kim, S.H., Marshall, J., 2015. Modulating the Transport Characteristics of Bruch's Membrane With Steroidal Glycosides and its Relevance to Age-Related Macular Degeneration (AMD). Investigative ophthalmology \& visual science 56, 8403-8418. 164. Lengyel, I., Csutak, A., Florea, D., Leung, I., Bird, A.C., Jonasson, F., Peto, T., 2015. A PopulationBased Ultra-Widefield Digital Image Grading Study for Age-Related Macular Degeneration-Like Lesions at the Peripheral Retina. Ophthalmology 122, 1340-1347.

165. Lengyel, I., Flinn, J.M., Peto, T., Linkous, D.H., Cano, K., Bird, A.C., Lanzirotti, A., Frederickson, C.J., van Kuijk, F.J., 2007. High concentration of zinc in sub-retinal pigment epithelial deposits. Exp Eye Res 84, 772-780. 
166. Lengyel, I., Tufail, A., Hosaini, H.A., Luthert, P., Bird, A.C., Jeffery, G., 2004. Association of drusen deposition with choroidal intercapillary pillars in the aging human eye. Investigative ophthalmology \& visual science 45, 2886-2892.

167. Li, C.M., Chung, B.H., Presley, J.B., Malek, G., Zhang, X., Dashti, N., Li, L., Chen, J., Bradley, K., Kruth, H.S., Curcio, C.A., 2005a. Lipoprotein-like particles and cholesteryl esters in human Bruch's membrane: initial characterization. Investigative ophthalmology \& visual science 46, 2576-2586. 168. Li, C.M., Presley, J.B., Zhang, X., Dashti, N., Chung, B.H., Medeiros, N.E., Guidry, C., Curcio, C.A., 2005b. Retina expresses microsomal triglyceride transfer protein: implications for age-related maculopathy. J Lipid Res 46, 628-640. 169. Li, M., Dolz-Marco, R., Messinger, J.D., Wang, L., Feist, R.M., Girkin, C.A., Gattoussi, S., Ferrara, D., Curcio, C.A., Freund, K.B., 2018. Clinicopathologic Correlation of Anti-Vascular Endothelial Growth Factor-Treated Type 3 Neovascularization in Age-Related Macular Degeneration. Ophthalmology 125, 276-287.

170. Li, M., Jia, C., Kazmierkiewicz, K.L., Bowman, A.S., Tian, L., Liu, Y., Gupta, N.A., Gudiseva, H.V., Yee, S.S., Kim, M., Dentchev, T., Kimble, J.A., Parker, J.S., Messinger, J.D., Hakonarson, H., Curcio, C.A., Stambolian, D., 2014. Comprehensive analysis of gene expression in human retina and supporting tissues. Human molecular genetics 23, 4001-4014.

171. Loeffler, K.U., Lee, W.R., 1998. Terminology of sub-RPE deposits: do we all speak the same language? The British journal of ophthalmology 82, 1104-1105.

172. Lutty, G.A., Hasegawa, T., Baba, T., Grebe, R., Bhutto, I., McLeod, D.S., 2010. Development of the human choriocapillaris. Eye (Lond) 24, 408-415.

173. Machalinska, A., Safranow, K., Dziedziejko, V., Mozolewska-Piotrowska, K., Paczkowska, E., Klos, P., Pius, E., Grymula, K., Wiszniewska, B., Karczewicz, D., Machalinski, B., 2011. Different populations of circulating endothelial cells in patients with age-related macular degeneration: a novel insight into pathogenesis. Investigative ophthalmology \& visual science 52, 93-100.

174. Mahley, R.W., 2016. Apolipoprotein E: from cardiovascular disease to neurodegenerative disorders. J Mol Med (Berl) 94, 739-746.

175. Malek, G., Li, C.M., Guidry, C., Medeiros, N.E., Curcio, C.A., 2003. Apolipoprotein B in cholesterol-containing drusen and basal deposits of human eyes with age-related maculopathy. Am J Pathol 162, 413-425.

176. Maltzman, B.A., Mulvihill, M.N., Greenbaum, A., 1979. Senile macular degeneration and risk factors: a case-control study. Ann Ophthalmol 11, 1197-1201.

177. Mancini, M.A., Frank, R.N., Keirn, R.J., Kennedy, A., Khoury, J.K., 1986. Does the retinal pigment epithelium polarize the choriocapillaris? Investigative ophthalmology \& visual science 27, 336-345. 178. Marshall, G.E., Konstas, A.G., Reid, G.G., Edwards, J.G., Lee, W.R., 1992. Type IV collagen and laminin in Bruch's membrane and basal linear deposit in the human macula. The British journal of ophthalmology 76, 607-614.

179. McLeod, D.S., Grebe, R., Bhutto, I., Merges, C., Baba, T., Lutty, G.A., 2009. Relationship between RPE and choriocapillaris in age-related macular degeneration. Investigative ophthalmology \& visual science $50,4982-4991$.

180. Miteva, K., Madonna, R., De Caterina, R., Van Linthout, S., 2018. Innate and adaptive immunity in atherosclerosis. Vascul Pharmacol.

181. Molins, B., Romero-Vazquez, S., Fuentes-Prior, P., Adan, A., Dick, A.D., 2018. C-Reactive Protein as a Therapeutic Target in Age-Related Macular Degeneration. Front Immunol 9, 808.

182. Moore, D.J., Clover, G.M., 2001. The effect of age on the macromolecular permeability of human Bruch's membrane. Investigative ophthalmology \& visual science 42, 2970-2975.

183. Moore, D.J., Hussain, A.A., Marshall, J., 1995. Age-related variation in the hydraulic conductivity of Bruch's membrane. Investigative ophthalmology \& visual science 36, 1290-1297.

184. Moreira-Neto, C.A., Moult, E.M., Fujimoto, J.G., Waheed, N.K., Ferrara, D., 2018. Choriocapillaris Loss in Advanced Age-Related Macular Degeneration. J Ophthalmol 2018, 8125267. 
185. Mullins, R.F., Johnson, M.N., Faidley, E.A., Skeie, J.M., Huang, J., 2011. Choriocapillaris vascular dropout related to density of drusen in human eyes with early age-related macular degeneration. Investigative ophthalmology \& visual science 52, 1606-1612. 186. Mullins, R.F., Russell, S.R., Anderson, D.H., Hageman, G.S., 2000. Drusen associated with aging and age-related macular degeneration contain proteins common to extracellular deposits associated with atherosclerosis, elastosis, amyloidosis, and dense deposit disease. FASEB journal : official publication of the Federation of American Societies for Experimental Biology 14, 835-846. 187. Mullins, R.F., Schoo, D.P., Sohn, E.H., Flamme-Wiese, M.J., Workamelahu, G., Johnston, R.M., Wang, K., Tucker, B.A., Stone, E.M., 2014. The membrane attack complex in aging human choriocapillaris: relationship to macular degeneration and choroidal thinning. Am J Pathol 184, 31423153. 188. Mungrue, I.N., Zhao, P., Yao, Y., Meng, H., Rau, C., Havel, J.V., Gorgels, T.G., Bergen, A.A., MacLellan, W.R., Drake, T.A., Bostrom, K.I., Lusis, A.J., 2011. Abcc6 deficiency causes increased infarct size and apoptosis in a mouse cardiac ischemia-reperfusion model. Arterioscler Thromb Vasc Biol 31, 2806-2812.

189. Musser, J.M., Arendt, D., 2017. Loss and gain of cone types in vertebrate ciliary photoreceptor evolution. Dev Biol 431, 26-35.

190. Nakanishi, M., Grebe, R., Bhutto, I.A., Edwards, M., McLeod, D.S., Lutty, G.A., 2016. Albumen Transport to Bruch's Membrane and RPE by Choriocapillaris Caveolae. Investigative ophthalmology \& visual science 57, 2213-2224.

191. Nakata, K., Crabb, J.W., Hollyfield, J.G., 2005. Crystallin distribution in Bruch's membranechoroid complex from AMD and age-matched donor eyes. Exp Eye Res 80, 821-826.

192. Nan, R., Farabella, I., Schumacher, F.F., Miller, A., Gor, J., Martin, A.C., Jones, D.T., Lengyel, I., Perkins, S.J., 2011. Zinc binding to the Tyr402 and His402 allotypes of complement factor H: possible implications for age-related macular degeneration. J Mol Biol 408, 714-735.

193. Nan, R., Gor, J., Lengyel, I., Perkins, S.J., 2008. Uncontrolled zinc- and copper-induced oligomerisation of the human complement regulator factor $\mathrm{H}$ and its possible implications for function and disease. J Mol Biol 384, 1341-1352.

194. Nan, R., Tetchner, S., Rodriguez, E., Pao, P.J., Gor, J., Lengyel, I., Perkins, S.J., 2013. Zinc-induced self-association of complement $\mathrm{C} 3 \mathrm{~b}$ and Factor $\mathrm{H}$ : implications for inflammation and age-related macular degeneration. J Biol Chem 288, 19197-19210.

195. Narumi, K., Miyakawa, R., Ueda, R., Hashimoto, H., Yamamoto, Y., Yoshida, T., Aoki, K., 2015. Proinflammatory Proteins S100A8/S100A9 Activate NK Cells via Interaction with RAGE. J Immunol 194, 5539-5548.

196. Newsome, D.A., Hewitt, A.T., Huh, W., Robey, P.G., Hassell, J.R., 1987. Detection of specific extracellular matrix molecules in drusen, Bruch's membrane, and ciliary body. Am J Ophthalmol 104, 373-381.

197. Nijholt, D.A., ljsselstijn, L., van der Weiden, M.M., Zheng, P.P., Sillevis Smitt, P.A., Koudstaal, P.J., Luider, T.M., Kros, J.M., 2015. Pregnancy Zone Protein is Increased in the Alzheimer's Disease Brain and Associates with Senile Plaques. J Alzheimers Dis 46, 227-238.

198. Nordgaard, C.L., Berg, K.M., Kapphahn, R.J., Reilly, C., Feng, X., Olsen, T.W., Ferrington, D.A., 2006. Proteomics of the retinal pigment epithelium reveals altered protein expression at progressive stages of age-related macular degeneration. Investigative ophthalmology \& visual science $47,815-$ 822.

199. Novais, E.A., Badaro, E., Regatieri, C.V., Duker, J., de Oliveira Bonomo, P.P., 2015. Regression of drusen after combined treatment using photodynamic therapy with verteporfin and ranibizumab. Ophthalmic Surg Lasers Imaging Retina 46, 275-278.

200. Okuno, S., Ishimura, E., Kitatani, K., Fujino, Y., Kohno, K., Maeno, Y., Maekawa, K., Yamakawa, T., Imanishi, Y., Inaba, M., Nishizawa, Y., 2007. Presence of abdominal aortic calcification is significantly associated with all-cause and cardiovascular mortality in maintenance hemodialysis patients. Am J Kidney Dis 49, 417-425. 
201. Oshikawa, M., Tsutsui, C., Ikegami, T., Fuchida, Y., Matsubara, M., Toyama, S., Usami, R., Ohtoko, K., Kato, S., 2011. Full-length transcriptome analysis of human retina-derived cell lines ARPE19 and Y79 using the vector-capping method. Investigative ophthalmology \& visual science 52, 66626670. 202. Pao, P.J., Emri, E., Abdirahman, S.B., Soorma, T., Zeng, H.H., Hauck, S.M., Thompson, R.B., Lengyel, I., 2018. The effects of zinc supplementation on primary human retinal pigment epithelium. J Trace Elem Med Biol 49, 184-191. age-related Bruch's membrane change. Am J Ophthalmol 109, 211-217. 204. Pelisek, J., Wendorff, H., Wendorff, C., Kuehnl, A., Eckstein, H.H., 2016. Age-associated changes in human carotid atherosclerotic plaques. Ann Med 48, 541-551. 205. Penfold, P.L., Madigan, M.C., Gillies, M.C., Provis, J.M., 2001. Immunological and aetiological aspects of macular degeneration. Prog Retin Eye Res 20, 385-414.

206. Pikuleva, I.A., Curcio, C.A., 2014. Cholesterol in the retina: the best is yet to come. Prog Retin Eye Res 41, 64-89.

207. Pilgrim, M.G., Lengyel, I., Lanzirotti, A., Newville, M., Fearn, S., Emri, E., Knowles, J.C., Messinger, J.D., Read, R.W., Guidry, C., Curcio, C.A., 2017. Subretinal Pigment Epithelial Deposition of Drusen Components Including Hydroxyapatite in a Primary Cell Culture Model. Investigative ophthalmology \& visual science $58,708-719$.

208. Pino, R.M., 1985. Restriction to endogenous plasma proteins by a fenestrated capillary endothelium: an ultrastructural immunocytochemical study of the choriocapillary endothelium. Am J Anat 172, 279-289.

209. Pino, R.M., Essner, E., 1981. Permeability of rat choriocapillaris to hemeproteins. Restriction of tracers by a fenestrated endothelium. J Histochem Cytochem 29, 281-290.

210. Pinto, E., 2007. Blood pressure and ageing. Postgrad Med J 83, 109-114.

211. Radu, R.A., Hu, J., Jiang, Z., Bok, D., 2014. Bisretinoid-mediated complement activation on retinal pigment epithelial cells is dependent on complement factor $\mathrm{H}$ haplotype. J Biol Chem 289, 91139120.

212. Rakoczy, P.E., Sarks, S.H., Daw, N., Constable, I.J., 1999. Distribution of cathepsin D in human eyes with or without age-related maculopathy. Exp Eye Res 69, 367-374.

213. Ramrattan, R.S., van der Schaft, T.L., Mooy, C.M., de Bruijn, W.C., Mulder, P.G., de Jong, P.T., 1994. Morphometric analysis of Bruch's membrane, the choriocapillaris, and the choroid in aging. Investigative ophthalmology \& visual science 35, 2857-2864.

214. Rayborn, M.E., Sakaguchi, H., Shadrach, K.G., Crabb, J.W., Hollyfield, J.G., 2006. Annexins in Bruch's membrane and drusen. Adv Exp Med Biol 572, 75-78.

215. Ronchetti, I., Boraldi, F., Annovi, G., Cianciulli, P., Quaglino, D., 2013. Fibroblast involvement in soft connective tissue calcification. Front Genet 4, 22.

216. Ruiz, A., Brett, P., Bok, D., 1996. TIMP-3 is expressed in the human retinal pigment epithelium. Biochemical and biophysical research communications 226, 467-474.

217. Sakaguchi, H., Miyagi, M., Shadrach, K.G., Rayborn, M.E., Crabb, J.W., Hollyfield, J.G., 2002. Clusterin is present in drusen in age-related macular degeneration. Exp Eye Res 74, 547-549.

218. Sallo, F.B., Rechtman, E., Peto, T., Stanescu-Segall, D., Vogt, G., Bird, A.C., Fitzke, F.W., 2009. Functional aspects of drusen regression in age-related macular degeneration. The British journal of ophthalmology 93, 1345-1350.

219. Sarks, J.P., Sarks, S.H., Killingsworth, M.C., 1988. Evolution of geographic atrophy of the retinal pigment epithelium. Eye (Lond) 2 ( Pt 5), 552-577.

220. Sarks, J.P., Sarks, S.H., Killingsworth, M.C., 1994. Evolution of soft drusen in age-related macular degeneration. Eye (Lond) 8 ( Pt 3), 269-283.

221. Sarks, S.H., 1976. Ageing and degeneration in the macular region: a clinico-pathological study. The British journal of ophthalmology 60, 324-341. 
222. Sarks, S.H., Arnold, J.J., Killingsworth, M.C., Sarks, J.P., 1999. Early drusen formation in the normal and aging eye and their relation to age related maculopathy: a clinicopathological study. The British journal of ophthalmology 83, 358-368.

223. Sarks, S.H., Van Driel, D., Maxwell, L., Killingsworth, M., 1980. Softening of drusen and subretinal neovascularization. Trans Ophthalmol Soc U K 100, 414-422. 224. Schaumberg, D.A., Christen, W.G., Buring, J.E., Glynn, R.J., Rifai, N., Ridker, P.M., 2007. Highsensitivity C-reactive protein, other markers of inflammation, and the incidence of macular degeneration in women. Arch Ophthalmol 125, 300-305.

225. Schlanitz, F., Baumann, B., Sacu, S., Baumann, L., Pircher, M., Hitzenberger, C.K., SchmidtErfurth, U.M., 2018. Impact of drusen and drusenoid retinal pigment epithelium elevation size and structure on the integrity of the retinal pigment epithelium layer. The British journal of ophthalmology. 226. Schlieper, G., Aretz, A., Verberckmoes, S.C., Kruger, T., Behets, G.J., Ghadimi, R., Weirich, T.E., Rohrmann, D., Langer, S., Tordoir, J.H., Amann, K., Westenfeld, R., Brandenburg, V.M., D'Haese, P.C., Mayer, J., Ketteler, M., McKee, M.D., Floege, J., 2010. Ultrastructural analysis of vascular calcifications in uremia. J Am Soc Nephrol 21, 689-696.

227. Schunkert, H., von Scheidt, M., Kessler, T., Stiller, B., Zeng, L., Vilne, B., 2018. Genetics of coronary artery disease in the light of genome-wide association studies. Clin Res Cardiol 107, 2-9. 228. Serban, C., Dragan, S., 2014. The relationship between inflammatory and oxidative stress biomarkers, atherosclerosis and rheumatic diseases. Curr Pharm Des 20, 585-600.

229. Serhan, C.N., Dalli, J., Colas, R.A., Winkler, J.W., Chiang, N., 2015. Protectins and maresins: New pro-resolving families of mediators in acute inflammation and resolution bioactive metabolome. Biochim Biophys Acta 1851, 397-413.

230. Shah, F.A., Lee, B.E.J., Tedesco, J., Larsson Wexell, C., Persson, C., Thomsen, P., Grandfield, K., Palmquist, A., 2017. Micrometer-Sized Magnesium Whitlockite Crystals in Micropetrosis of Bisphosphonate-Exposed Human Alveolar Bone. Nano Lett 17, 6210-6216. 231. Simmons, R.D., Kumar, S., Thabet, S.R., Sur, S., Jo, H., 2016. Omics-based approaches to understand mechanosensitive endothelial biology and atherosclerosis. Wiley Interdiscip Rev Syst Biol Med 8, 378-401.

232. Sivaprasad, S., Bailey, T.A., Chong, V.N., 2005. Bruch's membrane and the vascular intima: is there a common basis for age-related changes and disease? Clin Exp Ophthalmol 33, 518-523. 233. Skeie, J.M., Mahajan, V.B., 2014. Proteomic landscape of the human choroid-retinal pigment epithelial complex. JAMA Ophthalmol 132, 1271-1281.

234. Smith, S.S., Pino, R.M., Thouron, C.L., 1989. Binding and transport of transthyretin-gold by the endothelium of the rat choriocapillaris. J Histochem Cytochem 37, 1497-1502.

235. Snow, K.K., Seddon, J.M., 1999. Do age-related macular degeneration and cardiovascular disease share common antecedents? Ophthalmic Epidemiol 6, 125-143.

236. Sohn, E.H., Wang, K., Thompson, S., Riker, M.J., Hoffmann, J.M., Stone, E.M., Mullins, R.F., 2015. Comparison of drusen and modifying genes in autosomal dominant radial drusen and age-related macular degeneration. Retina 35, 48-57.

237. Song, Y., Stampfer, M.J., Liu, S., 2004. Meta-analysis: apolipoprotein E genotypes and risk for coronary heart disease. Ann Intern Med 141, 137-147.

238. Spaide, R.F., Ooto, S., Curcio, C.A., 2018. Subretinal Drusenoid Deposits AKA Pseudodrusen. Surv Ophthalmol.

239. Spraul, C.W., Lang, G.E., Grossniklaus, H.E., Lang, G.K., 1999. Histologic and morphometric analysis of the choroid, Bruch's membrane, and retinal pigment epithelium in postmortem eyes with age-related macular degeneration and histologic examination of surgically excised choroidal neovascular membranes. Surv Ophthalmol 44 Suppl 1, S10-32.

240. Starita, C., Hussain, A.A., Patmore, A., Marshall, J., 1997. Localization of the site of major resistance to fluid transport in Bruch's membrane. Investigative ophthalmology \& visual science 38, 762-767. 
241. Stefansson, E., Geirsdottir, A., Sigurdsson, H., 2011. Metabolic physiology in age related macular degeneration. Prog Retin Eye Res 30, 72-80.

242. Strauss, O., 2005. The retinal pigment epithelium in visual function. Physiol Rev 85, 845-881. 243. Strunnikova, N.V., Maminishkis, A., Barb, J.J., Wang, F., Zhi, C., Sergeev, Y., Chen, W., Edwards, A.O., Stambolian, D., Abecasis, G., Swaroop, A., Munson, P.J., Miller, S.S., 2010. Transcriptome analysis and molecular signature of human retinal pigment epithelium. Human molecular genetics 19, 2468-2486.

244. Suzuki, M., Curcio, C.A., Mullins, R.F., Spaide, R.F., 2015. REFRACTILE DRUSEN: Clinical Imaging and Candidate Histology. Retina 35, 859-865.

245. Tabas, I., Williams, K.J., Boren, J., 2007. Subendothelial lipoprotein retention as the initiating process in atherosclerosis: update and therapeutic implications. Circulation 116, 1832-1844.

246. Tas, A.C., 2000. Synthesis of biomimetic Ca-hydroxyapatite powders at 37 degrees $\mathrm{C}$ in synthetic body fluids. Biomaterials 21, 1429-1438.

247. Tate, D.J., Jr., Oliver, P.D., Miceli, M.V., Stern, R., Shuster, S., Newsome, D.A., 1993. Agedependent change in the hyaluronic acid content of the human chorioretinal complex. Arch Ophthalmol 111, 963-967.

248. Templeton, J.P., Wang, X., Freeman, N.E., Ma, Z., Lu, A., Hejtmancik, F., Geisert, E.E., 2013. A crystallin gene network in the mouse retina. Exp Eye Res 116, 129-140.

249. Tessarz, P., Kouzarides, T., 2014. Histone core modifications regulating nucleosome structure and dynamics. Nat Rev Mol Cell Biol 15, 703-708.

250. Thanos, S., Bohm, M.R., Meyer zu Horste, M., Prokosch-Willing, V., Hennig, M., Bauer, D., Heiligenhaus, A., 2014. Role of crystallins in ocular neuroprotection and axonal regeneration. Prog Retin Eye Res 42, 145-161.

251. The Eye Disease Case-Control Study, C., 1992. Risk factors for neovascular age-related macular degeneration. Arch Ophthalmol 110, 1701-1708.

252. Thompson, R.B., Reffatto, V., Bundy, J.G., Kortvely, E., Flinn, J.M., Lanzirotti, A., Jones, E.A., McPhail, D.S., Fearn, S., Boldt, K., Ueffing, M., Ratu, S.G., Pauleikhoff, L., Bird, A.C., Lengyel, I., 2015. Identification of hydroxyapatite spherules provides new insight into subretinal pigment epithelial deposit formation in the aging eye. Proc Natl Acad Sci U S A 112, 1565-1570.

253. Tian, L., Kazmierkiewicz, K.L., Bowman, A.S., Li, M., Curcio, C.A., Stambolian, D.E., 2015. Transcriptome of the human retina, retinal pigmented epithelium and choroid. Genomics $105,253-$ 264.

254. Tikellis, G., Sun, C., Gorin, M.B., Klein, R., Klein, B.E., Larsen, E.K., Siscovick, D.S., Hubbard, L.D., Wong, T.Y., 2007. Apolipoprotein e gene and age-related maculopathy in older individuals: the cardiovascular health study. Arch Ophthalmol 125, 68-73.

255. Tohyama, J., Nakashima, M., Nabatame, S., Gaik-Siew, C., Miyata, R., Rener-Primec, Z., Kato, M., Matsumoto, N., Saitsu, H., 2015. SPTAN1 encephalopathy: distinct phenotypes and genotypes. J Hum Genet 60, 167-173.

256. Toomey, C.B., Johnson, L.V., Bowes Rickman, C., 2018. Complement factor H in AMD: Bridging genetic associations and pathobiology. Prog Retin Eye Res 62, 38-57.

257. Toops, K.A., Tan, L.X., Lakkaraju, A., 2016. Apolipoprotein E Isoforms and AMD. Adv Exp Med Biol 854, 3-9.

258. Toy, B.C., Krishnadev, N., Indaram, M., Cunningham, D., Cukras, C.A., Chew, E.Y., Wong, W.T., 2013. Drusen regression is associated with local changes in fundus autofluorescence in intermediate age-related macular degeneration. Am J Ophthalmol 156, 532-542.e531.

259. Tu, H., Okamoto, A.Y., Shan, B., 2000. FXR, a bile acid receptor and biological sensor. Trends Cardiovasc Med 10, 30-35.

260. Ulshafer, R.J., Allen, C.B., Nicolaissen, B., Jr., Rubin, M.L., 1987. Scanning electron microscopy of human drusen. Investigative ophthalmology \& visual science 28, 683-689.

261. van der Schaft, T.L., de Bruijn, W.C., Mooy, C.M., Ketelaars, D.A., de Jong, P.T., 1992. Element analysis of the early stages of age-related macular degeneration. Arch Ophthalmol 110, 389-394. 

macular degeneration: an immunofluorescence and electron microscopy study. The British journal of ophthalmology 77, 657-661. 263. van Leeuwen, E.M., Emri, E., Merle, B.M.J., Colijn, J.M., Kersten, E., Cougnard-Gregoire, A., Dammeier, S., Meester-Smoor, M., Pool, F.M., de Jong, E.K., Delcourt, C., Rodrigez-Bocanegra, E., 2018. A new perspective on lipid research in age-related macular degeneration. Prog Retin Eye Res. 264. Verhoeff, F.H., Grossman, H.P., 1937. The Pathogenesis of Disciform Degeneration of the Macula. Trans Am Ophthalmol Soc 35, 262-294.

265. Vidaurri, J.S., Pe'er, J., Halfon, S.T., Halperin, G., Zauberman, H., 1984. Association between drusen and some of the risk factors for coronary artery disease. Ophthalmologica 188, 243-247. 266. Vingerling, J.R., Dielemans, I., Bots, M.L., Hofman, A., Grobbee, D.E., de Jong, P.T., 1995. Agerelated macular degeneration is associated with atherosclerosis. The Rotterdam Study. Am J Epidemiol 142, 404-409.

267. Wakatsuki, Y., Shinojima, A., Kawamura, A., Yuzawa, M., 2015. Correlation of Aging and Segmental Choroidal Thickness Measurement using Swept Source Optical Coherence Tomography in Healthy Eyes. PLoS One 10, e0144156.

268. Wang, J., Gu, B.J., Masters, C.L., Wang, Y.J., 2017. A systemic view of Alzheimer disease - insights from amyloid-beta metabolism beyond the brain. Nat Rev Neurol 13, 612-623.

269. Wang, L., Clark, M.E., Crossman, D.K., Kojima, K., Messinger, J.D., Mobley, J.A., Curcio, C.A., 2010. Abundant lipid and protein components of drusen. PLoS One 5, e10329. 270. Warwick, A., Khandhadia, S., Ennis, S., Lotery, A., 2014. Age-Related Macular Degeneration: A Disease of Systemic or Local Complement Dysregulation? J Clin Med 3, 1234-1257.

271. Wasmuth, S., Lueck, K., Baehler, H., Lommatzsch, A., Pauleikhoff, D., 2009. Increased vitronectin production by complement-stimulated human retinal pigment epithelial cells. Investigative ophthalmology \& visual science 50, 5304-5309.

272. Weber, B.H., Vogt, G., Pruett, R.C., Stohr, H., Felbor, U., 1994. Mutations in the tissue inhibitor of metalloproteinases-3 (TIMP3) in patients with Sorsby's fundus dystrophy. Nature genetics 8, 352356.

273. Whitmore, S.S., Wagner, A.H., DeLuca, A.P., Drack, A.V., Stone, E.M., Tucker, B.A., Zeng, S., Braun, T.A., Mullins, R.F., Scheetz, T.E., 2014. Transcriptomic analysis across nasal, temporal, and macular regions of human neural retina and RPE/choroid by RNA-Seq. Exp Eye Res 129, 93-106. 274. Williams, K.J., Tabas, I., 1995. The response-to-retention hypothesis of early atherogenesis. Arterioscler Thromb Vasc Biol 15, 551-561.

275. Wilson, C.J., Das, M., Jayaraman, S., Gursky, O., Engen, J.R., 2018. Effects of Disease-Causing Mutations on the Conformation of Human Apolipoprotein A-I in Model Lipoproteins. Biochemistry. 276. Wilson, M.R., Zoubeidi, A., 2017. Clusterin as a therapeutic target. Expert Opin Ther Targets 21, 201-213.

277. Woodell, A., Rohrer, B., 2014. A mechanistic review of cigarette smoke and age-related macular degeneration. Adv Exp Med Biol 801, 301-307.

278. Xu, H., Chen, M., Forrester, J.V., 2009. Para-inflammation in the aging retina. Prog Retin Eye Res 28, 348-368.

279. Xu, Q., Cao, S., Rajapakse, S., Matsubara, J.A., 2018. Understanding AMD by analogy: systematic review of lipid-related common pathogenic mechanisms in AMD, AD, AS and GN. Lipids Health Dis 17, 3.

280. Yang, J., Xu, Z., Sui, M., Han, J., Sun, L., Jia, X., Zhang, H., Han, C., Jin, X., Gao, F., Liu, Y., Li, Y., Cao, J., Ling, H., Zhang, F., Ren, H., 2015. Co-Positivity for Anti-dsDNA, -Nucleosome and -Histone Antibodies in Lupus Nephritis Is Indicative of High Serum Levels and Severe Nephropathy. PLoS One 10, e0140441.

281. Yehoshua, Z., Wang, F., Rosenfeld, P.J., Penha, F.M., Feuer, W.J., Gregori, G., 2011. Natural history of drusen morphology in age-related macular degeneration using spectral domain optical coherence tomography. Ophthalmology 118, 2434-2441. 
282. Young, R.W., 1987. Pathophysiology of age-related macular degeneration. Surv Ophthalmol 31, 291-306.

283. Yuan, X., Gu, X., Crabb, J.S., Yue, X., Shadrach, K., Hollyfield, J.G., Crabb, J.W., 2010. Quantitative proteomics: comparison of the macular Bruch membrane/choroid complex from age-related macular degeneration and normal eyes. Mol Cell Proteomics 9, 1031-1046. 284. Zamiri, P., Masli, S., Streilein, J.W., Taylor, A.W., 2006. Pigment epithelial growth factor suppresses inflammation by modulating macrophage activation. Investigative ophthalmology \& visual science 47, 3912-3918. 285. Zhang, J.J., Sun, Y., Hussain, A.A., Marshall, J., 2012. Laser-mediated activation of human retinal pigment epithelial cells and concomitant release of matrix metalloproteinases. Investigative ophthalmology \& visual science 53, 2928-2937. 286. Zhang, P., Dufresne, C., Turner, R., Ferri, S., Venkatraman, V., Karani, R., Lutty, G.A., Van Eyk, J.E., Semba, R.D., 2015a. The proteome of human retina. Proteomics 15, 836-840.

287. Zhang, P., Kirby, D., Dufresne, C., Chen, Y., Turner, R., Ferri, S., Edward, D.P., Van Eyk, J.E., Semba, R.D., 2016. Defining the proteome of human iris, ciliary body, retinal pigment epithelium, and choroid. Proteomics 16, 1146-1153.

288. Zhang, Y., Wen, Z., Guan, L., Jiang, P., Gu, T., Zhao, J., Lv, X., Wen, T., 2015b. Extracellular histones play an inflammatory role in acid aspiration-induced acute respiratory distress syndrome. Anesthesiology 122, 127-139. 289. Zhang, Z., Chen, X.Y., Baum, L., Ng, H.K., Mok, V., Wong, K.S., 2018. Association Between the Apolipoprotein E Gene Polymorphism and Atherosclerotic Middle Cerebral Artery Stenosis. Neurologist 23, 47-50.

290. Zheng, W., Mast, N., Saadane, A., Pikuleva, I.A., 2015. Pathways of cholesterol homeostasis in mouse retina responsive to dietary and pharmacologic treatments. J Lipid Res 56, 81-97. 291. Zweifel, S.A., Spaide, R.F., Curcio, C.A., Malek, G., Imamura, Y., 2010. Reticular pseudodrusen are subretinal drusenoid deposits. Ophthalmology 117, 303-312.e301. 


\section{Figure legends:}

2398 Figure 1. Heterogeneity of drusen. Imaging of drusen and drusen content with various clinical and laboratory methods. On color fundus images, the yellow spots identify drusen (A). On OCT image the elongated RPE is reflective. Drusen appear as homogeneous and hyper-reflective sub-RPE-BL space focal entities. (B); scale bar: 500 $\mu \mathrm{m}$. On hematoxylin-eosin staining, drusen appears between the brown pigments of the RPE and the Bruch's membrane (C); scale bar: $10 \mu \mathrm{m}$. Note the inclusions without staining. Drusen contain numerous von Kossa positive spherule structures identifying hydroxyapatite spherules (D); scale bar: $10 \mu \mathrm{m}$. Auto-fluorescence of the more or less circular drusen is indicative of the protein and lipid accumulation. Auto-fluorescence of the RPE is more intense and yellowish. Auto-fluorescence of the BrM adjacent to the RPE is greenish (E); scale bar: $10 \mu \mathrm{m}$.

Figure 2 a-d. Functional molecular network analysis (4 networks). For all four networks: Molecular network analysis of physical or functional interactions between 89 drusen genes/proteins using Ingenuity. The knowledge database generated four most likely functional networks from the given input (drusen proteins). The functionalities in the figures are generated based on a combination of available molecular and cellular experimental data in human, mouse, rat, and in vitro data. In each network the circles, squares and other symbols represent proteins from a homologue from either human, rat or mouse. The systematic name of the gene/protein is printed on each symbol. Double circles in a single symbol denotes a group or /family of entries with a specific function and are sometimes introduced by the knowledge database to make networks possible or to simplify them. Solid lines represent strong physical or functional interaction between the entries, taken from published peer reviewed literature and/or transcriptomics and proteomics databases. Dotted lines represent weaker, associated relationships between the genes/proteins based on published peer reviewed experimental data (for example co-upregulation of expression in an in vitro experiment). The lines represent thus functionalities found in either, both, or all experiments on human, rat or mice (tissues) and in vitro findings. For example, the functional relationship between molecules A, B, C, could possibly be defined as follows A-functional mouse finding-B-functional human 
finding-C. The underlying hypothesis is that the functionalities in human, mouse and rat are very similar. One can also generate networks of human (or rat or mice) functional data separately, but they are frequently quite similar, but less extensive. In the first network (Figure 2a), clearly three functional clusters of closely related entries can be recognized: The complement cluster, the collagen cluster and the crystallin cluster. The second network (Figure $2 \mathrm{~b}$ ) is much more complicated and heterogeneous and is a network of genes and proteins related to development and genetic or ophthalmic disorders. The common theme of the third network (Figure 2c) is the immune response. Finally, the fourth and last network (Figure 2d) presents functional and structural relationships between entries involved in cell-cell interactions and systemic involvement.

Figure 3. Schematic overview of various strategies used for dataset curation. This figure shows several ways to curate (pre-existing) transcriptomics or proteomics datasets to form an improved, thorough or more specific dataset. For example, in (A) several datasets are merged into a cumulative new one by simply combining the datasets. The possible overlap is counted only once in the new merged database. One dataset was deleted, because it did not adhere to quality standard or had a different signature as the other ones. Strategy (B) has been published before (Booij et al., 2010b). In this case the original enriched RPE database contains $10 \%$ of the highest expressed genes in the cell. Some of the expressed genes in the RPE10\% dataset overlap with the genes expressed in the adjacent tissues (photoreceptors and/or choroid). These "overlapping expressed genes" are therefore not specific of the RPE. Thus, to obtain a more specific (smaller) dataset, we discard of all the "overlapping expressed genes" in the RPE dataset, to obtain a highly enriched RPE dataset. Curation strategy $C$ shows the breakdown of two datasets into desired subfamilies: The overlap between datasets $\mathrm{X}$ and $\mathrm{Z}$ is $\mathrm{Y}$. Dataset $\mathrm{Y}$ can be used if overlap between $\mathrm{X}$ and $\mathrm{Z}$ is desired. Dataset $\mathrm{X}$ minus $\mathrm{Y}$ can be used to obtain unique entries from $\mathrm{X}$ (compared to set $\mathrm{Z}$ ).

Figure 4. Scheme of the relationships between the respective transcriptomic and proteomic datasets used for quantitative studies. The curated drusen protein dataset represents 89 proteins known to be present in drusen/sub-RPE-BL space deposits (black box in the middle). These were compared with the entries present or produced 
uniquely from the neural side of drusen (photoreceptor/RPE neural source), and with entries uniquely from the systemic side of drusen (blood /choroid basal source). The "neural source" and "systemic source" merged data-sets each consist of non-curated datasets and curated datasets. The non-curated (pure) dataset contain, by virtue of their nature or previous curation in the literature) only entries from, respectively, the neural (RPE-ST; RPE-IVS) and systemic side (BL-SP1; BL-SP2) of drusen. The curated datasets (cPRos; cPR-ET and cChor-ET)) contained, before curation, a number of entries expressed/present in both the neural and systemic side (see PRos; PR-ET and Chor-ET). Thus, we removed all overlapping expressed genes between the PRos; PR-ET and ChorET datasets, to obtain unique datasets from both sides of drusen.

Figure 5. Potential contribution of neural and systemically expressed/present proteins to drusen formation. Venn diagram showing overlap between (A) neural RPE and photoreceptor-derived proteins, (B) systemically derived choroid and blood proteins and (C) drusen-associated proteins.

Figure 6. Hydroxyapatite spherules can retain proteins originating from blood in the sub-RPE-BL space. (A) Immunocytochemical labelling of histidine-rich glycoprotein (HRG) using a specific anti-HRG primary antibody (green) on the surface of a HAP spherule labelled by LiCor680 (magenta); scale bar: $10 \mu \mathrm{m}$. (B) Binding of purified human HRG to HAP-coated magnetic beads. Binding assays were performed using 0.3 mg beads per sample. HAP-beads were washed with 50 mM Tris, $140 \mathrm{mM} \mathrm{NaCl}$, pH 7.4 and incubated with $400 \mu \mathrm{l}$ of $0-1 \mu \mathrm{M}$ human $\mathrm{HRG}$ for an hour at room temperature. The protein-bound beads were washed with the same buffer twice followed by blocking with 1\% BSA for an hour. Rabbit anti-human HRG antibody (1:1000 dilution) and HRPconjugated anti-rabbit antibody (1:10000 dilution) were respectively used as primary and secondary antibodies. Detection was done at $492 \mathrm{~nm}$ using o-phenylenediamine dihydrochloride (OPD, Sigma Aldrich) substrate.

Figure 7. A model for drusen formation. Top row (A-E) is adopted from the schematic diagram proposed for sub-RPE-BL space deposit formation by Thompson and colleagues (Thompson et al., 2015). (A) Healthy eyes show no sub-RPE-BL space deposit formation. 
Stage 2 mineralization occurs surrounding the lipid droplets (magenta ring). (D) At

2495

2496

2497

2498

2499

2500

2501

2502

2503

2504

2505

2506

2507

2508

2509

2510

2511

2512

2513

2514

2515

2516

2517

2518

2519

2520

2521

2522

2523

2524

2525

2526

Stage 3 proteins bind to the HAP surfaces (blue ring). (E) At Stage 4 proteins and lipids start accumulating around the "seed" (yellow material). The bottom row (A'-E') shows morphological evidence for the prediction in the top row. (A') Retinal pigment epithelium forms a monolayer along the inner collagenous layer of the Bruch's membrane in healthy eyes (scanning electron microscopic image); scale bar: $10 \mu \mathrm{m}$. (B') Transmission electron micrograph of lipid droplets that accumulate in the sub-RPE-BL space; reproduced with permission from Curcio and Millican (Curcio and Millican, 1999); scale bar: $2 \mu \mathrm{m}$. (C') Scanning electron microscopic identification of a single spherule located between the RPE basement membrane and the inner collagenous layer of Bruch's membrane; scale bar: $2 \mu \mathrm{m}$. (D') Immunofluorescent labelling of HRG (green) on the surface of a HAP spherule (magenta); scale bar: $2 \mu \mathrm{m}$. (E') An immunofluorescent labelling of complement factor $\mathrm{H}$ on a spherule surrounded by the autofluorescence of drusen (green) and RPE cells (yellow) (blue is DAPI staining the cell nuclei); scale bar: $10 \mu \mathrm{m}$.

Figure 8. Schematic showing factors that are identified to contribute to mineralization of soft tissues and may contribute to HAP deposition in the sub-RPE-BL space.

Abbreviations: ABCC6, ATP binding cassette subfamily C member 6; ANKH, ankylosis protein homolog; ATP, adenosine triphosphate; BrMP2, bone morphogenetic protein-2;

BrMP2R, bone morphogenetic protein-2 receptor; BSP, bone sialoprotein; Ca, calcium;

Cbfa-1, core-binding factor alpha-1; ENPP1, ectonucleotide

pyrophosphatase/phosphodiesterase; Glu- and Gla-MGP, uncarboxylated- and carboxylated-matrix Gla protein; OPG, osteoprotegerin; OPN, osteopontin; Pi, inorganic phosphate; Pit-1, phosphate transporter-1; PPi, pyrophosphate; RANKL, receptor activator of nuclear factor kappa-B ligand; TNAP, tissue non-specific alkaline phosphatase. Figure adapted from (Ronchetti et al., 2013).

Figure 9. Proteins present in atherosclerotic plaques and drusen. A. Venn diagram showing 64 out of 89 drusen proteins overlap with the atherosclerotic plaque proteome, while 25 entries are unique to drusen in this comparison. B. Venn diagram showing 50 out of 60 proteins (from the 89 drusen proteins) that come from blood (as unique source or shared with the PR/RPE) are actually present in atherosclerotic plaques. C. 
Venn diagram displaying the uniqueness and overlap of proteins between drusen (C.A), Alzheimer plaque proteins (C.B.) and atherosclerotic plaque proteins (C.C). The corresponding STable 11 and STable 11a present the corresponding entries in detail.

\section{Table Legends:}

Table 1. List of proteins present in the curated drusen dataset. We assembled a list of 89 drusen proteins, mostly derived from the macular area, from the literature. For each entry the Gene symbol, Entrez gene name, location and type, human immunohistochemistry source and literature references are provided based on information found via the Ingenuity knowledge database (Qiagen, all rights reserved), relevant literature (PubMed searches) and other public databases, such as Genecard (www.genecard.org) and DAVID (https://david.ncifcrf.gov/)

Crabb 2002 (Crabb et al., 2002); Wang 2002 (Wang et al., 2010); Entries with *: although assigned to drusen by proteomics, IHC studies suggest a more likely protein location around or directly external from drusen. Further detailed investigation is warranted for these entries. ${ }^{* *}$ First detected in cynomolgus monkeys, afterwards in human drusen.

Table 2. Summary of Ingenuity knowledge database core analysis of 89 proteins present in the curated drusen protein dataset. Summary of enriched motifs present in the dataset presented as top disease and biological functions, canonical pathways and discrete molecular networks. Note that these functional annotations types relate to either cellular (LRX/RXR/FXR activation; macrophages) or systemic (acute phase, atherosclerosis) entities. In the top disease and biological functions, we see that the dataset is enriched for hereditary disorders, ophthalmic disease, injury, metabolic diseases and developmental disorders. Finally, in the top functional or structural molecular networks, we find combinations of very basic functions (cancer and cellular) to more specific pathobiological ones (ophthalmic and neurological disease etc.

Table 3. Summary of datasets used in this study and their respective functional clusters. Table displaying various datasets used in this study, along with their characteristics. In the first column, the result of the Ingenuity network analysis of drusen proteins is given in 4 significant molecular networks $(\mathrm{N}=1-4)$ corresponding to the networks shown in 
2560 Figure 2a-2d. Within these networks, six functional molecule clusters can be observed.

2561 For example, Network 1 (N1) contains 3 functional clusters: the complement (Network

2562 1. cluster 1), the collagen (1.2) and the crystallines (heatshock) (1.3). Network 2 consist

2563 of 1 large cluster (2.4) being genetic and developmental ophthalmic disorders. Network

25643 can be viewed as a cluster (\# 5) of injury and inflammatory response and

2565 dermatological disease. Network 4 (N4) contains a cluster (4.6) of cell-to cell-signaling

2566 and systemic involvement. Column B gives the actual gene/protein names in these

2567 clusters. Column C states the overall functional annotation of these clusters. The first

2568 row of the Table from column D onward states the compartment of the datasets to be

2569 compared with drusen proteins in the functional clusters (within brackets, the number

2570 of entire in each dataset are given). In row 2 (acronym) from column D onward, the

2571 short and systematic acronym of each dataset is given. Row 3 (reference) contains from

2572 column D onward, the reference where the dataset can be found. Row 4 (methodology),

2573 from column D onward, contains the method by which the data were generated

2574 (transcriptomics, proteomics). Row five (source), from column D onward, contains the

2575 primary author who submitted the data or who can be contacted to obtain further

2576 information. The remaining boxes contains information which entries of the functional

2577 cluster are present both in drusen as well as in the transcriptomics or proteomics

2578 dataset(s). Combined analysis of the clusters in different datasets gives a qualitative

2579 idea from which cell type(s) drusen protein are derived.

2581 Table 4. Summary of Ingenuity knowledge database core analysis of the curated

2582 photoreceptor gene expression (cPR-ET) dataset. Functional annotation of the curated

2583 and highly enriched photoreceptor cPR-ET database using the ingenuity knowledge

2584 database. The data driven top canonical pathways are highly relevant for photoreceptor

2585 function: Phototransduction pathway, glutamate receptor signaling, cholesterol

2586 biosynthesis and Wnt/Ca2+ signaling. The only surprise in our data-driven analysis

2587 could be the Huntinton disease signaling pathway. However, it has recently become

2588 clear that in Huntington's disease (HD), an inherited neurodegenerative disorder

2589 resulting in motor disturbances, cognitive and behavioral changes, deficits in retinal and

2590 visual processing function are significantly present (Coppen et al., 2018). Although we

2591 curated the PR database quite extensively, and thus selected for specific photoreceptor

2592 molecular signature and function, it is interesting to see that these motifs occur also in a 
number of other (top) diseases and functions, such as cancer, organismal injury, gastrointestinal disease, Hepatic disease and reproductive system disease. This may reflect the accumulating evidence that a substantial number of genetic or metabolic disease are also affect photoreceptor function. Similar to the canonical pathways and the biological motifs, the functional annotation of the photoreceptor selected molecular machinery apparently reflects a broad spectrum of biological and disease processes.

Table 5. Summary of Ingenuity knowledge database core analysis of the curated choroid, cChor-ET datasets. In this Table, we present the summary of the functional annotation of the choroid. Of course, the choroid is not a single tissue, but contains multiple cell types (endothelial cells, fibroblasts, macrophages, etc.) and the sample is inevitably contaminated with the blood. Within these limitations, data driven analysis of this specifically curated data set yielded a number of interesting enriched motifs, which indeed can be contributed to the choroid or blood: The canonical pathways indicate enriched immunological themes, such as the complement system, acute phase response signaling, and antigen-presenting cells, which is confirmed by several biological motifs (inflammatory disease and response, injury). Further, the canonical pathways generated, suggest an overlap between the molecular machinery of the choroid and atherosclerosis signaling. Indeed, in this manuscript, we devoted a whole section (8) to the pathobiological and molecular similarities between drusen and atherosclerotic plaques, and their -in time-associated diseases: AMD and atherosclerosis. Finally, a homology between hepatic function and choroid was observed. Indeed, there are a number of reports in the literature of cross-talk between liver and choroidal function, but that potential relationship remains to be elucidated. The final biological motifs are cancer and connective tissue disorders. Cancer, is of course very broad and frequently relates to blood vessel metabolism or (abnormal) cell division, while the connective tissue motif may relate to the action of local fibroblasts. The choroidal networks, show, again a very broad spectrum of molecular interactions, but this spectrum is quite distinct from the functional annotation of the photoreceptor networks presented in Table 5.

Table 6. Drusen proteins expressed or present in the PR/RPE and their characteristics. Overview and characteristics of ten drusen proteins, which most likely originate from 
the neural side of drusen (namely PR and Chor). In the first column (A), general used abbreviations (according Gen bank) for gene/protein names are given. In column B, C, D respectively systematic Entrez number, cellular location and protein type corresponding to these proteins are presented. Column E and F contain the amino acid (aa) size and Molecular weight (Mw) of the proteins. Further the isoelectric point (pI; column G), the number of negative and positive charged aa residues (column $\mathrm{H}$ ), the protein instability Index number (column I); the Alipathic index for solubility (J), and the GRAVY (hydrophobicity and hydrophilicity index). These are all standard characteristic of proteins which can be found in the Ingenuity database (Qiagen all right reserved) and public databases such as DAVID, (https://david.ncifcrf.gov), SWISS-prot (https://www.ebi.ac.uk/uniprot), Genecards (www.genecard.org) and/or the data shows that these entries apparently do not have specific characteristics, except perhaps for their ability to interact with one another, that could explain why they would get stuck in BrM as a drusen protein. We conclude that, if it is not the proteins that explain this, it must be the structure of BrM.

\section{Supplementary Table Legends:}

Table S1. List of 276 proteins present in the RPE-IVS dataset. For each entry the gene symbol, Entrez gene name, location and type are provided based on information found

Table S2. List of 170 proteins present in the RPE-ST dataset. For each entry the gene symbol, Entrez gene name, location and type are provided based on information found in the Ingenuity knowledge database.

Table S3. List of 412 proteins present in the Pros-EP dataset. For each entry the gene symbol, Entrez gene name, location and type are provided based on information found in the Ingenuity knowledge database.

Table S4. List of 995 proteins present in the BLP-SP1 dataset. For each entry the gene symbol, Entrez gene name, location and type are provided based on information found in the Ingenuity knowledge database. 
2660 Table S5. List of 262 HAP binding proteins in the BL-PHP blood proteome dataset. For 2661 each entry the gene symbol, Entrez gene name, location and type are provided based on 2662 information found in the Ingenuity knowledge database.

Table S6. List of 754 expressed genes present in the cPR-ET dataset. For each entry the gene symbol, Entrez gene IDs for human and mouse are provided.

Table S7. List of 848 expressed genes present in the cChor-ET dataset. For each entry the gene symbol, Entrez gene IDs for human and mouse are provided.

Table S8. Annotation of 37 drusen proteins (out of 89) that may uniquely originate from the blood. For each entry, the gene symbol. Entrez gene IDs for human and mouse are presented.

Table S8a Functional annotation of 37 drusen proteins that may originate from the blood. Combinations of genes/proteins in this group makes up specific functional categories associated with biological function or disease.

Table S9. Annotation of 23 drusen proteins that may originate either from the neural or from the systemic side, using Ingenuity. For each entry its functional category, specific associated disease or function, p-value, gene names of associated proteins and number of proteins in each category are provided.

Table S9a Functional annotation of 23 drusen proteins that may originate from either the neural or the systemic side of drusen using Ingenuity. Combinations of genes/proteins in this group makes up specific functional categories associated with biological function or disease.

Table S10 Annotation of 19 drusen proteins of unclear origin. Entrez gene IDs for human and mouse are presented. 
2691 Table S10a Functional annotation of 19 drusen proteins of unclear origin using

2692 Ingenuity. For each entry its functional category, specific associated disease or function,

2693 p-value, gene names of associated proteins and number of proteins in each category are

2694 provided.

2695

2696 Table S11 List of 64 proteins common to both drusen and atherosclerotic plaques. For each entry, the gene symbol and Entrez Gene IDs for human and mouse and are

2698 provided.

2699

2700 Table S11a Functional annotation of 64 proteins common to both drusen and

2701 atherosclerotic plaques. For each entry its functional category, specific associated

2702 disease or function, $p$-value, gene names of associated proteins and number of proteins

2703 in each category are provided.

2704

2705

2706

2707

2708

2709

2710

2711

2712

2713

2714

2715

2716

2717

2718

2719

2720

2721

2722

2723 Next page : Table 1: 89 drusen proteins used in this study. 


\begin{tabular}{|c|c|c|c|c|c|}
\hline ID/Symbol & Entrez Gene Name & Location & Type(s) & Source & Human IHC ref \\
\hline ACTB & Actin beta & Cytoplasm & other & (Crabb et al., 2002) & \\
\hline ACTN1 & Actinin alpha 1 & Cytoplasm & $\begin{array}{l}\text { transcription } \\
\text { regulator }\end{array}$ & (Crabb et al., 2002) & \\
\hline ALB & Albumin & $\begin{array}{l}\text { Extracellular } \\
\text { Space }\end{array}$ & transporter & (Crabb et al., 2002) & (Hollyfield et al., 2003) \\
\hline ALDH1A1 & Aldehyde dehydrogenase 1 family, A1 & Cytoplasm & enzyme & (Crabb et al., 2002) & \\
\hline AMBP & $\begin{array}{l}\text { Alpha-1-microglobulin/bikufinbulin } 5 \\
\text { drusennin precursor }\end{array}$ & $\begin{array}{l}\text { Extracellular } \\
\text { Space }\end{array}$ & transporter & (Crabb et al., 2002) & \\
\hline ANXA1 & Annexin A1 & Plasma Membrane & enzyme & (Crabb et al., 2002) & (Rayborn et al., 2006) \\
\hline ANXA2 & Annexin $\mathrm{A} 2^{*}$ & Plasma Membrane & other & (Crabb et al., 2002) & $($ Crabb et al., 2002)* \\
\hline ANXA5 & Annexin A5 & Plasma Membrane & transporter & (Crabb et al., 2002) & \\
\hline ANXA6 & Annexin A6 & Plasma Membrane & ion channel & (Crabb et al., 2002) & $\begin{array}{l}\text { (Crabb et al., 2002); } \\
\text { (Rayborn et al., 2006) }\end{array}$ \\
\hline APCS & Amyloid P component, serum & $\begin{array}{l}\text { Extracellular } \\
\text { Space }\end{array}$ & other & (Crabb et al., 2002) & (Mullins et al., 2000) \\
\hline APOA1 & Apolipoprotein A1 & $\begin{array}{l}\text { Extracellular } \\
\text { Space }\end{array}$ & transporter & (Crabb et al., 2002) & (Mullins et al., 2000) \\
\hline APOA4 & Apolipoprotein A4 & $\begin{array}{l}\text { Extracellular } \\
\text { Space }\end{array}$ & transporter & (Crabb et al., 2002) & \\
\hline APOE & Apolipoprotein E & $\begin{array}{l}\text { Extracellular } \\
\text { Space }\end{array}$ & transporter & (Crabb et al., 2002) & (Mullins et al., 2000) \\
\hline ATP5A1 & $\begin{array}{l}\text { ATP synth., H+ transp., mitochondr. F1 } \\
\text { compl., alpha sub. } 1 \text {, cardiac muscle }\end{array}$ & Cytoplasm & transporter & (Crabb et al., 2002) & \\
\hline ATP5B & $\begin{array}{l}\text { ATP synth., } \mathrm{H}+\text { transp., mitochondr. F1 } \\
\text { compl., beta pp }\end{array}$ & Cytoplasm & transporter & (Wang et al., 2010) & \\
\hline BFSP1 & Beaded filament structural protein 1 & Cytoplasm & enzyme & (Crabb et al., 2002) & \\
\hline BFSP2 & Beaded filament structural protein 2 & Cytoplasm & other & (Crabb et al., 2002) & \\
\hline BGN & Biglycan & $\begin{array}{l}\text { Extracellular } \\
\text { Space }\end{array}$ & other & (Crabb et al., 2002) & \\
\hline
\end{tabular}




\begin{tabular}{|c|c|c|c|c|c|}
\hline $\mathrm{C} 7$ & Complement C7 & $\begin{array}{l}\text { Extracellular } \\
\text { Space }\end{array}$ & other & (Crabb et al., 2002) & \\
\hline C8A & Complement C8 alpha chain & $\begin{array}{l}\text { Extracellular } \\
\text { Space }\end{array}$ & other & (Crabb et al., 2002) & (Wang et al., 2010) \\
\hline C8B & Complement C8 beta chain & $\begin{array}{l}\text { Extracellular } \\
\text { Space }\end{array}$ & other & (Crabb et al., 2002) & (Wang et al., 2010) \\
\hline C8G & Complement C8 gamma chain & $\begin{array}{l}\text { Extracellular } \\
\text { Space }\end{array}$ & transporter & (Crabb et al., 2002) & (Wang et al., 2010) \\
\hline $\mathrm{CFH}$ & Complement factor $\mathrm{H}$ & $\begin{array}{l}\text { Extracellular } \\
\text { Space }\end{array}$ & other & (Wang et al., 2010) & (Arya et al., 2018) \\
\hline CKB & Creatine kinase B & Cytoplasm & kinase & (Crabb et al., 2002) & \\
\hline $\mathrm{CLU}$ & Clusterin & Cytoplasm & other & (Crabb et al., 2002) & (Sakaguchi et al., 2002) \\
\hline COL1A2 & Collagen type I alpha 2 chain & $\begin{array}{l}\text { Extracellular } \\
\text { Space }\end{array}$ & other & (Crabb et al., 2002) & (Newsome et al., 1987) \\
\hline COL6A1 & Collagen type VI alpha 1 chain & $\begin{array}{l}\text { Extracellular } \\
\text { Space }\end{array}$ & other & (Crabb et al., 2002) & \\
\hline COL6A2 & Collagen type VI alpha 2 chain & $\begin{array}{l}\text { Extracellular } \\
\text { Space }\end{array}$ & other & (Crabb et al., 2002) & \\
\hline COL8A1 & Collagen type VIII alpha 1 chain & $\begin{array}{l}\text { Extracellular } \\
\text { Space }\end{array}$ & other & (Crabb et al., 2002) & \\
\hline CRYAB & Crystallin alpha B* & Nucleus & other & (Crabb et al., 2002) & (De et al., 2007)* \\
\hline CRYBA1 & Crystallin beta A1 & Other & other & (Crabb et al., 2002) & \\
\hline CRYBA4 & Crystallin beta A4 & Other & other & (Crabb et al., 2002) & \\
\hline CRYBB1 & Crystallin beta B1 & Other & other & (Crabb et al., 2002) & \\
\hline CRYBB2 & Crystallin beta B2 & Other & other & (Crabb et al., 2002) & \\
\hline CRYGB & Crystallin gamma B & Nucleus & other & (Crabb et al., 2002) & \\
\hline CRYGC & Crystallin gamma C & Cytoplasm & other & (Crabb et al., 2002) & \\
\hline CRYGD & Crystallin gamma D & Cytoplasm & other & (Crabb et al., 2002) & \\
\hline CRYGS & Crystallin gamma S & Other & other & (Crabb et al., 2002) & \\
\hline CTSD & Cathepsin D* & Cytoplasm & peptidase & (Crabb et al., 2002) & (Rakoczy et al., 1999)* \\
\hline
\end{tabular}




\begin{tabular}{|c|c|c|c|c|c|}
\hline DIP2C & Disco interacting protein 2 homolog C & Other & other & (Crabb et al., 2002) & \\
\hline EFEMP1 & $\begin{array}{l}\text { EGF containing fibulin like ECM } \\
\text { protein } 1\end{array}$ & $\begin{array}{l}\text { Extracellular } \\
\text { Space }\end{array}$ & enzyme & (Crabb et al., 2002) & \\
\hline ELN & Elastin* & $\begin{array}{l}\text { Extracellular } \\
\text { Space }\end{array}$ & other & (Crabb et al., 2002)* & \\
\hline ENO2 & Enolase 2 & Cytoplasm & enzyme & (Wang et al., 2010) & \\
\hline FBLN5 & Fibulin 5 & $\begin{array}{l}\text { Extracellular } \\
\text { Space }\end{array}$ & other & (Crabb et al., 2002) & (Mullins et al., 2000) \\
\hline FGG & Fbrinogen gamma chain & $\begin{array}{l}\text { Extracellular } \\
\text { Space }\end{array}$ & other & (Crabb et al., 2002) & (Mullins et al., 2000) \\
\hline FHAD1 & $\begin{array}{l}\text { Forkhead ass.phosphopept.bind. dom. } \\
1\end{array}$ & Other & other & (Wang et al., 2010) & \\
\hline FN1 & Fibronectin 1 & $\begin{array}{l}\text { Extracellular } \\
\text { Space }\end{array}$ & enzyme & (Crabb et al., 2002) & (Newsome et al., 1987) \\
\hline FRZB & Frizzled-related protein & $\begin{array}{l}\text { Extracellular } \\
\text { Space }\end{array}$ & other & (Crabb et al., 2002) & \\
\hline GAPDH & $\begin{array}{l}\text { Glyceraldehyde-3-phosphate } \\
\text { dehydrogenase }\end{array}$ & Cytoplasm & enzyme & (Crabb et al., 2002) & \\
\hline GPNMB & Glycoprotein nmb & Plasma Membrane & enzyme & (Crabb et al., 2002) & \\
\hline HIST1H1E & Histone cluster $1 \mathrm{H} 1$ family member e & Nucleus & other & (Crabb et al., 2002) & \\
\hline HIST1H2BJ & Histone cluster 1 H2B family member $\mathrm{j}$ & Nucleus & other & (Crabb et al., 2002) & \\
\hline $\begin{array}{l}\text { HIST1H2B } \\
\text { L }\end{array}$ & Histone cluster $1 \mathrm{H} 2 \mathrm{~B}$ family member $\mathrm{l}$ & Nucleus & other & (Crabb et al., 2002) & \\
\hline $\begin{array}{l}\text { HIST2H2B } \\
\text { E }\end{array}$ & $\begin{array}{l}\text { Histone cluster } 2 \text { H2B family member } \\
\mathrm{e}\end{array}$ & Nucleus & other & (Crabb et al., 2002) & \\
\hline HLA-DRA & $\begin{array}{l}\text { Major histocompatibility complex, } \\
\text { class II, DR alpha }\end{array}$ & Plasma Membrane & $\begin{array}{l}\text { transmembrane } \\
\text { receptor }\end{array}$ & (Wang et al., 2010) & \\
\hline HRG & Histidine rich glycoprotein & $\begin{array}{l}\text { Extracellular } \\
\text { Space }\end{array}$ & other & $\begin{array}{l}\text { (Kobayashi et al., } \\
2014)^{* *}\end{array}$ & Figure 6 and 7 (this study) \\
\hline LAMB2 & Laminin subunit beta 2 & $\begin{array}{l}\text { Extracellular } \\
\text { Space }\end{array}$ & enzyme & (Crabb et al., 2002) & (Newsome et al., 1987) \\
\hline
\end{tabular}




\begin{tabular}{|c|c|c|c|c|c|}
\hline LTF & Lactotransferrin & $\begin{array}{l}\text { Extracellular } \\
\text { Space }\end{array}$ & peptidase & (Crabb et al., 2002) & \\
\hline LUM & Lumican & $\begin{array}{l}\text { Extracellular } \\
\text { Space }\end{array}$ & other & (Crabb et al., 2002) & \\
\hline MFAP4 & Microfibril associated protein 4 & $\begin{array}{l}\text { Extracellular } \\
\text { Space }\end{array}$ & other & (Crabb et al., 2002) & \\
\hline MYH9 & Myosin heavy chain 9 & Cytoplasm & enzyme & (Crabb et al., 2002) & \\
\hline OGN & Osteoglycin & $\begin{array}{l}\text { Extracellular } \\
\text { Space }\end{array}$ & growth factor & (Crabb et al., 2002) & \\
\hline ORM1 & Orosomucoid 1 & $\begin{array}{l}\text { Extracellular } \\
\text { Space }\end{array}$ & other & (Crabb et al., 2002) & \\
\hline PLG & Plasminogen & $\begin{array}{l}\text { Extracellular } \\
\text { Space }\end{array}$ & peptidase & (Crabb et al., 2002) & \\
\hline PRDX1 & peroxiredoxin 1 & Cytoplasm & enzyme & (Crabb et al., 2002) & \\
\hline PRELP & $\begin{array}{l}\text { Pro, Arg rich end Leu rich repeat } \\
\text { protein }\end{array}$ & $\begin{array}{l}\text { Extracellular } \\
\text { Space }\end{array}$ & other & (Crabb et al., 2002) & \\
\hline PSMB5 & Proteasome subunit beta 5 & Cytoplasm & peptidase & (Crabb et al., 2002) & \\
\hline RBP3 & Retinol binding protein 3 & $\begin{array}{l}\text { Extracellular } \\
\text { Space }\end{array}$ & transporter & (Crabb et al., 2002) & \\
\hline RDH5 & Retinol dehydrogenase 5 & Cytoplasm & enzyme & (Wang et al., 2010) & \\
\hline RGR & Retinal G protein coupled receptor & Plasma Membrane & $\begin{array}{l}\text { G-protein } \\
\text { coupled recept. }\end{array}$ & (Crabb et al., 2002) & \\
\hline RNASE4 & Ribonuclease A family member 4 & $\begin{array}{l}\text { Extracellular } \\
\text { Space } \\
\end{array}$ & enzyme & (Crabb et al., 2002) & \\
\hline S100A7 & S100 calcium binding proteA7 & Cytoplasm & other & (Crabb et al., 2002) & (Crabb et al., 2002) \\
\hline S100A8 & S100 calcium binding protein A8 & Cytoplasm & other & (Crabb et al., 2002) & (Crabb et al., 2002) \\
\hline S100A9 & S100 calcium binding protein A9 & Cytoplasm & other & (Crabb et al., 2002) & (Crabb et al., 2002) \\
\hline SAA1 & Serum amyloid A1 & $\begin{array}{l}\text { Extracellular } \\
\text { Space }\end{array}$ & transporter & (Crabb et al., 2002) & \\
\hline SCARB2 & Scavenger receptor class B member 2 & Plasma Membrane & other & (Wang et al., 2010) & \\
\hline
\end{tabular}




\begin{tabular}{|c|c|c|c|c|c|}
\hline SEMA3B & Semaphorin 3B & $\begin{array}{l}\text { Extracellular } \\
\text { Space }\end{array}$ & other & (Crabb et al., 2002) & \\
\hline SERPINA1 & Serpin family A member 1 & $\begin{array}{l}\text { Extracellular } \\
\text { Space }\end{array}$ & other & (Crabb et al., 2002) & \\
\hline SERPINA3 & Serpin family A member 3 & $\begin{array}{l}\text { Extracellular } \\
\text { Space }\end{array}$ & other & (Crabb et al., 2002) & \\
\hline SERPINF1 & Serpin family F member 1 & $\begin{array}{l}\text { Extracellular } \\
\text { Space }\end{array}$ & other & (Crabb et al., 2002) & \\
\hline SPP2 & Secreted phosphoprotein 2 & $\begin{array}{l}\text { Extracellular } \\
\text { Space }\end{array}$ & other & (Crabb et al., 2002) & \\
\hline SPTAN1 & Spectrin alpha, non-erythrocytic 1 & Plasma Membrane & other & (Crabb et al., 2002) & \\
\hline THBS4 & Thrombospondin 4 & $\begin{array}{l}\text { Extracellular } \\
\text { Space }\end{array}$ & other & (Crabb et al., 2002) & \\
\hline TIMP3 & TIMP metallopeptidase inhibitor $3^{*}$ & $\begin{array}{l}\text { Extracellular } \\
\text { Space }\end{array}$ & other & (Crabb et al., 2002) & $\begin{array}{l}\text { (Kamei and Hollyfield, } \\
\text { 1999)* }\end{array}$ \\
\hline TNC & Tenascin C & $\begin{array}{l}\text { Extracellular } \\
\text { Space }\end{array}$ & other & (Crabb et al., 2002) & \\
\hline TUBA1C & Tubulin alpha 1c & Cytoplasm & other & (Crabb et al., 2002) & \\
\hline TUBB3 & Tubulin beta 3 class III & Cytoplasm & other & (Crabb et al., 2002) & \\
\hline TYRP1 & Tyrosinase related protein 1 & Cytoplasm & enzyme & (Crabb et al., 2002) & \\
\hline VIM & Vimentin* & Cytoplasm & other & (Crabb et al., 2002) & (Johnson et al., 2003)* \\
\hline
\end{tabular}



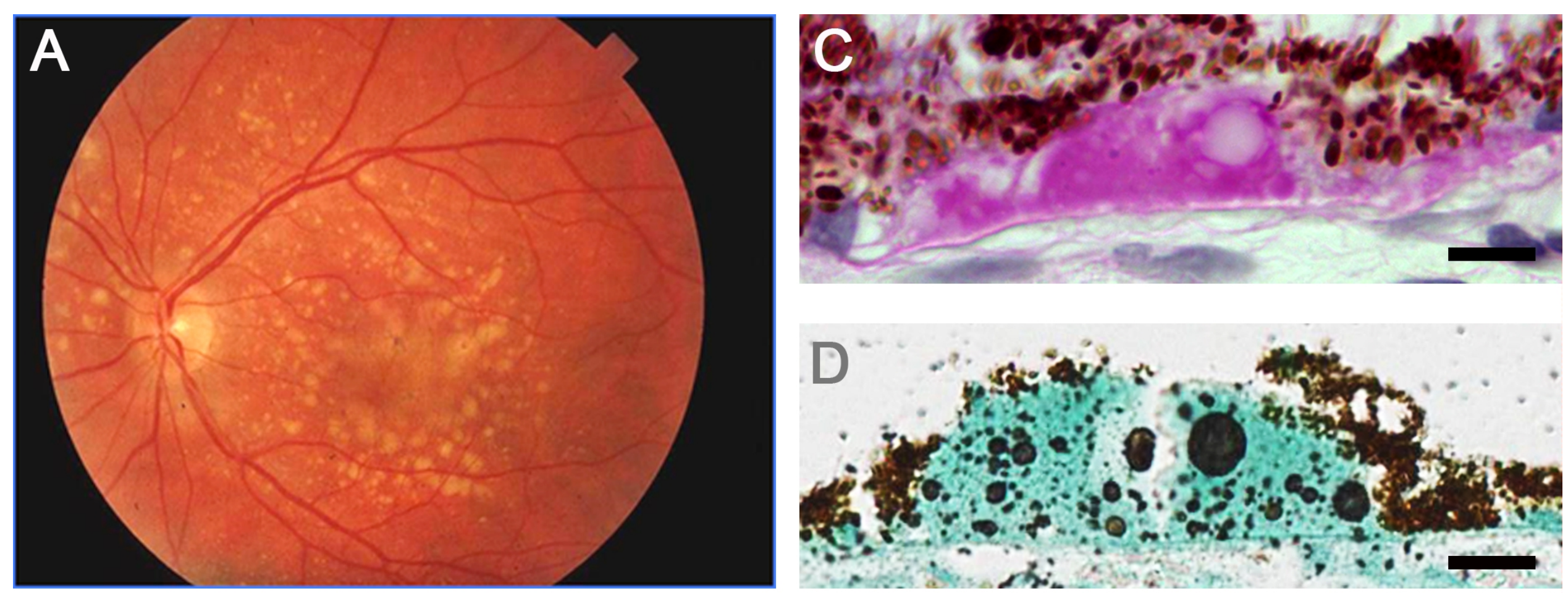

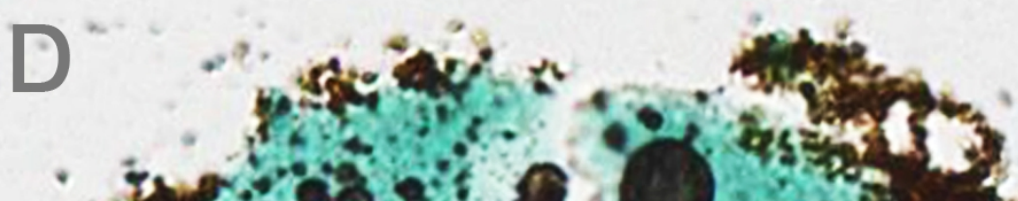

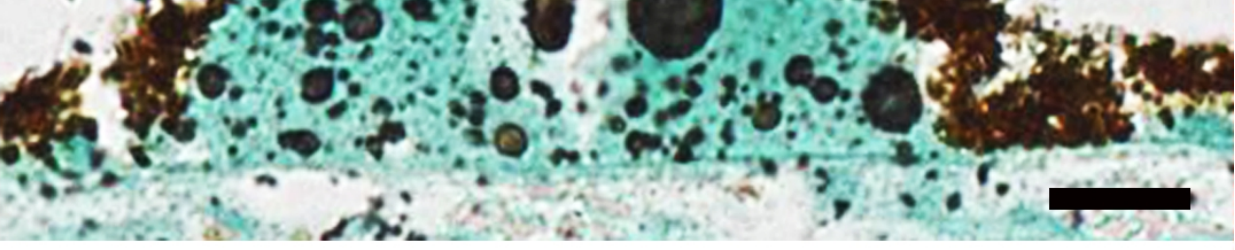
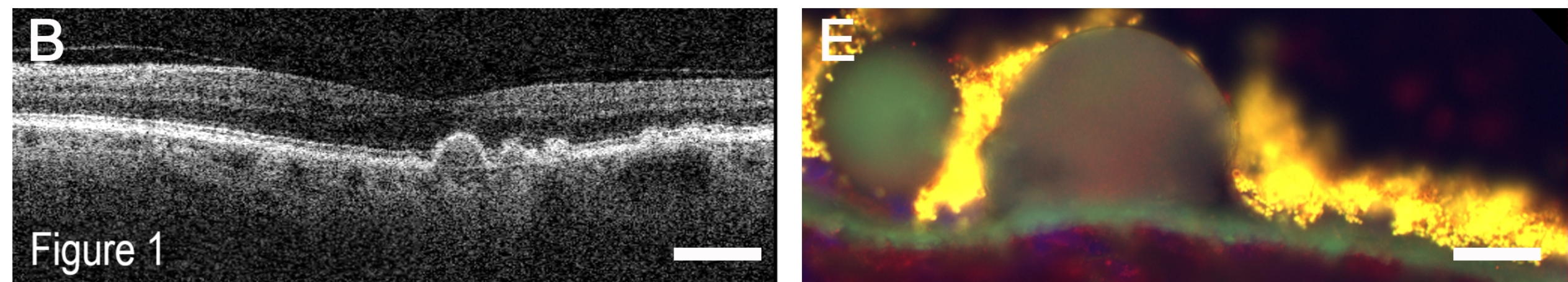


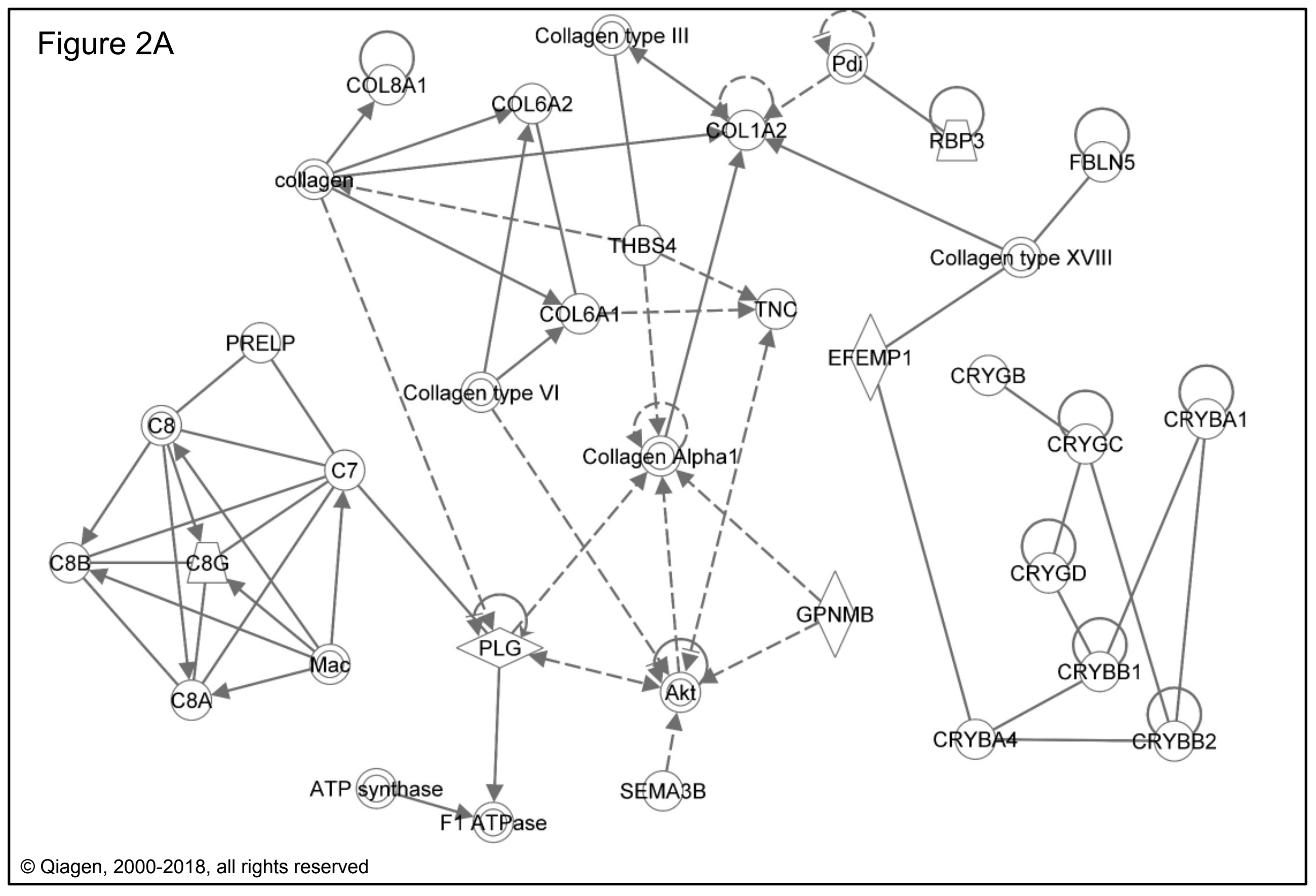




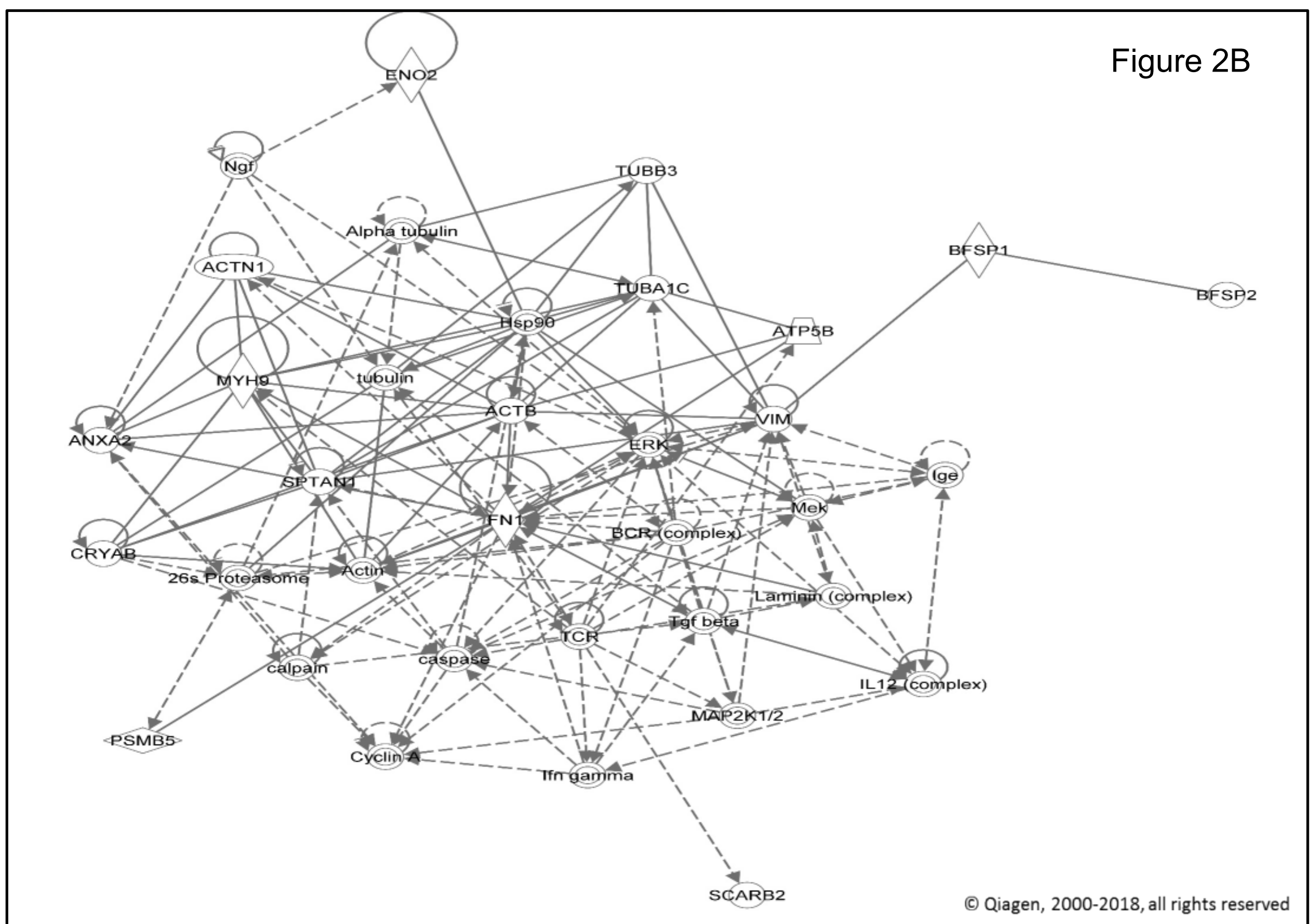




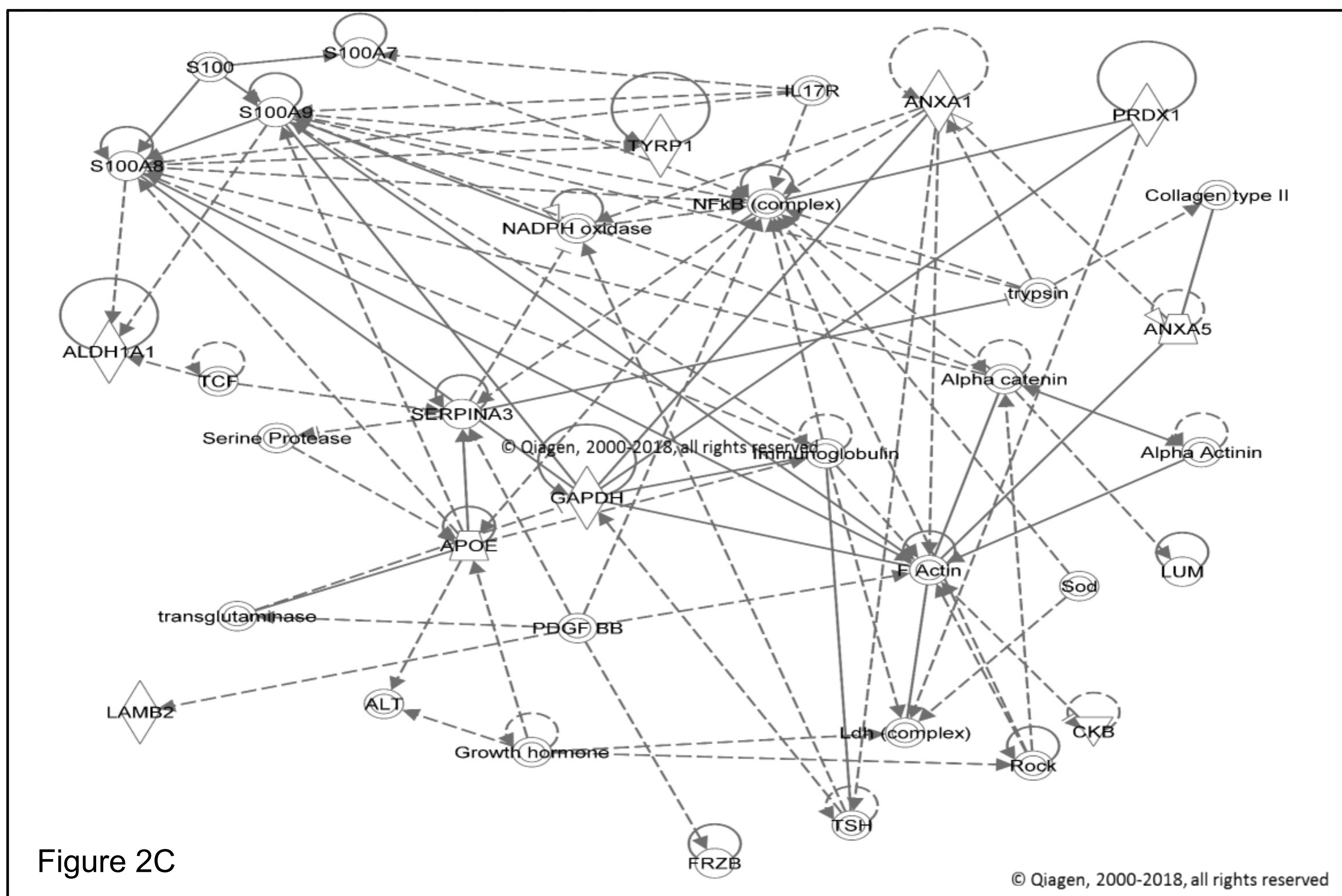




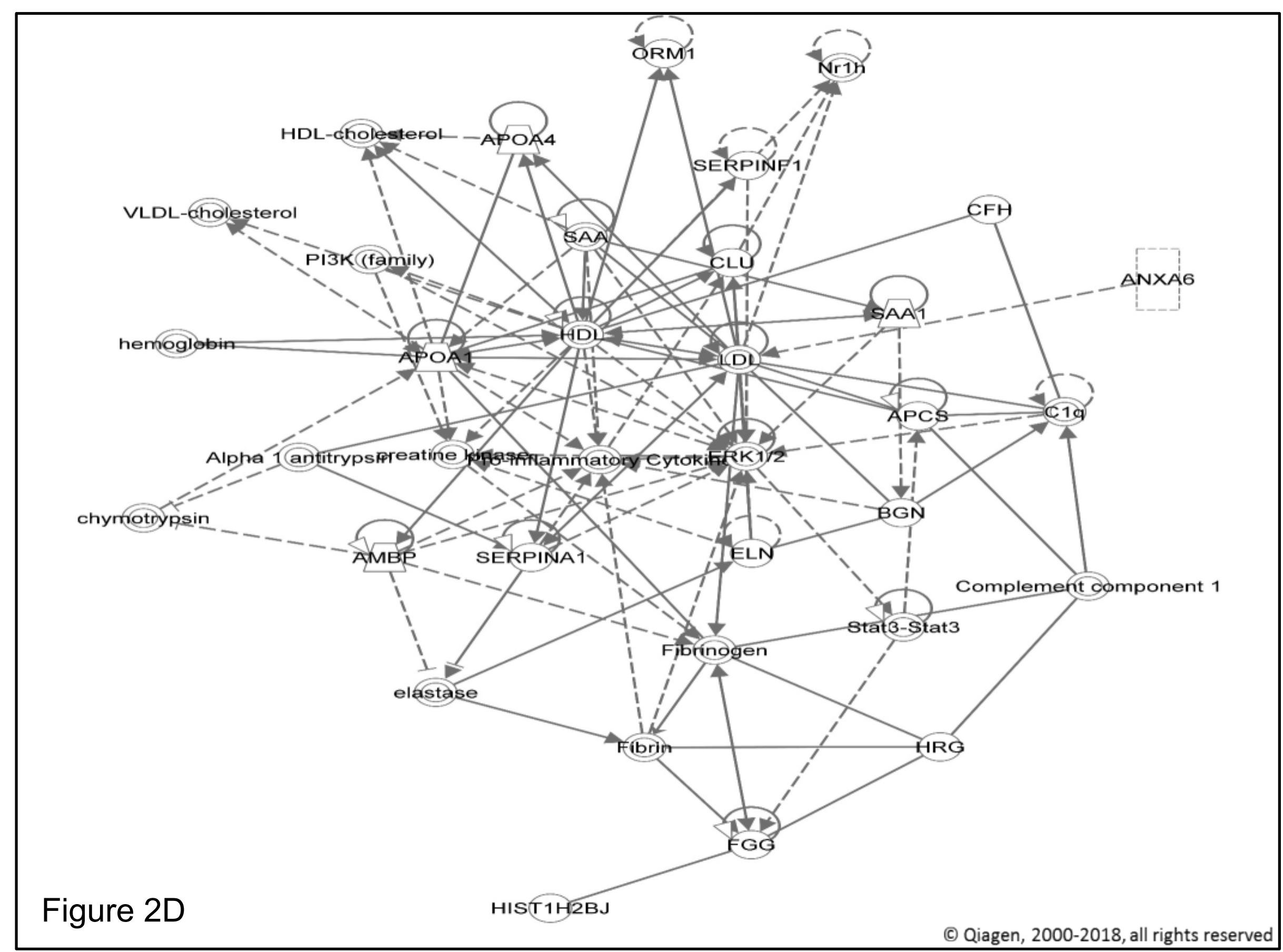




\section{Database curation examples}

Figure 3
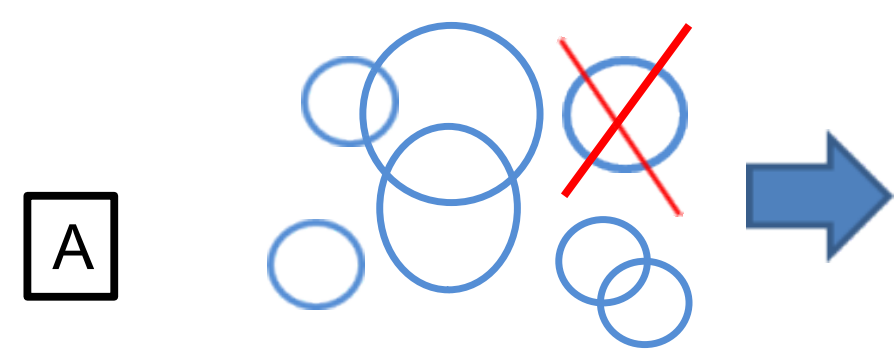

strip and merge

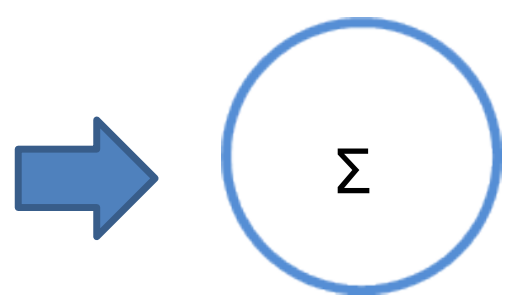

$B$

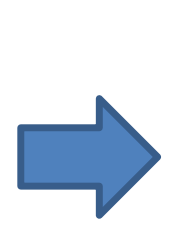
Photorcpt.(top) 10\% select

RPE (top 10\%) enriched

Choroid (top) $10 \%$
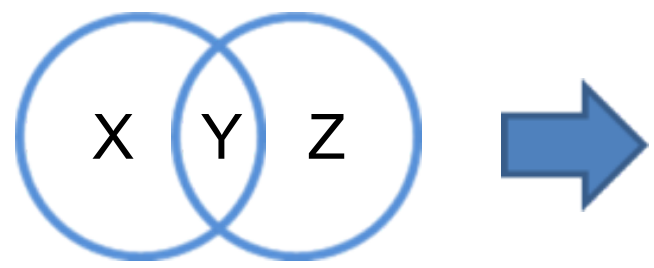

substract
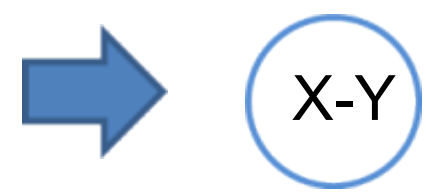


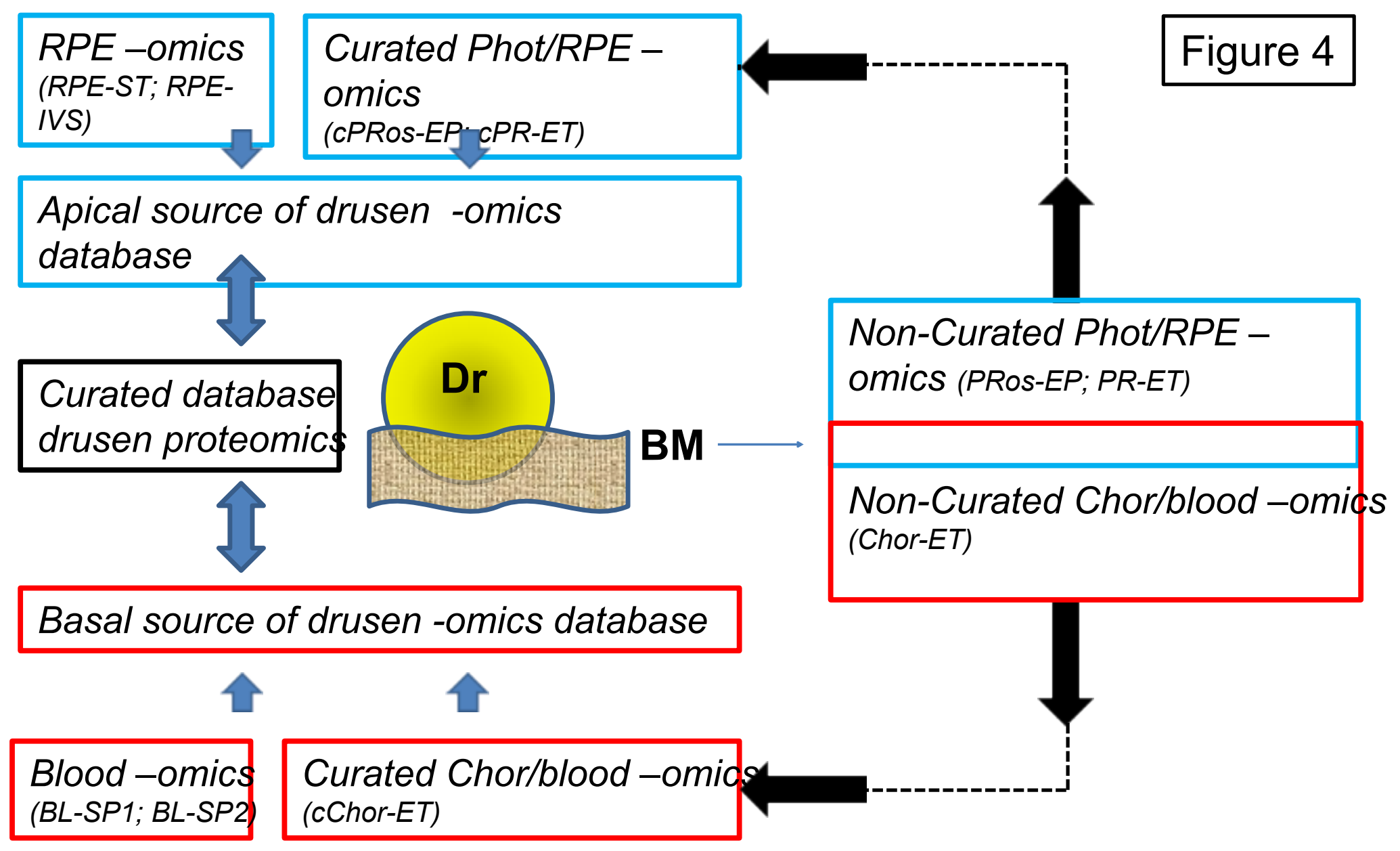


Figure 5

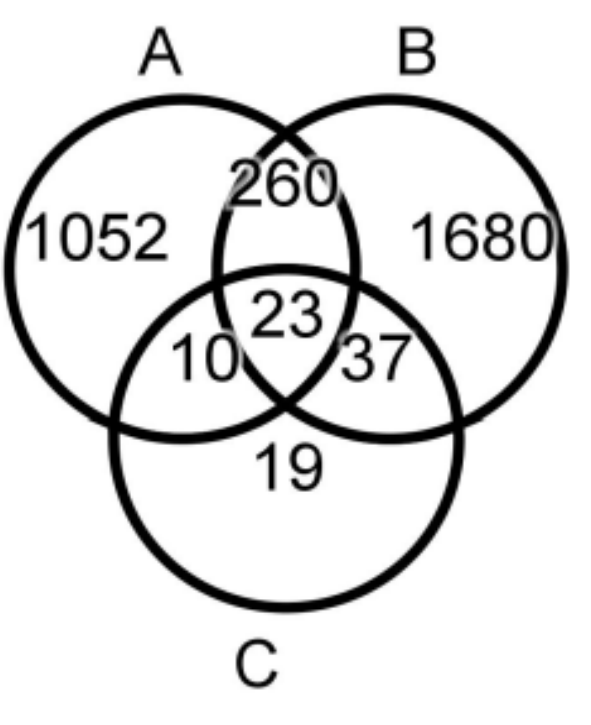


A

Figure 6

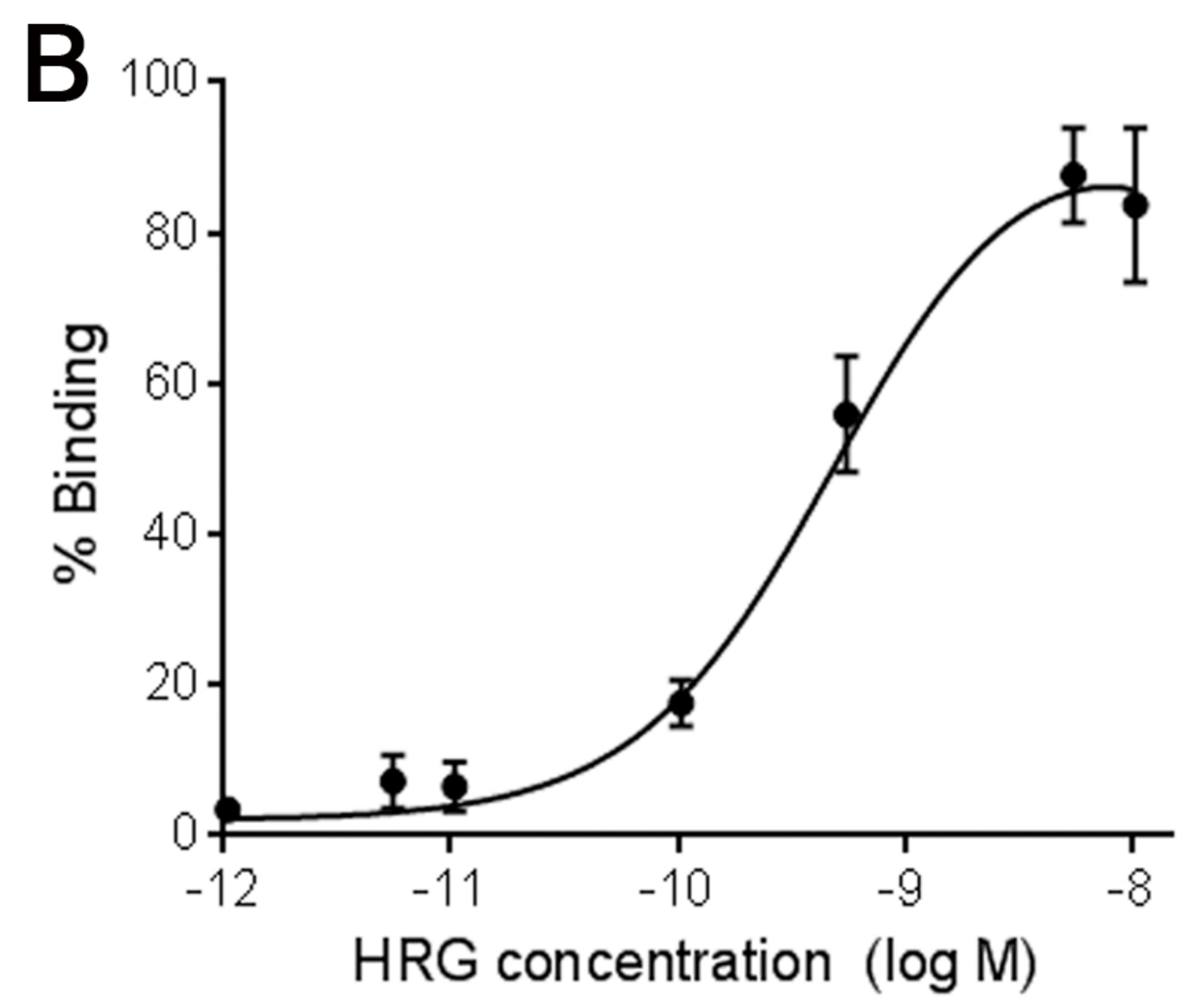




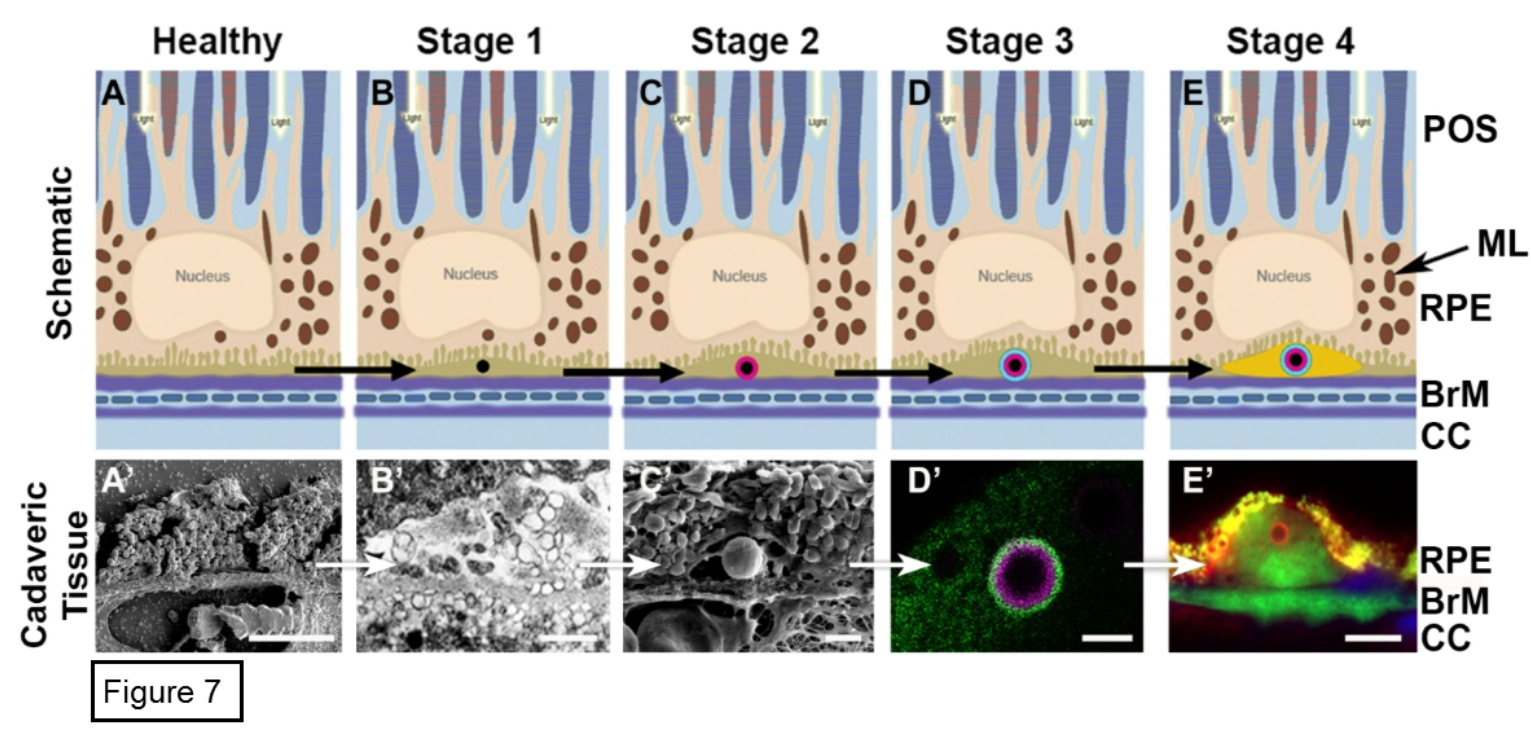




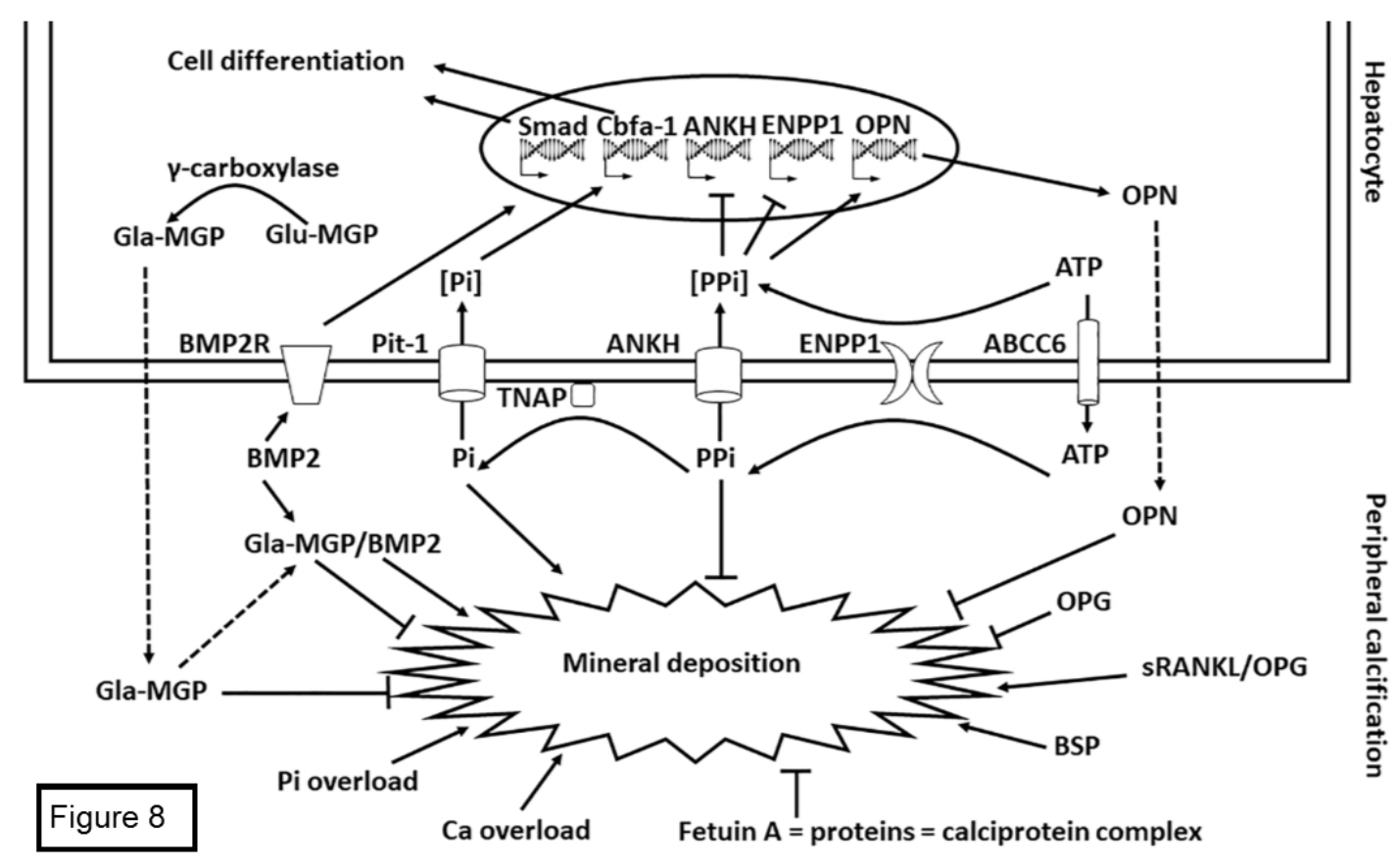



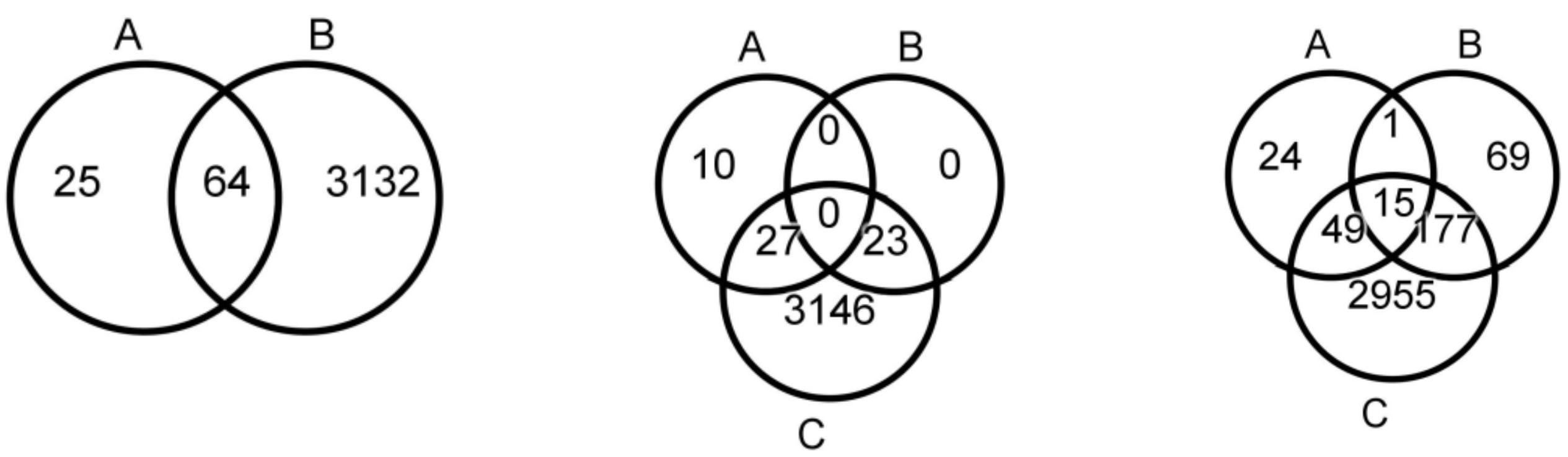

Figure 9A

Figure 9B

Figure 9C 


\section{Ingenuity Pathway Analysis (IPA). Table 2.}

Analysis Name: Table 2 Functional annotation 89 drusen proteins

Bergen et al.09:05 AM Analysis Creation Date: 2018-05-02

Build version: $470319 \mathrm{M}$

Content version: 43605602 (Release Date: 2018-03-28)

\section{Top Canonical Pathways}

Name

p-value

Overlap

Acute Phase Response Signaling

$7,51 \mathrm{E}-15$

$2,29 \mathrm{E}-12$

$9,39 \mathrm{E}-11$

2,35E-09

FXR/RXR Activation

Atherosclerosis Signaling

IL-12 Signaling and Production in Macrophages

$1,42 \mathrm{E}-07$
$8,2 \% 14 / 170$

$9,1 \% \quad 11 / 121$

$7,9 \% \quad 10 / 126$

$7,1 \% 9 / 127$

$5,5 \% \quad 8 / 146$

\section{Top Diseases and Bio Functions}

\section{Diseases and Disorders}

\section{Name}

Hereditary Disorder

Ophthalmic Disease

Organismal Injury and Abnormalities

Metabolic Disease

Developmental Disorder

\#Molecules

51

37

88

47

34

Molecular and Cellular Functions

Name

p-value

1,18E-04 - 2,86E-16
\#Molecules

44 


\section{Physiological System Development and Function}

Name

Embryonic Development

Nervous System Development and Function

Organ Development

Organismal Development

Tissue Development

\section{Top Networks}

ID Associated Network Functions

1.Cancer, Connective Tissue Disorders, Organismal Injury and Abnormalities 


\section{Ingenuity Pathway Analysis (IPA). Table 4.}

Analysis Name:Table 4 Summary photoreceptor core annotation analysis (745); Bergen et al.

2018-05-07 10:07 PM Analysis Creation Date: 2018-05-07

Build version: 470319M

Content version: 43605602 (Release Date: 2018-03-28)

\section{Top Canonical Pathways}

Name

p-value

Overlap

Phototransduction Pathway

7,98E-11

2,04E-04

4,79E-04

1,87E-03

$4,20 \mathrm{E}-03$

$28,3 \% 15 / 53$

Huntington's Disease Signaling

$8,0 \% \quad 20 / 250$

$14,0 \% \quad 8 / 57$

$17,9 \% \quad 5 / 28$

$11,1 \% \quad 7 / 63$

\section{Top Diseases and Bio Functions}

Diseases and Disorders

Name

Cancer

Organismal Injury and Abnormalities

Gastrointestinal Disease

Hepatic System Disease

Reproductive System Disease

p-value
1,31E-02 - 6,87E-28
1,33E-02 - 6,87E-28
1,21E-02 - 4,26E-22
2,47E-03 - 8,92E-15
1,27E-02 - 3,21E-08

p-value

1,28E-02 - 1,06E-08
\#Molecules

680

685

629

474

420

\section{Molecular and Cellular Functions}

Name

Cellular Assembly and Organization

\#Molecules

165 
Cellular Function and Maintenance

Cell Death and Survival

Cell Morphology

Cell-To-Cell Signaling and Interaction
1,31E-02 - 1,06E-08

1,32E-02 - 3,71E-06

1,31E-02 - 5,38E-06

1,16E-02 - 8,21E-06

p-value

1,25E-02 - 3,12E-06

1,28E-02 - 3,12E-06

1,16E-02 - 3,12E-06

1,28E-02 - 8,07E-06

$1,28 \mathrm{E}-02-9,43 \mathrm{E}-06$ \#olecules

88

129

30

161

92

\section{Top Networks}

ID Associated Network Functions

1.Cellular Assembly and Organization, Cellular Function and Maintenance, Molecular Transport

3.Developmental Disorder, Neurological Disease, Cellular Assembly and Organization 


\section{Ingenuity Pathway Analysis (IPA). Table 5.}

Analysis Name: Table 5 Summary Functional Annotation Choroid- Bergen et al

Analysis Creation Date: 2018-05-07

Build version: $470319 \mathrm{M}$

Content version: 43605602 (Release Date: 2018-03-28)

\section{Top Canonical Pathways}

Name

p-value

Overlap

Antigen Presentation Pathway

$7,58 \mathrm{E}-12$

$3,26 \mathrm{E}-11$

$3,88 \mathrm{E}-11$

$5,19 \mathrm{E}-10$

Hepatic Fibrosis / Hepatic Stellate Cell Activation

1,90E-09

$\begin{array}{ll}36,8 \% & 14 / 38 \\ 18,0 \% & 23 / 128 \\ 14,7 \% & 28 / 191 \\ 14,5 \% & 25 / 172 \\ 31,6 \% & 12 / 38\end{array}$

Complement System

p-value
1,44E-06 - 4,74E-32
1,48E-06 - 4,74E-32
1,09E-06 - 1,87E-21
1,48E-06 - 1,46E-17
4,57E-08 - 1,46E-17

\#Molecules

Name

Cancer

Organismal Injury and Abnormalities

Inflammatory Response

Connective Tissue Disorders

4,57E-08 - 1,46E-17

730

746

263

192

174

\section{Molecular and Cellular Functions}

Name

p-value

\#Molecules

Cellular Movement

1,26E-06 - 1,81E-32

257 


\section{Physiological System Development and Function}

$$
\begin{gathered}
\text { p-value } \\
\text { 9,30E-07 - 1,46E-28 } \\
\text { 1,47E-06 - 1,38E-24 } \\
\text { 1,29E-06 - 1,10E-23 } \\
\text { 1,29E-06 - 3,90E-23 } \\
\text { 5,54E-08 - 1,79E-22 }
\end{gathered}
$$

\#Molecules

Name

Organismal Development

Immune Cell Trafficking

Hematological System Development and Function

\section{Top Networks}

ID Associated Network Functions

1.Organ Morphology, Organismal Injury and Abnormalities, Renal Atrophy

3.Molecular Transport, Nucleic Acid Metabolism, Small Molecule Biochemistry

4. Tissue Development, Cellular Movement, Hair and Skin Development and Function 


\section{Authors' statement}

All authors have seen and approved the final version of the manuscript being submitted. They warrant that the article is the authors' original work, hasn't received prior publication and isn't under consideration for publication elsewhere.

None of the authors has a financial or personal conflicts of interest defined as a set of conditions in which professional judgment concerning a primary interest, such as the validity of research, may be influenced by a secondary interest, such as financial gain.

The work on this manuscript is approximately divided as follows:

AAB $28 \%$, SA $5 \%$, CK $5 \%$, MP 5 \%, DW 4 \%, PvdS 4\%, SMH $4 \%$, CJFB $4 \%$, EE 5 \%, AJS $18 \%$, IL $18 \%$ 